Portland State University

PDXScholar

\title{
Juvenile Sex Offenders: A Consideration of Attachment Deficits in the Etiology of Offending
}

Lee Anna Knox

Portland State University

Follow this and additional works at: https://pdxscholar.library.pdx.edu/open_access_etds

Part of the Psychology Commons

Let us know how access to this document benefits you.

\section{Recommended Citation}

Knox, Lee Anna, "Juvenile Sex Offenders: A Consideration of Attachment Deficits in the Etiology of Offending" (2009). Dissertations and Theses. Paper 4143.

https://doi.org/10.15760/etd.6027

This Thesis is brought to you for free and open access. It has been accepted for inclusion in Dissertations and Theses by an authorized administrator of PDXScholar. Please contact us if we can make this document more accessible: pdxscholar@pdx.edu. 


\section{THESIS APPROVAL}

The abstract and thesis of Lee Anna Knox for the Master of Science in Psychology were presented July 23, 2009, and accepted by the thesis committee and the department.

COMMITTEE APPROVALS:

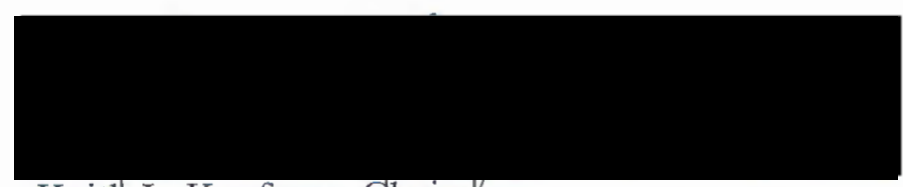

Keith L. Kaufman, Chair /

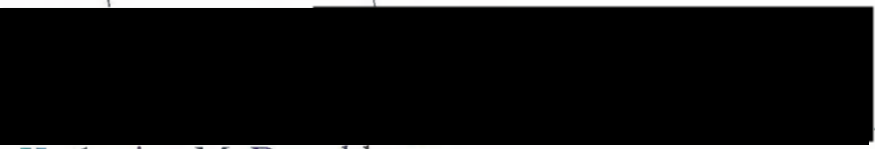

Katherine McDonald

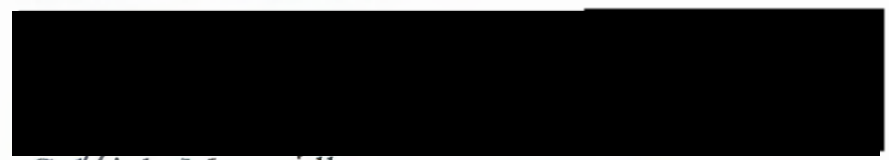

Gabriela Martorell

DEPARTMENT APPROVAL:

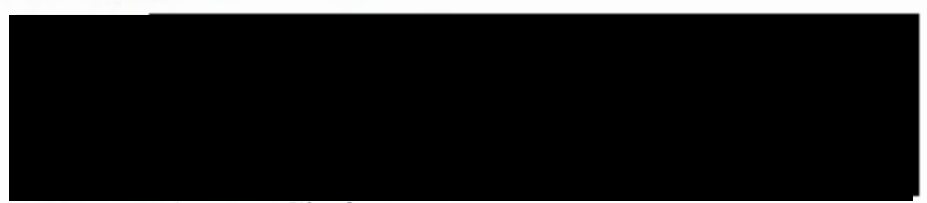

Ellen Skinner, Chair

Department of Psychology 


\begin{abstract}
An abstract of the thesis of Lee Anna Knox for the Master of Science in Psychology presented July 23, 2009.
\end{abstract}

Title: Juvenile Sex Offenders: A Consideration of Attachment Deficits in the Etiology of Offending.

Child sexual abuse is a serious and widespread problem that has been associated with a variety of short and long term consequences to victims, offenders, families, communities and society at large. In recent years, it has been recognized that up to $40 \%$ of sexual offenses occur at the hands of adolescent offenders (between 12-18 years of age). The literature suggests that early childhood familial experiences, specifically attachment deficits and experiencing abuse in childhood may be associated with offending behavior in adolescents. Important developments in attachment theory are reviewed and discussed as they relate to the etiology of offending behavior and resulting consequences. In this study, internal working models and the framework of Bartholomew's Four Category Model of Attachment (1991) are used to categorize participants based on their perceptions of the quality of their relationship with their supervisor (female caregiver) and personal histories of abuse. Study findings demonstrate that attachment style is significantly related to juvenile 
offender status (Sex Offender, Delinquent, and non-offending Comparison), and a significant number of Juvenile Sex Offenders report having suffered one or more types of childhood abuse. Finally, implications from this investigation are explored in regard to treatment and directions for future research are discussed. 


\section{'JUVENILE SEX OFFENDERS:'}

\section{A CONSIDERATION OF ATTACHMENT DEFICITS \\ IN THE ETIOLOGY OF OFFENDING}

by

LEE ANNA KNOX

A thesis submitted in partial fulfillment of the requirements for the degree of

\section{MASTER OF SCIENCE in PSYCHOLOGY}

Portland State University

2009 


\section{DEDICATION}

The following research paper is dedicated to the victims, families and communities that have suffered the effects of childhood sexual abuse along with the children that have sexually offended.

May we all find a way to work together to heal the wounds that sexual abuse has created and more importantly a way to prevent future instances of abuse.

\section{PERSONAL DEDICATION}

To Bill, quite simply, there are not enough words... 


\section{ACKNOWLEDGMENTS}

First, I acknowledge the members of my thesis committee: Dr. Keith Kaufman, Dr. Gabriela Martorell and Dr. Katherine McDonald. Their time, effort, insight and cooperation have truly been gifts.

I additionally acknowledge Dr. Keith Kaufman individually for his tireless work aimed at the prevention of childhood abuse. Specifically, the many years he spent developing contacts, designing measures and collecting valuable data that he has graciously shared with me and others before me.

I further acknowledge the Centers for Disease Control, whose monetary support allowed the collection of the data used for this paper.

I also acknowledge those I have had the pleasure of working with in my time at Portland State University including: L. Amber Hayes, Julie Yagoda, Debi Brannan, Sara Valenzuela, Lindsey Patterson, Maritza Martinez, Leah Kamin, \& Heidi Geil. Your support and assistance through this process has been and always will be appreciated.

Finally I want to thank my husband and friends that have read, re-read, edited, consulted, suggested and even nagged throughout this project. Without you, I would not be who I am today. 


\section{TABLE OF CONTENTS}

ACKNOWLEDGEMENTS

LIST OF TABLES vii

LIST OF FIGURES viii

LIST OF ABBREVIATIONS $\quad$ ix

INTRODUCTION

BACKGROUND AND INCIDENCE 1

DEFINING CSA OFFENSES 11

DEFINING JUVENILE SEX OFFENDERS (JSO) 14

DEFINING JUVENILE DELINQUENTS (JD) 16

$\begin{array}{ll}\text { DEFINING JUVENILE COMPARISON (JC) } & 17\end{array}$

$\begin{array}{ll}\text { DEFINING SUPERVISOR } & 18\end{array}$

A REVIEW OF THE LITERATURE

JUVENILE SEXUAL OFFENDERS ROLE IN CSA 19

ECOLOGICAL/PUBLIC HEALTH APPROACH 20

$\begin{array}{ll}\text { CONSEQUENCES TO VICTIMS } & 22\end{array}$

IMPACT OF CSA ON VICTIM'S FAMILY 28

$\begin{array}{ll}\text { IMPACT OF CSA ON OFFENDERS } & 29\end{array}$

IMPACT OF CSA ON OFFENDERS' FAMILIES 38

$\begin{array}{ll}\text { COMMUNITY AND SOCIETAL IMPACT } & 39\end{array}$

CHILD SEXUAL ABUSE MODELS 41 
GENERAL ATTACHMENT THEORY 45

ATTACHMENT CONCERNS WITH VICTIMS 51

ATTACHMENT IN JUVENILE SEX OFFENDERS 56

ATTACHMENT MEASUREMENT $\quad 64$

$\begin{array}{ll}\text { SUMMARY } & 69\end{array}$

$\begin{array}{ll}\text { HYPOTHESES } & 71\end{array}$

RESEARCH DESIGN AND METHODS

OVERVIEW

$\begin{array}{ll}\text { PARTICIPANT SAMPLE } & 73\end{array}$

$\begin{array}{ll}\text { SCREENING } & 76\end{array}$

$\begin{array}{ll}\text { MEASURES } & 77\end{array}$

RESULTS

$\begin{array}{ll}\text { DATA ANALYSIS } & 79\end{array}$

$\begin{array}{ll}\text { CORRELATIONS } & 79\end{array}$

$\begin{array}{lr}\text { EXPLORATORY FACTOR ANALYSIS } & 80\end{array}$

CONFIRMATORY FACTOR ANALYSIS $\quad 82$

$\begin{array}{ll}\text { SAMPLE DIFFERENCES } & 84\end{array}$

$\begin{array}{ll}\text { ATTACHMENT STYLE } & 85\end{array}$

ATTACHMENT STYLE PREDICTING GROUP MEMBERSHIP $\quad 87$

$\begin{array}{ll}\text { ABUSE TYPE } & 87\end{array}$ 
DISCUSSION

DISCUSSION

CONCLUSION

SIGNIFICANCE

STRENGTHS

LIMITATIONS

IMPLICATIONS

106

REFERENCES 
APPENDICES

$\begin{array}{lll}\text { APPENDIX A: } & 136\end{array}$

APPENDIX B: $\quad$ SQ - YOUR RELATIONSHIP WITH

YOUR SUPERVISOR

APPENDIX C: $\quad$ SQ - QUESTIONS ABOUT YOUR ABUSE

AND TREATMENT HISTORY

APPENDIX D: $\quad$ RESIDENCY RESTRICTION ZONES

APPENDIX E: $\quad$ CHILD ABUSE LAWS BY STATE 
LIST OF TABLES

$\begin{array}{ll}\text { TABLE 1: IPPA \& SQ SIMILARITY COMPARISON } 1 & 67\end{array}$

TABLE 2: IPPA \& SQ SIMILARITY COMPARISON 2

$\begin{array}{ll}\text { TABLE 3: EFA PATTERN MATRIX } & 81\end{array}$

TABLE 4: PARTICIPANT DISTRIBUTION IN BARTHOLOMEW'S MODEL

TABLE 5: VICTIM-OFFENDER RELATIONSHIP IN SEXUAL ASSAULT, 1991-96

TABLE 6: REGRESSION: ATTACHMENT STYLE PREDICTING GROUP MEMBERSHIP

TABLE 7: CHI-SQUARE: ATTACHMENT STYLE DIFFERENT THAN EXPECTED BY CHANCE

TABLE 8: ANOVA: DIFFERENCES IN NEGLECT

TABLE 9: ANOVA: DIFFERENCES IN PHYSICAL ABUSE

TABLE10: ANOVA: DIFFERENCES IN SEXUAL ABUSE

TABLE 11: ANOVA: DIFFERENCES IN COMPLEX ABUSE 


\section{LIST OF FIGURES}

FIGURE 1: BRONFENBRENNER'S ECOLOGICAL MODEL

FIGURE 2: BARTHOLOMEW'S FOUR CATEGORY MODEL

FIGURE 3: PARTICIPANT SAMPLE DEMOGRAPHICS

FIGURE 4: MODEL

FIGURE 5: ABUSE COMPARISON - (NEGLECT, PHYSICAL AND SEXUAL) BY GROUP

FIGURE 6: ABUSE COMPARISON - COMPOUND ABUSE BY GROUP 


\section{LIST OF ABBREVIATIONS}

CFA - Confirmatory Factor Analysis

CSA - Child Sexual Abuse

EFA - Exploratory Factor Analysis

IPPA - Inventory of Parent and Peer Attachment (Armsden \& Greenberg, 1987)

JC - Juvenile Comparison

JD - Juvenile Delinquent

JSO - Juvenile Sex Offender

MST - Multi-systemic Therapy

PRS - Perceived Relationship with Supervisor (Subscale from the Supervision Questionnaire (Kaufman, 2001)

Supervisor - Participants primary female caregiver

SQ - Supervision Questionnaire (Kaufman, 2001)

SVP - Sexually Violent Predator

VOO - View of Others

VOS - View of Self

WRAT - Wide Range Achievement Test (Wilkinson, 1993) 


\section{INTRODUCTION}

\section{BACKGROUND AND INCIDENCE}

The National Resource Council estimates that between 20-24\% to a high of 54-62\% of the U.S. population has been sexually abused (NRC, 1993). Additionally, a frequently cited report released by the US Department of Justice in 1999 included the following sobering statistics: Twenty seven percent of the victims in reported child sexual abuse are under the age of five years old, the average age of first assault is two years old, and the average age of children when the sexual abuse is first reported is 11 years of age (USDJ, 1999). Researchers have confirmed that child sexual abuse is widespread and underreported (Wyatt, Loeb, Solis, Carmona, \& Romero, 1999), and this abuse has been associated with a variety of negative health outcomes (McMahon and Puett, 1999; Polusny \& Follette, 1995; Banyard \& Williams, 1996; Mullen, Martin, Anderson, Romans \& Herbison, 1996). Brier \& Elliot (2003) found that childhood sexual abuse is relatively common in the general population, and is associated with a wide variety of psychological symptoms ranging from psychiatric disorders to mental health problems (Molnar, Buka \& Kessler, 2001; Banyard, Williams \& Siegel, 2001). In retrospective studies, researchers have found that between 6.8\% (Siegel, Sorenson, Golding, Burnam \& Stein, 1987) and 62\% (Wyatt, 1985) of women experienced some form of sexual abuse in childhood. Prevalence rates for men, although lower, are also significant. Gorey \& Leslie (1997) indicated that self reported rates for men averaged $8.5 \%$ in their review of the literature. These rates most likely underestimate the actual prevalence of CSA due to both 
underreporting and victims' inaccurate memories of events (Fergusson, Horwood \& Woodward, 2000; Widom \& Morris, 1997; Freyd, 1996).

Sexual offending continues to present a major social problem resulting in significant psychological and emotional costs to victims and their families (Johnston \& Ward, 1996). Respected researchers have hypothesized that CSA is associated with many long term effects on the victim, ranging from the most commonly studied symptom, sexualized behavior, (Kendall-Tackett, Williams \& Finkelhor, 1993) to suicide (Mullen et al., 1996; Polusny \& Follette, 1995, Brown, Cohen, Johnson, \& Smailes, 1999; Dube, Anda, Whitfield, Brown, Felitti, Dong et al., 2005). In their 1993 review of CSA literature, Kendall-Tackett and her colleagues found that children who experienced sexual abuse showed two consistent symptoms: PTSD (Post traumatic stress disorder) and sexualized behavior. Although sexuality is a normal, healthy part of life, sexualized behavior is often conceptualized as activity that is sexual in nature and is either compulsive or developmentally inappropriate. Investigators have also suggested that the long term effects of CSA may reach far into adulthood and affect more than just the primary victim of abuse (Wang \& Holton, 2007). These secondary victims can include family members (Rumstein-McKean \& Hunsley, 2001) and friends (Cearney, 1995) of the primary victim as well as communities as a whole (Wang \& Holton, 2007).

Although there has been an increase in research on CSA over the past 30 years, there have been a number of challenges associated with studies in this area. First, there are many different definitions of childhood sexual assault. According to Johnson, 
Ross, Taylor, Williams, Carvajal and Peters (2006), there is no consistent definition of CSA shared by all researchers. Second, CSA, particularly for African American and European American females, tend to be under reported (Wyatt et al., 1999). It is widely recognized that nationally reported statistics, such as those published by the United States Bureau of Justice Statistics, are underestimates (Bachman \& Saltzman, 1995; Finkelhor, 1994; Green, 1996; Kessler \& Hyden, 1991; Russell, 1983; Siegel, et al., 1987). In part, the difficulty in obtaining accurate prevalence rates is related to the way society views children. For example, generally we are uncomfortable discussing sexuality with children (Rosenthal, Feldman \& Edwards, 1998). We also teach our children from a very young age to obey adults. This puts children at a disadvantage when an adult does something inappropriate to them. Briggs, McVeity \& Love (2001) said that children will obey adults even when they know what the adult is doing is wrong. Normally-developing children have been found to be adept at reading social cues and avoiding topics they believe will embarrass others (Baron-Cohen, O'Riordan, Stone, Jones, and Plaisted, 1999). Moreover, most children want to please the adults around them (Hanna, Risden \& Alexander, 1997). As a result, children may not ask others for help or question inappropriate behavior on the part of adults or even older children. Briggs, and her colleagues (Briggs et al., 2001) stated that children will tolerate sexual misconduct rather than risk the disapproval of adults.

Another reason incidences of CSA may be under reported may be due to characteristics of the victim and their family. For instance, it has been suggested that families of low SES may underreport CSA for a number of reasons. First, low SES 
parents typically have less education and may not be very good observers of their child's behavior (Friedrich, 2006). Friedrich (2006) recognized that with increased education parents become attuned to watch their children for behavioral shifts (i.e. changes in eating habits or how children interact with others) as signs of distress. Additionally, Friedrich indicated lack of reporting may be due to the fact that low SES individuals have more experience with social service agencies and may have learned to distrust those agencies. Finally, Widom \& Shepard (1996) concluded that a "substantial underreporting" of CSA may occur as a result of "victim's forgetting”, victims feeling as if they deserved the abuse, victims' desire to protect the offending parent and their embarrassment about having been abused. Prevalence rates may depend upon ethnic and cultural differences, as well. For example, Thigpin, Pinkston \& Mayefsky (2003) found that black parents report less sexual behavior than Caucasian parents of similar economic status.

Research also demonstrates that CSA may go underreported for other reasons associated with the nature of the offenders' modus operandi. Many offenders convince child victims that abuse is a normal way of showing affection, a special game, or a secret (NSPCC, 2005). Offenders may also use the child's natural fear, embarrassment or guilt about what has happened, as well as threats of punishment or to hurt the child, a family member or a family pet (NSPCC, 2005) to perpetuate the abuse and maintain the victim's silence. Additionally, researchers have reported that many of children's sexually abusive experiences are never reported to authorities (Chaffin, Lawson, Selby \& Wherry, 1997; Finkelhor, 1994; MacMillian, Fleming, Trocome, Boyle, Wong \& 
Racine, 1997; Widom \& Morris, 1997; Williams, 1994) and therefore go undetected, further obscuring prevalence rates. Johnson et al. (2006) acknowledged that, while there is a wealth of research on CSA, the victims studied are most often female. They also suggested that societal norms regarding what it is to be male further encourage under-reporting and make it difficult to obtain accurate prevalence estimates. Finally, research into CSA is often hopelessly confounded by the presence of other forms of abuse. This confounding makes it difficult to parse out which effects are as a result of each form of child maltreatment. Children who are victims of one form of abuse are more likely to experience other forms of abuse (i.e. sexual, physical, verbal, and emotional - Mullen et al., 1996).

It is important to recognize that although there is significant research supporting the idea that CSA is underreported, the existing prevalence rates still demonstrate the large number of people in our country who are directly or indirectly impacted by abuse. It is also important to recognize that definitive causal or correlational links have not been found to explain what leads to sexual offending behavior. While the literature is by no means longstanding compared to research on general psychotherapy, there is a twenty-five plus year history of research in this area. Studies have examined at a variety of variables regarding, offender demographics, offenses and patterns of perpetration. Research indicates that sex offenders are a heterogeneous group (Daleiden, Kaufman, Hilliker, O’Neil, 1998; Smallbone \& McCabe, 2003; Hunter, Figueredo, Malamuth, and Becker, 2003), and as a result, numerous etiological theories have been proposed. 
At the same time, expanding the research literature is equally important to enhance our knowledge of treatment directions and treatment outcomes. As a foundation for this work, Hanson, Gordon, Harris, Marques, Murphy, Quinesy et al. (2002) reported what they termed indisputable evidence that adult sex offenders who undergo treatment have a significantly lower recidivism rate than untreated sex offenders.

The benefits of treatment for juvenile sex offenders are widely acknowledged, as well. In 1993, the National Task Force on Juvenile Sexual offending suggested the need for multiple treatment and management programs to respond to juvenile sex offending. Studies on the recidivism rates in juvenile sex offenders have yielded differing results. Steinberg (2006) found in her review of the literature that $40-60 \%$ of programs reported reduced recidivism rates for juvenile sex offenders who did receive treatment as opposed to those who did not receive treatment while incarcerated. She also found that the most effective programs were those that worked on improving social skills and cognitive programming focusing on coping skills, cognitive mediation (i.e., Cognitive Behavioral Therapy), primary interpersonal relationships, and peer support. Additionally, other researchers have found empirical evidence to support treatment intervention with juvenile sex offenders. For example Worling \& Curwin (2000) reported recidivism rates of $17.8 \%$ for untreated juvenile sexual offenders, while adolescents that underwent specialized treatment recidividated at a significantly lower rate of $5.17 \%$. In the past thirty-plus years, specialized treatment options for 
adolescent sex offenders have increased in the United States. In 1975, there was only one specialized treatment program for this population (Knopp, 1985), by 1995, Freeman-Longo, Bird, Stevenson \& Fiske (1995) found more than 600 such programs. The Center for Sex Offender Management (CSOM) offers that a continuum of care is particularly important when considering treatment and placement options for juvenile sex offenders (CSOM, 2009). Worling \& Curwin (2000) asserted that there is notable consensus regarding the specialized treatment of juvenile sex offenders and that the best treatment modalities share treatment goals including improving family relationships and social skills and addressing the offender's personal trauma. These specific treatment goals address the very constructs underpinning attachment deficits as discussed later in this paper. Further research has detailed that treatment approaches that include improving family functioning, such as Multi-systemic Therapy (MST), have also shown to significantly reduce recidivism rates with juvenile offenders (Schaeffer \& Borduin, 2005).

MST attempts to improve the youth's ability to make good decisions. Typically this is accomplished by improving the relationships (attachment) of the youth with his parents and peer group. MST seeks to bolster the positive aspects of family influence by improving communication, setting boundaries, and enhancing emotional support using behavioral parent training and functional family therapy. Research has also shown that peers play an important role in the development of social skills adolescence (Heppler, 1997). MST strives to increase positive peer 
influences by encouraging involvement with team sports, regular school attendance and less contact with delinquent peers.

Additional research and clinical work by Dr. Phil Rich has shown that an attachment-informed approach to treatment can be effective in treating those juveniles that have sexually offended (Rich, 2009). Information provided by Dr. Rich at a recent conference outlined the four main goals in attachment-informed treatment. The first goal of a treatment model informed by attachment theory is to understand insecure attachment and the related obstructions to secure attachment including whether or not any of these obstacles can be removed, perhaps through individual, family, or group therapy or even through medication. The second emphasis is to revive and re-engage social behavior that may exhibit as detached. The third goal is to help the client re-organize attachment systems and a fourth is to eliminate ambiguity and incoherence from attachment narratives, or the expression of internal working models (Rich, 2009).

Family interaction and attachment assume prominent roles in social control theories of delinquency (Cernkovich \& Giordano, 1987). Having a strong relationship with or attachment to parents/caregivers and other family members represents an important aspect of normal interpersonal development. Deficits in this area may be a significant etiological factor in the development of juvenile sex offending and, as such, could have important implications for assessment and treatment planning. Better developed research and information in this area could assist treatment providers in tailoring their work to address adolescents' attachment deficits. As mentioned, 
targeted interventions of this nature can help adolescent offenders by fostering stronger, more positive relationships with family members, peers, and other members of their community.

Many theorists and researchers have studied attachment since John Bowlby first discussed the importance of family interaction in the histories of juvenile nonsexual offenders in his paper entitled: "Forty-Four Juvenile Thieves: Their Characters and Home Lives" (Bowlby, 1944). Bowlby went on to describe this interaction as "attachment" in his trilogy of books on the subject published in 1969, 1973, 1980. Bowlby, Ainsworth, Main and Bartholomew are often cited as central contributors in the development of attachment theory. The current study evaluates attachment styles of juvenile sex offenders (JSO), juvenile delinquents (JD), and juvenile controls (JC, or adolescents with no criminal history) within Kim Bartholomew's Four Category framework (Bartholomew, 1990). The model suggests that individuals' may develop one of four attachment styles: secure; preoccupied; dismissive; or fearful. The current study utilized a self report questionnaire, the Perceived Relationship with Supervisor Questionnaire (PRS), which closely matches other tested measures of attachment such as the Inventory of Parent and Peer Attachment (IPPA). Because the PRS has not been qualified as an accurate measure of attachment, and the participants were not specifically evaluated regarding their view of self, the following shorthand terms will be used throughout. Secure, preoccupied, dismissive and fearful describe the measurement of participants' perceived relationship with their female caregiver and their reported history of abuse. 
In this study, Juvenile sex offenders were hypothesized to be more likely to be categorized as "Fearful" than either of the two comparison groups. While Juvenile Delinquents (JDs), were hypothesized as more likely to be categorized as "Fearful" than JCs. The current study was designed to include these three participant groups (JSO, JD and JC) for a number of reasons. First, a number of studies in the past have used only a single comparison group (i.e., either non-sexual offenders or community controls). Including two comparison groups provides richer analysis of the differences in attachment styles in the sex offender population. Including a JD comparison group, in particular, allowed for a contrast of two groups of participants that have been convicted of criminal behavior, are both experiencing sanctions by our justice system and, most likely, have spent time separated from family, friends and society in correctional or treatment facilities. It is assumed that individuals who have committed sexual offenses have characteristics or childhood experiences that allow them to perpetrate what our society considers the most heinous of crimes, the sexual abuse of a child (Vidmar, 1997). The use of multiple comparison groups in this study provided an opportunity to quantify key experiential differences.

Study hypotheses also related to study participants' own history of abuse and/or neglect. The importance of including this dimension is reflected in the findings of prominent researchers including Briere \& Elliot (2003) who have found that the most traumatic events in childhood are related to abuse. Additionally strong correlations between childhood abuse and low self esteem have been well-documented by many researchers (Brown \& Finkelhor, 1986; Gross \& Keller, 1992; Stern, Lynch, 
Oates, O'Toole, Cooney, 1995; Briere, 1998). Researchers have found that a large proportion of adolescent sexual offenders have experienced some form of maltreatment, either sexual or physical, during childhood (Aljazireh, 1993). Therefore, it was hypothesized that a significantly greater portion of the JSOs in this study would have suffered at least one type of childhood maltreatment than either the JDs or JC. In turn, more JDs would have suffered childhood abuse than JCs. For the purpose of this research study abuse is defined as having suffered one or more type(s) of maltreatment (sexual abuse, physical abuse, neglect) via self-report.

\section{DEFINING CSA OFFENSES}

As Wyatt \& Peters (1986) pointed out, there is an 80 year history of research investigating the prevalence of CSA perpetrated by adults. This history reflects a broad array of CSA definitions which represent a major challenge in the literature. In 1994, Finkelhor suggested that CSA covered a wide range of acts but that general legal and research definitions require two essential elements: 1) sexual activities (activities engaged in for sexual pleasure) involving a child; and 2) an abusive condition, such as coercion, or a large age gap between the participants (i.e., which indicates a lack of the ability to provide consent). In practice, specific legal definitions of terms including child sex abuse, rape, molestation, and sodomy are promulgated by each state's legislature. In other words, the actual elements that define what activities constitute criminal sexual abuse vary from state to state. Often, the term sexual offense is used as an umbrella term to cover a broad array of abusive acts. 
From a practical perspective, sexual offenses are often divided between those involving physical contact, known as "hands-on offenses", and those where physical contact is not present, known as "hands-off offenses" (Cooper, Murphy \& Haynes, 1986; Greenberg, Bradford, Firestone \& Curry, 2000). Hands-on offenses are often divided into three sub categories: 1) fondling and non-penetrative acts committed by the perpetrator on the victim; 2) forcing the victim to commit non-penetrative acts on the offender or others; and 3) penetrative acts, either committed by the offender upon the victim or forcing the victim to commit these acts upon the offender or others (Kaufman, 2001). Hands-off offenses include perpetrators' exposure of their genitalia to victims, sexualized phone calls, emails or text messages and showing victims sexually explicit pictures or video images (Kaufman, 2001).

According to Finkelhor (1991), other definitional disagreements exist regarding CSA including how a "child" is defined. As discussed above, each state exercises some latitude when passing their unique statutes. A brief example of different statutes on child abuse can be found in Appendix V. Most states include persons through age 16 or 18 as potential victims when defining CSA (Finkelhor, 1991). It is also important to acknowledge the fact that there are different parameters applied by researchers when defining and characterizing sex offenders. Many researchers break offenders into categories based on the offenders' previous relationship to their victim. These categories include: intra-familial (i.e. the offender and victim are related by blood or marriage) and extra-familial, the offender is not related to but known to the victim; and finally strangers. Estimates suggest that more 
than $93 \%$ of offenders are known to the juvenile victims of sexual assault and more than $43 \%$ are related to the victim (Snyder, 2000a). The high percentage of known or "intra-familial" offenders becomes especially salient when looking at sexual offenses committed by juveniles. Epidemiological evidence suggests that juveniles are responsible for a large percentage of sexual offenses; adolescent sexual offending accounts for up to $40 \%$ of reported sexual offenses in North America (Burton, 2000). Righthand \& Welch (2001) suggested in their report that juvenile sibling offenders (intra-familial) perpetrated the greatest number of sexually abusive acts and this abuse lasted for a longer periods of time than abuse perpetrated by extra-familial offenders. O'Brien (1991) hypothesized that intra-familial abuse by adolescents result from a number of specific circumstances that exist within the family structure, including the availability of access to their victim and the inherent trust that exists between siblings.

Until the early 1980's, sexual offenses committed by juveniles were often minimized and dismissed by family members, professionals and the public (Ryan, 1999a). In fact, intra-familial offending may go underreported because parents may be especially reluctant to report to authorities that one of their own children has sexually abused another child in their home (Righthand \& Welch, 2001). Experts in the field agree that sexually abusive behavior, juvenile or otherwise, is contact that is sexual in nature and occurs without consent, without equality, and as a result of coercion, manipulation, game-playing, or deception (Shaw, 1999). In order to conceptualize the specific research goals of the current project, some definitions must be established beyond that of CSA; including a working definition for juvenile sex offender (JSO), 
juvenile delinquent (JD), juvenile comparison (JC) and supervisor. The three groups of participants were defined within the context of the larger study from which participants were drawn. Details are provided in the following sections.

\section{DEFINING JUVENILE SEX OFFENDERS (JSO)}

Aljazireh (1993) defined juvenile or adolescent sex offenders as teens who commit sexual offenses while between the ages of puberty and the age of majority. For the purposes of this study, a juvenile sex offender (JSO) is defined as an individual who was convicted of a sexual offense while between the ages of 12 and 18 years of age. Sexual abuse is defined as: touching someone sexually; having someone touch you sexually or; forcing, threatening, tricking or bribing someone for the purpose of involving them in sexual activities. According to the Bureau of Justice Statistics, $23 \%$ of all sexual assault offenders were under age 18 at the time of the offense and about $3.7 \%$ were under the age of 12 (Snyder, 2000b).

The data used for the current study was taken from a larger data sample currently being gathered under the direction of Keith L. Kaufman, Ph.D. supported by funding from the Centers for Disease Control (CDC: Grant R49/CCR01651701 ) and with the intent of researching the connection between parental supervision and modus operandi (i.e., patterns of perpetration) in sexual offenders. Although this data collection is ongoing, only data gathered prior to June 1, 2008 was used for the current study. The majority of data from JSO participants were collected over approximately a five-year period from 2000-2005 from juvenile sexual 
offenders incarcerated for sexual offenses against child victims (i.e., under 12 years of age). JSO sites in seven states: (i.e. Oregon, Texas, Ohio, New York, New Jersey, South Carolina, and Florida) were selected based upon their geographic distribution as well as their reputations for providing high quality offender treatment and their abilities to provide a diverse sample of Hispanic, Black American and Caucasian participants. At all collection sites, the goal was to collect data from participants reflecting each of the three ethnic/racial groups to minimize potential bias related to regional differences in offending. Only offenders who had already been sentenced were included to minimize offenders' concerns related to pending legal matters and to reduce reluctance to participate in the study as a result of their attorneys' objections. To ensure intellectual diversity in the samples, efforts were made to include some JSO participants with known reading difficulties. This was accomplished by project staff reading the measures to at least one group of offenders at each data collection site (i.e., while they marked their own measure to preserve their privacy and anonymity). All participants were screened with the Wide Range Achievement Test (WRAT: Wilkinson, 1993) to identify reading difficulties. Participants unable to score at the $6^{\text {th }}$ grade reading level on the WRAT were dropped from the larger study at collection sites where no preplanned groups were organized to read to participants. Additionally, at the time of administration of the questionnaires for the larger study, a Spanish language version of the WRAT was not available and therefore Spanish speaking 
participants were included based on the recommendations of personnel at the individual facilities.

Exclusion criteria for the larger study included potential participants who were unable to comprehend questionnaire content. Participants with IQs lower than 80 , based on facility testing, and were excluded as well as offenders who had a mental health diagnosis suggesting difficulty maintaining contact with reality (e.g., Schizophrenia). Finally participants were excluded based on negative answers to the following questions:

1. Did you sexually abuse a child who was less than 12 years old?

2. Were you younger than 18 when you first sexually abused a child?

Prior to the application of exclusion criteria specific to this research study, the JSO group consisted of 368 participants.

\section{DEFINING JUVENILE DELINQUENT (JD)}

An act of juvenile delinquency is a violation of Federal law, committed by a person prior to age 18 , which would have been a crime if committed by an adult (18 U.S.C. $\S 5031$ ). For the purposes of this study, a juvenile delinquent (JD) is defined as an individual who was convicted of a non-sexual criminal offense between the ages of 12 and 18 years of age. JD participants were obtained from incarceration facilities and outpatient programs in seven states (Oregon, Texas, Ohio; New York, New Jersey, South Carolina, and Florida). The data were collected from the JD participants during the same approximate 5 year period of time from 2000-2005. The JD group in the 
participant sample, before the application of exclusion criteria, consisted of 402 participants.

JD participants were excluded based on the same IQ and comprehension requirements as the JSO group. Additionally JD participants were excluded based on an affirmative answer to either of the following questions:

1. Have you ever been arrested for a sexual abuse related crime?

2. Have you ever been convicted for a sexual abuse related crime?

Prior to the application of exclusion criteria specific to this research study, the JD group consisted of 402 participants.

\section{DEFINING JUVENILE COMPARISON (JC)}

The second comparison group utilized in the existing study was made up of individuals between the ages of 12 and 18 years of age with no history of criminal offense. These juvenile comparisons (JC) were recruited from community settings (e.g., community centers) in the same communities in which individuals in the JSO and JD groups were surveyed. Recruitment was accomplished via flyers, posters, and word of mouth. In addition to exclusion based on reading comprehension abilities as determined by WRAT cores, participants were excluded based on a negative answer to the following question:

1. Are you under the age of 18 ?

Or an affirmative answer to the following two questions:

2. Have you ever been convicted of ANY crime?

3. Do you have any mental disorders? 
Prior to the application of exclusion criteria specific to this research study, the JC group in the participant sample consisted of 271 participants.

\section{DEFINING SUPERVISOR}

The American family had changed dramatically over time. The nuclear family is now a minority in American society (Bengtson, 2001). Mintz \& Kellogg (1988) said that the family unit used to function as an economic team to meet mutual goals, such as owning a home, being economically secure, and raising children. The expectation that normal family structure reflects the nuclear family, consisting of a father, mother and children, has changed. Amato (2005) stated that nearly one million children experience divorce every year, and about half of all children will reside at least temporarily in single-parent households, usually with their mothers. The data set utilized in the current recent study was collected with the recognition that many children live in family units with a female head of household. All participants received detailed instructions directing them to think of their female caregiver as their supervisor before they completed their surveys. The term "supervisor" will be used throughout this paper to reference the female caregiver or head of household in the participant's family. This caregiver could be a biological mother, step-mother, adoptive mother, grand mother or other female who has taken on the role of parenting the teen participating in this study. 


\section{A REVIEW OF THE LITERATURE}

\section{JUVENILE SEXUAL OFFENDERS' ROLE IN CSA}

A degree of concern about juvenile sex offenders (JSO) is not without substance (Caldwell, 2002). JSOs are heavily overrepresented in the National Incident-Based Reporting System maintained by the Federal Bureau of Investigation (Caldwell, 2002). The problem of sexual assaults committed by adolescents is serious and widespread (Burton, 2000). Juveniles are responsible for a large proportion of sexual offenses. In the United States, up to $20-30 \%$ of rapes and $30-50 \%$ of child molestations may be committed by adolescents (Celini, 1995). Celini (1995) also reported $47-58 \%$ of adult sex offenders committed their first sex offence as adolescents or younger.

In 1995, 16,100 adolescents were arrested for sexual offenses not including rape and prostitution (Sickmund, Snyder, Poe-Yamagata, 1997). Evidence suggests that only a fraction of sex offenses are reported to the police (CSOM, 2002) and, therefore, data based in crime statistics, fails to reflect the true scope of the problem. Concerns result in uncertainties about the actual incidence of adolescent perpetrated child sexual abuse. Elliot, Huiznga and Morse (1985) reported that, on average for each rape for which a male adolescent had been arrested, he had committed approximately 25 other rapes that went unreported.

For many years, research on juveniles who sexually offend has been sparse. This dearth of studies may be due to a number of factors. First, in many states, juvenile records can be sealed or expunged (USDJ Bulletin, 1998) and are not 
available for research purposes. Second, there is a continuing societal belief in the need for secrecy surrounding sexuality in childhood (Alter-Reid, Gibbs, Lachenmeyer, Sigal, \& Massoth, 1986). It has long been recognized that child sexual abuse often occurs within the context of families (Finkelhor, 1994), and much of it remains known only to those within this context. This may explain, in part, why only one-fourth of identified cases of sexual abuse are available for research (Alter-Reid et al., 1986). Third, it is also telling that much of what is known about juvenile sex offenders comes from retrospective research on the childhood histories of adult sex offenders (Ford \& Linney, 1995). This information may not provide accurate assessments of juvenile behavior. Years of research on recalled events and clinical practice make it clear that memories are not perfect records of past events (Lindsay \& Read, 1994). Recent improvements in research on juveniles who sexually offend include assessing their behavior within a much shorter time period after their offenses occur to negate memory confounds. In keeping with this trend, the current studies surveyed 1,041 participants while they were still juveniles and within a relatively short period of time after their offenses were committed. Caldwell (2002), among others, says that early identification and effective intervention holds the promise of preventing numerous sexual offenses that might otherwise be committed by that offender over the course of his or her lifetime if no intervention occurs.

\section{ECOLOGICAL/PUBLIC HEALTH APPROACH}

Although it is easy to understand how victims of sexual abuse are impacted by their abuse, it is also important to recognize that the consequences of abuse extend far 
beyond the primary victim. In order to do so, many investigators have adopted an ecological perspective. This model was developed by Urie Bronfenbrenner (1979) to explain the factors that influence a child's development and focuses on the quality and context of the child's environment. He explained that each of these complex "layers"

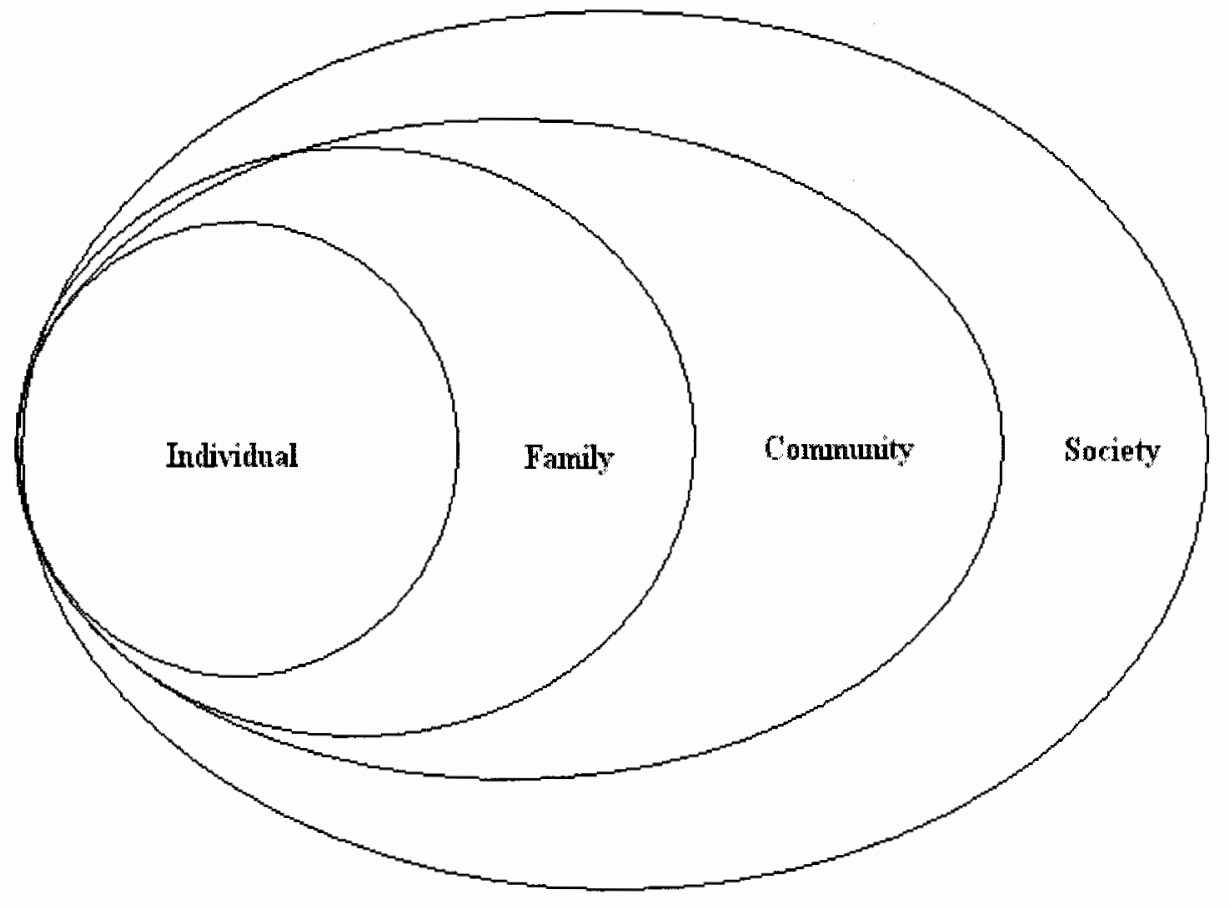

Figure 1: Bronfenbrenner's Ecological

in the child's environment affect how a child develops. Bronfenbrenner's model is often depicted as nested concentric circles. The individual (or child) is nested within the family, which is nested inside of the community or culture which is nested within society at large. Using this framework to explore the multiple levels that affect the child fosters a more in depth investigation of the consequences of CSA (Cicchetti \& Toth, 1995) and encourages recognition of the far reaching effects of CSA. In fact, the 
Centers for Disease Control and Prevention (CDC) and the World Health Assembly have declared all forms of sexual violence a public health priority (McMahon and Puett, 1999). Defining violence as a public health issue acknowledges the need to assess and address the problem at multiple levels across the ecological model (i.e., individual, family, community, society). In order to comprehend fully the public health impacts of CSA, it is necessary to investigate its consequences not only on the primary victims, but also to those on each level of Bronfenbrenner's ecological model. The following sections explore the impact of abuse on victims and their families, offenders and their families, as well as the larger community and society as a whole. CONSEQUENCES TO VICTIMS

Often, the most visible and talked about consequences of CSA are those that occur in victims. Even though recognized, the consequences to victims of CSA remain understudied (Malinosky-Rummell \& Hansen, 1993) and underestimated (Alter-Reid et al. 1986), especially in very young victims of CSA (Lyons, 1988). Childhood sexual abuse is a major risk factor for a variety of problems, both in the short term, and throughout later life.

Physical signs of child sexual abuse are not always present (Botash, 2008). Further, Kendall-Tackett et al. (1993) noted that 20 to $40 \%$ of children show no signs of symptoms or problems associated with sexual abuse at the time of initial assessment. When physical indicators are present they include bruises to the skin on the arms, legs and genital areas, abrasions on the wrists and ankles, as well as hymeneal or rectal abnormalities (Botash, 2008). Physical symptoms of abuse may 
also include bleeding, irritation or discharge of the genitalia or anus, painful urination and frequent urinary tract infections (Lahoti, McClain, Girardet, McNeese \& Cheung, 2001). Many researchers also report that child victims of sex abuse can test positive for sexually transmitted infections (Botash, 2008; Lahoti et al., 2001; Gutman, St. Clair, \& Weedy, 1991). Somatic symptoms attributed to children within a short time after suffering CSA can include headaches, abdominal pain, constipation, diarrhea, incontinence, and general fatigue (Botash, 2008). Sudden changes in behavior may also occur, such as acting out sexually, acts of aggression, problems in school, regression (e.g., return to thumb sucking, use of a security blanket), sleep disturbances, depression and eating disturbances (Lahoti et. al., 2001). The literature suggests that physical and behavioral impacts, adverse developmental consequences affecting emotional, social and cognitive functioning are often evident in many CSA victims, as well (Wang \& Holton, 2007). Social pressures often preclude children from talking about their abuse. In the case of many young children, however, failing to recognize their victimization as child sexual abuse is a common problem (Gilbert, 1988; Young, 1997; Summit, 1983). This failure further contributes to the silence surrounding some instances of CSA. Young (1997) stated that the sexual abuse is normalized by the offender in the form of a game, appropriate caretaking, socialization or "normal" family interaction. This "normalization" contributes to some children's lack of recognition that they have been victimized. In support of this contention, Summit (1983) asserts that children find it difficult to image trusted adults hurting them. Ackerman \& Graham (1990) supported this supposition in stating that, in the 
absence of other information, children assume that their childhood experiences are universal norms. Although many children have been exposed to some form of child abuse prevention information, child advocacy groups, such as Prevent Child Abuse America (2009), have suggested that the major barrier to addressing prevention in a meaningful way is the public's current understanding of child abuse as those extreme dramatic cases profiled in television dramas and the evening news. This extreme view of what constitutes abuse negates consideration of emotional cruelty as abuse and instances where parents fail to assume parental responsibilities as neglect.

It is important to acknowledge that the experiences of all CSA victims are unique and cannot be measured or explained simply by aggregate data. As Finkelhor \& Brown (1985) pointed out, sexual abuse experiences can vary dramatically in terms of the ages of the victims, the amount and kind of trauma they experience, and the support and treatment they receive following the abuse. When a victim lives in a nonsupportive environment, he or she is more likely to experience negative consequences from traumatic experiences. Factors that can increase or decrease distress related to sexual abuse include: characteristics of the crime itself, characteristics of the individual child, and characteristics of the environment (Dominquez, Nelke, \& Perry, 2002). There has been a great deal of controversy within the research community regarding which age group experiences the highest incidence of psychopathology as a result of childhood sexual abuse. Finkelhor \& Brown (1985) found that adolescent victims in the 7-13 year old age group suffered the strongest effects while other researchers have found that younger children suffer more deleterious effects (Wolfe, 
Gentile \& Wolfe, 1989; Courtois, 1979; Meiselman, 1978; Russell, 1986). Work by other researchers, including Gomes-Schwartz, Horowitz, \& Sauzier (1985) and Peters (1976) supports Beichtman's conclusion that the disparity of outcomes found by researchers may be produced by the confounding effects of age at abuse onset, abuse duration, and the type of acts committed against the victims (Beitchman, Zucker, Hood, daCosta, \& Akman, 1991).

When looking past the immediate effects of CSA in children, many researchers have studied the short term effects in the context of behaviors and consequences documented prior to adulthood. The list of deleterious consequences in children suffering from CSA is long. Depression is evidenced across all age groups of children who experience CSA and in adults molested as children (Beitchman, Zucker, Hood, deCosta, Akman \& Cassavia, 1992; McGrath, Keita, Strickland \& Russo, 1990; AlterReid et. al, 1986; Banyard \& Williams, 1996). Additionally, CSA places victims at increased risk for suicide attempts (Mullen et al. 1996; Polusny \& Follette, 1995; Brown, Cohen, Johnson, \& Smailes, 1999; Dube et al.,2005 ), low-self esteem (Mullen et al., 1996), increased occurrence of sexually transmitted diseases (Fergusson, Horwood \& Lynskey, 1997), subsequent substance abuse and subsequent re-victimization (Wang \& Holton, 2007; McMahon and Puett, 1999; Banyard \& Williams, 1996), eating disorders (Kendler, 2000; Wonderlich, Brewerton, Zeljko, Dansky, \& Abbott, D., 1997; Polusny \& Follette, 1995; Briere \& Elliott, 1994), truancy, running away, drug involvement (Polusny \& Follette, 1995), and conflicts with authorities (Alter-Reid et al. 1986). Sexually abused children exhibit other 
behavior problems, including excessive and inappropriate sexual behavior (Margolin \& Gordis, 2000; Briere \& Elliot, 1994; Finkelhor \& Brown, 1985). Finkelhor \& Brown (1985) developed a concept that addresses the disrupted sexual development of victims of CSA which they term "Traumatic Sexualization" (TS). Their explanation of the process of TS suggests that victims of CSA may develop sexual feelings and sexual attitudes that have been shaped in developmentally inappropriate ways as part of the abuse and therefore experience interpersonal dysfunction.

Researchers have also found that victims of CSA rate themselves lower than non-abused children on self-concept regarding intellectual and school status, physical appearance and attributes, anxiety, popularity, happiness, and satisfaction (Margolin \& Gordis, 2000). This negative view of self is an important construct to consider when looking at how individuals relate socially. This construct will be discussed in greater detail later in the proposal (See "Attachment Concerns with Victims"). Margolin \& Gordis (2000) found that children who have suffered sexual abuse have disorganized and insecure attachments to their primary caregivers and become sensitized to anger. Research with adolescent victims of CSA have indicated that childhood abuse of any kind (including sex abuse) can also lead to life altering decisions made by teenagers. For example, adolescents with a history of physical abuse are more likely to smoke cigarettes, use cocaine, and engage in sexual intercourse with multiple partners than non-physically abused children (Rodgers, Lang, Laffaye, \& Satz, 2004). Those reporting sexual abuse also had significantly poorer overall mental health and a higher incidence of sexual problems (Mullen et al., 1996). 
Researchers have documented that the previously described consequences for victims of CSA can be long lasting and extend far beyond childhood, through adolescence and into adulthood, potentially compromising the lifetime productivity of maltreatment victims (Daro, 1988). Dube and her colleagues (Dube et al., 2005) published the results of a retrospective study in which they compared the long term effects of CSA based on victims of both genders. They found that a history of suicide attempts was more than twice as likely among both men and women who experienced CSA as compared to individuals reporting no history of CSA. In a similar vein, Dube et al. (2005) further reported that both men and women exposed to CSA were at a $40 \%$ increased risk of marrying an alcoholic and were $40 \%$ to $50 \%$ more likely to report current problems with their marriage. CSA has also been associated with poor selfesteem in adulthood (Mullen et al., 1996; Bagley \& Young, 1990), as well as impaired psychological adjustment, social relations, and academic achievement (Margolin \& Gordis, 2000). Mullen et al. (1996) reported that women who have been sexually abused as children were more likely to marry earlier and become pregnant prior to the age of 19 years of age.

Most studies of CSA have focused on female survivors (Saunders, Kilpatrick, Hanson, Resnick, Walker, 1999; Fromuth, 1986; Harter, Alexander \& Neimeyer, 1988; Arias, 2004; Miller, Downs, Gondoli \& Keil, 1987; Merrill, Newell, Thomsen, Gold, Milner, Koss et al., 1999). The lack of focus on male victims in research examining CSA limits the amount of available information about the long-term impact of CSA on male survivors. In 1986, Freeman-Longo concluded that male children who 
have experienced multiple episodes of sexual and physical victimization are greater risk to become abusers themselves. Of note, however, is the facts that available data suggest that relatively few sexually abused males go on to sexually perpetrate (Hunter, Figueredo, Malamuth \& Becker, 2003). While sex offenders report higher rates of sexual abuse in their own histories, early childhood sexual victimization does not automatically lead to sexually aggressive behavior (CSOM, 2000). Even with the recognized underreporting of CSA, researchers have come to realize that childhood sexual abuse victims can have long lasting consequences affecting them physically, socially and psychologically (Mullen, Martin, Anderson, Romans \& Herbison, 1994; Briere \& Elliott, 2003).

\section{IMPACT OF CSA ON VICTIM'S FAMILY}

As previously noted the consequences to the victim can be severe and is often the primary focus of the literature. However, the consequences to those close to the victim are also of critical concern. Johnston \& Ward (1996) recognized that sexual offending continues to emerge as a major social crisis resulting in significant psychological and emotional costs to victims' family members as well. As family and friends support and care for the primary victim, they too can suffer adverse consequences. In response to the abuse disclosure, an initial consequence may be what has been called "compassion fatigue"; as these individuals' function as the victim's support network, the act of caring for the victim becomes physically and emotionally exhausting (Cerney, 1995). Compassion fatigue was first used to describe burnout in nurses exposed to traumatic work-related experiences (Johnson, 1992). “Secondary 
traumatic stress" (STS) has also been applied as a label for this phenomenon (Stark \& Flitcraft, 1988; Williams 1994).

Lieb, Quinsey and Berliner (1998) reported that $60 \%$ of boys and $80 \%$ of girls sexually victimized as children were assaulted by someone they knew. Freyd and her colleagues (Freyd, Putnam, Lyon, Becker-Blease, Cheit, Siegel et al., 2005) agreed that most CSA is committed by family members or individuals close to the child. Rates of intra-familial sexual abuse have been reported to be between 12\% (Wyatt et al., 1999) and 56\% (Vogeltanz, Wilsnak, Harris, Wilsnack, Wondrlich, \& Kirsjanson, 1999). When CSA occurs within the a familial context, it is easy to recognize how disintegration of the family unit due to divorce or other conflict resulting from the abuse disclosure can take a significant toll on all family members. Mullen et al. (1994) found that disorganized family systems and high levels of marital distress were associated with CSA. Additionally, CSA survivors' families exhibit a lack of adaptability, lowered emotional engagement and less cohesion (Alexander \& Lupfer, 1987).

\section{IMPACT OF CSA ON OFFENDERS}

Given the public's abhorrence of CSA offenders, there can be a tendency to ignore the impact of CSA on perpetrators and their families. This lack of attention to the needs of the offender is a critical failure. This is particularly true given evidence that offenders do respond to treatment. In fact, in a meta-analysis Alexander (1999) found both that juveniles who sexually offend respond well to treatment and will most likely return to the community, virtually without exception. The importance of 
addressing offenders' needs and the impact of perpetrating CSA with regard to community safety are underscored by their ongoing presence in the community; in the case of juvenile sex offenders, the vast majority never leaves a community setting (CSOM, 2002). The following section reviews the impact of being identified as an offender on JSOs including their alienation, ostracism, restriction of movement, physical and mental health problems as well as financial consequences.

CSOM (2002) estimated that in 1997 , some $60 \%$ of convicted sex offenders were supervised in the community. Consequences to the offender may be categorized as those that are more and less apparent. In 1994, Congress passed The Jacob Wetterling Crimes against Children and Sexually Violent Offender Registration Act mandating all 50 states to require sex offenders to register with local law enforcement agencies. This process facilitates the ability of state agencies to notify the public as to the location of registered sex offenders within their community. The overall effect of this act is to make public the names and addresses of registered sex offenders, thus alienating them within our society and branding them with a modern version of the "scarlet letter". Although it seems perfectly reasonable to notify communities as to the whereabouts of sex offenders (i.e. so that parents can better protect their children), this organized ostracism causes negative consequences both to the offender and the community. The following paragraphs will discuss a few of the problems with existing policies surrounding public notification and registration of sex offenders.

Many researchers have suggested that community notification is an emotionally driven response that provides a false sense of security to members of the 
community (Freeman-Longo, 1996; Jones, 1999; Levi, 2000; Lotke, 1997; Prentky, 1996). Patricia Wetterling, mother of Jacob Wetterling, for whom the Jacob Wetterling Crimes Against Children and Sexually Violent Offender Registration Act is named, has been quoted as identifying the problem with registration, notification and residency restriction laws for sex offenders in the following terms: "People want a silver bullet that will protect their children, [but] there is no silver bullet. There is no simple cure to the very complex problem of sexual violence" (Tofte, 2007 pg. 2).

In an article published in 2005, Tewksbury detailed the collateral consequences to living life as a registered sex offender. This account provided insights as to the impacts of being identified publicly as an offender. Although understandable when viewed from the perspective of communities attempting to keep children safe, community notification and registration efforts increase the likelihood of collateral consequences to offenders (Tewksbury, 2005). When the public is notified of a sex offender's presence in their community, there are likely to be a host of barriers erected against their full and successful reintegration (Zevitz \& Farkas, 2000). The most common barriers are those associated with finding employment and securing housing. It is important to note that social isolation and frustration can, in and of itself, create conditions that could lead to recidivism (Tewksbury, 2005). This outcome is the exact opposite of what is desired when considering offender registration. Goffman (1962) has often been quoted saying, "An offender may feel that his case is helpless and he will always be seen in a negative light, and thus re-offending would make little difference to him" (add page number). There has been little research, however, as to 
whether sex offender registration will actually lower the number of children who are sexually abused in the United States (Malesky \& Keim, 2001).

Freedom of movement and association may also be restricted for individuals identified as sex offenders. Many state legislatures have enacted exclusionary zone statutes that limit where offenders may reside and work. A brief overview of theses statues can be found in Appendix V, as compiled by the Council of State Governments (2008). For example, the State Legislature has mandated that the Oregon Department of Corrections establish criteria to be considered in the residential placement of sex offenders. These criteria include a prohibition against allowing sex offenders to reside near locations where children are the primary occupants or users (Oregon Revised Statute 144.642, 2008). These same restrictions can affect adolescents under the jurisdiction of The Oregon Youth Authority, the juvenile corrections agency in the State of Oregon, who are remaining with immediate family, during community placement or during post-incarceration supervision. While the purpose of this legislation is laudable, it may restrict offenders' habitation and employment so much as to increase the risk to the community. By denying sex offenders a variety of employment, social and educational opportunities, the sex offender label may prevent these individuals from starting a new life and making new acquaintances, thus resulting in difficulty in discarding their criminal patterns (Wakefield, 2006). Levenson \& Cotter (2005b) found that although housing restrictions aimed at sex offenders were enacted to protect our communities, they may, in fact, achieve the opposite. Such laws greatly diminish housing options for sex offenders, often forcing 
them out of metropolitan areas where they tend to be farther away from social support, employment opportunities, treatment centers, and social services (Tofte, 2007;

Levenson \& Cotter, 2000b). These consequences may inadvertently contribute to dynamic risk factors that ultimately increase their danger to the community (Levenson \& Cotter, 2000b). Further, these restrictive laws may also force offenders to live in proximity to each other concentrating them in the limited housing available. Grouping released sex offenders in this way may decrease their integration into the community, increase isolation and create financial and emotional distress (Levenson \& Carter, 2005b). In fact, current social policies including residency restrictions may, in fact, contribute to dynamic risk factors for offenders in the community, ultimately becoming counter-productive and increasing their risk of re-offense (Levenson \& Carter, 2005b).

Other jurisdictions have instituted polices that prohibit convicted sex offenders from being in public places. In Illinois, convicted sex offenders are now prohibited from being in public parks and school zones (Sample \& Bray, 2003). These exclusionary statutes, and other socially acceptable forms of ostracism, were formulated due to the belief that sex offenders have a high propensity to recidivate. Many researchers have found, however, that compared to other non-sexual offending groups, sex offenders actually exhibit lower rates of re-offending (Langan \& Levin, 2002; Hanson, Scott \& Steffy, 1995; Sapsford, 1998; Sipe, Jensen \& Everett, 1998). In 1998, Hanson \& Bussiere evaluated recidivism rates for all sexual offenders and found overall, recidivism rates for sexual offenders to be $13.4 \%$. This recidivism rate 
is comparatively low to individuals that commit non-sexual offenses. Langan \& Levin (2002) reported that of prisoners released in $1994,73.8 \%$ of those that were arrested for property crimes were re-arrested within three years, and $78.8 \%$ of those arrested for motor vehicle theft recidivated. Juveniles who sexually offend have recidivism rates even lower than their adult counterparts. Available treatment outcome research suggests that the detected sexual relapses among teenage offenders who have been in treatment programs are as low as 5\% (Chaffin \& Bonner, 1998).

Concerns have been voiced that recidivism rates may actually be much higher and contain other inaccuracies due to lack of reporting. The Center for Sex Offender Management (CSOM, 2009) acknowledges that reliance on reported crimes as a measure of recidivism most definitely results in smaller statistics. While this method of calculating recidivism rates may indeed result in artificially low recidivism rates, it unlikely that rates of reporting will change dramatically in the near future and bring recidivism rates closer to actual re-offense rates. Professionals in the field have stated that "The Light" shown on juvenile offenders by the justice system in acknowledgement that they have committed a crime, along with the restrictions on offenders already discussed, greatly reduces their opportunities to reoffend (Cambra, 2008). It is also important to acknowledge that while there have been increasing amounts of research over the last 15 to 20 years, there remains much more to learn about the factors associated with juvenile recidivism including the accuracy of the reported rates of re-offense. 
Sample \& Bray (2003) stated that sex offender legislation is unprecedented in its ability to penalize a specific type of offender after his/her judicially prescribed punishment has been served. They also reported that at least 21 states have created legislation that allows sex offenders to become "eligible" for civil commitment after their prison sentence has been served. Civil commitment statutes allow a judge or jury to determine that at individual is unsafe to be released to the community following their court mandated sentence for an offense and allows them to be placed in a secure facility for control, care and treatment. Specifically, involuntary commitment of sexually violent predators (SVP) in states such as Washington permits the state to retain custody of individuals found by a judge or jury to pose risks for reoffending. Concerns have surfaced by organizations such as the American Civil Liberties Union (ACLU) that this process violates individuals' federal civil rights. The United States Supreme Court, however, has upheld the rights of states to civilly commit SVP, and clarified that selected individuals must have a history of criminal sexual behavior and must meet two other criteria for SVP civil commitment. These two criteria are: 1) a mental abnormality or personality disorder predisposing the individual to sexual violence, and 2) likelihood of future sexually violent behavior (Levenson, 2004).

Beyond the experiences of alienation, ostracism, and institutionalization offenders also suffer financially. First, in addition to the obvious expenses of court and legal fees, many offenders may be required to make restitution to their victim and pay for their own treatment after release from custody (Tewksbury, 2005). Serving time in prison causes additional hardships, as well. While incarcerated, offenders typically 
lack the ability to earn wages and gather work experience. Once released, the obvious gap in employment coupled with their "scarlet letter" and restrictions based on registration laws as to where they can work make finding employment difficult. Institutionalization may also affect how prisoners adjust to community life after release (Goodstein, 1979).

Having committed child sexual abuse has also been shown to affect the mental and physical health of the offender. A sexual offender's mental health can be affected in many ways. First, sexual offenders rarely meet diagnostic criteria for major mental illness, but they often show signs of low self-esteem and assertiveness deficits (Marshall, 1993). Second, individuals convicted of sexual offenses often speak of the stigma attached to being labeled as a sex offender (Meloy, 2006). Becker (1998) said that what we label or call an individual can have a tremendous impact, not only on the individual, but on how others relate and regard that person. She also suggested that labeling a child (i.e. a youth that has offended sexually) has the potential to stigmatize youth and to isolate them further from peers, adults and potential sources of social and psychological support. Third, the commission of CSA has been associated with higher incidences of depression and other mental health problems (Motiuk \& Porporino, 1992). Finally, the fear of retribution from the community also affects the mental health of offenders (Meloy, 2006). Sadly, this fear is often realized. For example, Levenson \& Cotter (2005a) found that one-third to one-half of sex offenders subjected to community notification in Florida reported dire consequences such as the loss of a job or home, threats or harassment or property damage. 
In addition to the negative mental health outcomes affecting released sex offenders, researchers have found that there are consequences that affect their physical health as well. Motiuk \& Porporino (1992) reported that convicted sex offenders have higher incidences of alcoholism than non-offenders. A 2006 report aimed at preventing suicide in Pennsylvania (OMHSAS, 2006) found that sex offenders were also at an increased risk of suicide. Further, during their periods of incarceration, juvenile offenders commonly lack regular access to preventive health care in their communities and suffer significantly greater health deficiencies, including psychosocial disorders, chronic illness, exposure to illicit drugs, and physical trauma when compared with adolescents who avoid the juvenile justice system (Pickering 2003). Despite the fact that inmates are the only individuals with a guaranteed right to health care in the United States, there is a long history of inadequate and substandard care for this population (Morris, 2005). Finally, because of their status as sex offenders, many individuals face an increased risk of assault from other inmates while incarcerated (Stewart, 2007), and from community members post-release. Levenson \& Cotter (2005a) stated that $16 \%$ of the participants in their study reported being physically assaulted because of their status as registered sex offenders. They went on to say that the negative consequences of offender registration affected other members of their household, a consequence of CSA that is often overlooked (Levenson \& Cotter, 2005a). 


\section{IMPACT OF CSA ON OFFENDERS' FAMILIES}

In assessing the impact of CSA, it is important to take into account the physical, financial, psychological and other consequences to the families of offenders. Often, offenders' family members become targets of public criticism. They may be subjected to ostracism and harassment from community members and may suffer emotional difficulties as well (Tewksbury, 2005). Family members may lose the social support of friends, work colleagues and extended family members for choosing to continue their involvement with the offender. In 2007, Human Rights Watch published a report on sex offender laws, authored by Sarah Tofte. This report included interviews with individuals affected by residency restrictions placed on offenders. Many of the interviews with offenders and their family members describe how registration laws have adversely affected their lives (e.g. losing homes, jobs and having to live apart). Families of offenders may also face the financial burdens of being expected to "shoulder" the responsibility for paying costs associated with the "offender's" legal proceedings and treatment. Additionally, in cases where the offender has been assigned to provide restitution, family members may suffer from diminished financial resources as the offender meets his or her restitution obligations. Families of intra-familial juvenile offenders may be hardest hit, paying, in some cases, for offender, victim and family treatment costs as well as legal fees. In some cases, families must relocate, either to avoid harsh social consequences or to be involved in the offender's treatment while he or she is incarcerated. Many family members may also miss work to address the emotional and physical needs of their family, to attend 
court hearings in support of the offender and/or the victim and to visit the offender after they have been incarcerated. In considering all of the ways in which offenders' families are affected, it is easy to see that they quickly become secondary victims of the offending behavior.

\section{COMMUNITY AND SOCIETAL IMPACT}

Finally, it is important to consider the consequences of CSA on the local community and on society as a whole. Quantifiable consequences to the community include: reduced feelings of safety; a decreased sense of freedom (e.g., to have their children play unsupervised safely), a waning trust of others (e.g., enhanced concerns about neighbors and babysitters); and greater taxpayer responsibility to cover the expenses associated with CSA related investigations, prosecutions, incarcerations, and treatment. Expenses also include funding for police, judicial and children's services employees, victims' services staff, and prevention programs. A 1996 report from the United States Department of Justice estimated that the rape and sexual abuse of children cost American taxpayers 1.5 billion in medical expenses and $\$ 23$ billion annually overall (Putnam, 2001). This estimate demonstrates how costly CSA is to us as a society. Public funds are used to provide support for victims, to support our judicial system, to pay for incarceration and treatment for offenders and for personnel to monitor offenders on parole and probation. In 2001, Shanahan \& Donoto's (2001) cost-benefit analysis of treating adult offenders of child sex abuse was one of the few peer reviewed articles to discuss the costs of sexual offending beyond those experienced by justice related institutions. Previously, a study by Prentky \& Burgess 
(1990) was recognized as the only attempt at gathering data on the costs incurred by the families of victims and to society at large. Shanahan and Donoto (2001) estimated that the tangible cost to victims averaged $\$ 1,000$ (1998 Australian dollars). This would have been equivalent to $\$ 1,650$ in US currency (FRB, 1998). They also recognized that the intangible damages were the most difficult to calculate and were, perhaps, the most difficult to overcome. In a comprehensive report prepared by the United States Department of Justice on the economic costs of crime, the injuries compensated for in child sex abuse were found to be the most expensive of all crime categories. The report estimated the intangible costs of child sex abuse to be approximately $\$ 90,000$ (1993 US dollars) per criminal victimization (Miller, Cohen \& Wiersma, 1996). At the same time, questions remain regarding the efficacy of community level efforts, including offender registration and community notification. According to a Human Rights Watch report (Tofte, 2007), there is insufficient evidence to determine whether posting information about registered sex offenders on the Internet is a valuable and effective public safety tool. Researchers have suggested that registration laws and subsequent community notification actually results in the community developing a false sense of security (USDJ, 1997b). Additionally, because a majority of sex offenders do not appear on registration lists, the child may be in close proximity to or endangered by "sex offenders" without parents realizing it (Matson \& Lieb, 1996). Offenders may not appear on registration lists for a variety of reasons including the fact that each state has different requirements and procedures surrounding registration of sex offenders (USDJ, 2008) For example, some offenders plead to 
lesser charges in legal proceedings and, thus, avoid registration requirements (Ingram, 1999). Finally, it is important to consider that many offenders do not face any charges because they are simply never caught (Salter, 2003). Conversely, notification may actually cause immediate problems for the community. Zevitz (2004) suggested that residents notified of a convicted sex offender moving into their neighborhood actually experienced negative consequences and experienced a heightened sense of vulnerability, a lack of control over their environment, and a sense of helplessness and anxiety. The acceptability of these unintended consequences is questionable given the current lack of evidence supporting the efficacy of notification initiatives.

\section{CHILD SEXUAL ABUSE MODELS}

Given that childhood sexual abuse is a serious public health concern and that research indicates a large percentage of childhood sexual abuse occurs at the hands of adolescent offenders, it is important to investigate possible correlates and causes of this behavior. Many theories regarding adolescent offending have been suggested, and most, if not all, of these theories have been based on conceptualizations previously applied to adult sex offenders. Ryan (1999a) stated that the most striking comparison between adolescent offenders and their adult counterparts is that issues, patterns and distortions may be very similar, but are much less ingrained in adolescents. She also stated that the juvenile offenders exhibit more extreme stances in their perception of the deviance and seriousness of their behavior. At one extreme, the youth seem unaware that what they have done is wrong or hurtful, while JSOs at the other end of the spectrum are intensely aware that their behavior is in opposition to what is right. 
Ryan (1999a) found that only a small percentage of youthful offenders are cognizant at the time of the offense that that their behavior is abusive or exhibit signs of sadistic motivations. The most important conclusion to be drawn from Ryan's work is that the majority of JSO differ from adults in that they do not intend to hurt others. This difference is important to consider when reviewing the various theories intended to explain sexual offending.

Theories relating to sexual offending include a broad array of single factor and multi-factor models. Single factor models include: Biological; Behavioral; Sociocultural; and Attachment/Intimacy. A brief explanation for each of these single factor models is presented. Biological models suggest that biological factors predispose individuals to offend sexually. One of the most common biological factors involves having a high testosterone level, which has been found to be associated with an increased sex drive and raised aggression levels. Behavioral models suggest that offending behaviors develop as a result of conditioning or learning. An example of this model would be an individual raised in a family with a father who committed domestic violence against a female partner in front of him/her. This exposure to a demeaning and degrading attitude toward women teaches the individual to act in a similar way. Socio-cultural models emphasize that cultural and social norms influence the way individuals view violence. For example, these theories suggest that exposure to violent video games and television shows encourage violence and the domination of women. Briefly, attachment theory suggests that individuals who were not able to develop close relationships with care givers or others early in life may not have the 
ability or desire to engage in developmentally appropriate relationships. As a result, they engage in "abusive" or developmentally inappropriate behaviors in an attempt to fulfill their intimacy needs and/or to express their negative or angry feelings toward others. A more in depth explanation of attachment will be offered later in this paper. Multi-factor models posit that offending behavior results from a combination of factors. The three most recognized multi-factor models include the integrated theory of offending, the confluence model and the relapse-prevention model. Marshall, Laws \& Barbaree (1990) developed the influential integrated theory of offending. This theory recognizes that offending behavior may be the result of a combination of biological, developmental, environmental and cultural influences, individual vulnerabilities, and situational factors. The confluence model of offending is similar to both attachment theory and the integrated theory. Developed by Malamuth and others (Malamuth, 1996; Malamuth, Heavey, \& Linz, 1996; Malamuth, Sockloskie, Koss, \& Tanaka, 1991) the confluence model of offending is based on the idea that negative developmental experiences shape how individuals view themselves and others and their ability to form meaningful and healthy relationships. Additionally, this theory asserts that an antisocial orientation results from these negative developmental experiences, and that the individual uses sexual offending in order to improve his/her status among peers and in an effort to improve their self esteem. The final multi-factor model often used to conceptualize how sexually abusive behavior develops is the relapse-prevention model. According to the relapse prevention model (Laws, 1989), sexual offending behavior is the end result of a common chain of events. In 
explanation, an individual experiences a negative emotional state during which cognitive impairment allows him/her to justify deviant fantasies and resulting behavior. An important underlying part of the relapse prevention model includes the belief that experiences in childhood including family dysfunction, chaos and experiencing child abuse are precursors to offending.

As described above, multi-factor models are integrated theories comprised of different combinations of biological influences, developmental influences, environmental influences, cultural influences, individual vulnerabilities and situational factor models. Many of the multi-factor models include components of attachment theory in their explanations. These theories recognize that failing to have quality relationships with family in early life and the inability to form intimate connections with appropriate others are risk factors for delinquency (Sprott, Jenkins \& Doob, 2000).

Many experts in field suggest that adult treatment models do not work for children who offend sexually (Jones, 2007, Ryan, 1999a). This study attempts to evaluate the importance of attachment, and more specifically, internal working models in the evaluation and treatment of juvenile sex offenders. Ryan (1999a) stated that there is more optimism in the treatment of juveniles because it is believed that early intervention with this population can prevent patterns and behaviors from being reinforced and therefore decrease the chance of these children reoffending. If attachment deficits are found to manifest in a significant percentage of the JSO population in this study, the interventions Ryan (1999a) mentioned could include 
targeted therapy directed at improving the quality of interpersonal relationships or attachment to others. Before providing details about how attachment has been linked to juvenile sexual offending, it is important to describe attachment theory.

\section{GENERAL ATTACHMENT THEORY}

Attachment theory has been used to describe and explain individuals' enduring patterns of relationships from birth to death. According to Bowlby (1980) and Ainsworth (1989), the love between a mother and an infant is the result of an attachment bond formed during the first year of life; interactions between a child and his or her mother form behavioral patterns that are reflected in later relationships. Attachment has also been conceptualized as the stable tendency of an individual to seek and maintain proximity to and contact with one or a few specific individuals (Montebarocci, Codispoti, Baldaro, \& Rossi, 2004). Prominent researchers in the field of attachment have included John Bowlby, Mary Salter Ainsworth, Mary Main and Kim Bartholomew.

Early in his career, John Bowlby became convinced of the significance of reallife events on the course of child development. Specifically, he chose to focus on a child's early separation from his/her mother because, while documentation on disturbed family interactions was difficult to obtain, information regarding familial separation was available through existing, records (Ainsworth \& Bowlby, 1991). His investigations led to the formulation of his attachment theory (Bowlby, 1969; 1973; 1980). Bowlby proposed that, early in life, all children are dependant on others for their basic needs. To meet those needs, they form relationships with other individuals 
called "attachment figures." Bowlby described attachment as an emotional bond that impacts behavior from the cradle to the grave. He further asserted that the quality of those early attachments influence relationships later in life. This insight revolutionized our thinking about a child's connection to his or her mother and the long-term harm caused by disruption of this relationship through separation, deprivation, and bereavement (Bretherton, 1992). Bowlby's work emphasized the importance of bonds between individuals as indicated in his following statement, "Attachment behavior is any form of behavior that results in a person attaining or maintaining a proximity to some other individual who is conceived as better able to cope with the world" (Bowlby, 1988, 26-27). Bowlby (1969) said that the mental representations or working models of self and others form in the context of the child-caregiver relationship. He also said that these working models carry forward and influence thought, feeling and behavior in adult relationships.

Mary Ainsworth also began her research career concerned about how secure an infant felt with his or her caregiver (Ainsworth \& Bowlby, 1991). In graduate school in the 1940's, Ainsworth worked with William Blatz and studied his Security Theory (Blatz, 1966). In the early 1950's, Ainsworth worked as part of Bowlby's research team, which she often said shaped her work tremendously (cite). During the 1950's and 1960's, Ainsworth continued her work studying infants. She developed a system for the classifying infants into one of three categories: securely attached; insecurely attached; and non-attached (Ainsworth \& Bowlby, 1991). During the 1970's, Mary Ainsworth expanded her work in attachment when she developed a laboratory 
experiment she called the "Strange Situation". Ainsworth and her colleagues Blehar, Waters, and Wall (1978) observed the behavior of children (12 to 18 months of age) in response to their primary caregiver leaving or returning to the research laboratory where the study was conducted. Ainsworth and her colleagues watched for a variety of behavioral indicators including signs of anxiety, anger, positive affect and avoidance. All of these behaviors share a focus on maintaining proximity or closeness to their caregiver and reflected attachment behaviors triggered by perceived threat. Based on these observations Ainsworth and her colleagues (Ainsworth, Blehar, Waters \& Wall, 1978) concluded that there were three major "styles" of attachment: secure attachment; ambivalent-insecure attachment; and avoidant-insecure attachment. Findings from Ainsworth's work contributed to the conceptualization of an "attachment figure" as a secure base from which an infant can explore the world. She also formulated the concept of maternal sensitivity to infant signals and its role in the development of infant-mother attachment patterns (Bretherton, 1992).

Following Ainsworth's development of the Strange Situation paradigm, a number of other researchers conducted a variety of studies examining different aspects of the attachment relationship in infants. As a result, researchers began to find exceptions to the three category system (Main \& Weston, 1981; Lyons-Ruth, Connell, Zoll \& Stahl, 1987). Eventually, this led to the development of an additional category referred to as the "disorganized" attachment style (Main \& Solomon, 1990). Disordered attachment is aptly named, as it reflects a lack of recognized coherence and organization in the behavior of the child (Martorell, 2009). As might be expected, 
disorganized attachment has been related to physical abuse at the hands of parents (Carlson, Cicchetti, Barnett \& Braunwald, 1989), maternal depression (Radke-Yarrow, Cummings, Kuczynski \& Chapman, 1985) and to less severe, although still frightening, parental behavior such as intrusive or hostile care giving (Lyons-Ruth, Repacholi, McLeod \& Silva, 1991). While Ainsworth's original three attachment styles can be conceptualized as existing on a continuum of normal behavior, disorganized attachment is thought to be a marker of problems in the infant-caregiver relationship (Martorell, 2009).

Building on this research foundation, Bartholomew (1990) developed a framework that conceptualized attachment styles or internal working models into four categories: secure, preoccupied, fearful and dismissing. The four categories can be understood as representations of the dichotomous levels of an individual's positive or negative model of self, or level of dependence, and the positive or negative model of other, also termed "avoidance" (Bartholomew, 1990). This framework expanded the working models first referenced by Bowlby in 1973. Figure 2 depicts these four different categories and their placement within the internal working model.

As described above, Bartholomew's model categorized individuals' attachment styles based on the four different combinations of positive or negative view of self and positive or negative view of others (Bartholomew, 1990). The first attachment type Bartholomew labeled as "Secure." This category represented those individuals that have a positive view of themselves and a positive view of others. "Secure" individuals 
were described as exhibiting high coherence, high self-confidence, a positive approach to others, and high intimacy in relationships. Bartholomew's second category is

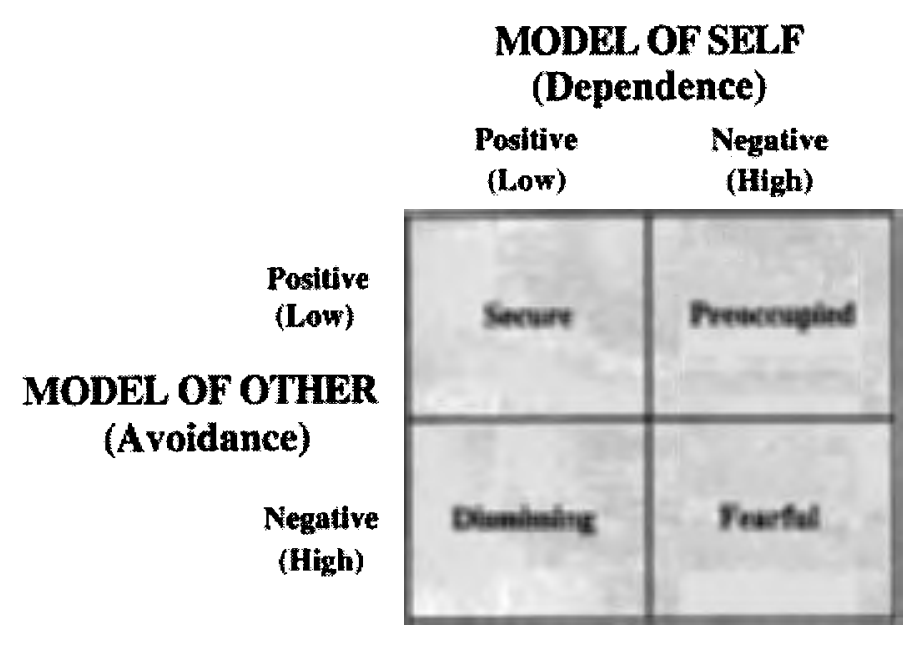

Figure 2: Bartholomew's Four Category Model

labeled "Fearful". The "Fearful" attachment style is analogous to the disorganized attachment style used in earlier attachment research by researchers including Mary Main (Shaver \& Clark, 1996). This form of attachment represents those individuals who have a negative view of self and a negative view of others. Key features of fearful individuals include: low self-confidence and avoidance of intimacy due to fear of rejection, conflicting motives of both wanting and fearing intimacy, and high selfconsciousness. The third type of attachment defined by Bartholomew is "Preoccupied." This category reflects individuals with a negative view of self and a positive view of others. The key features of a preoccupied individual include being consumed with relationships, incoherent and idealizing in discussing relationships, highly dependent on others for self-esteem, and approach oriented in relationships. 
Bartholomew's final attachment type is called "Dismissing”. This type represents those individuals with a positive view of self and a negative view of others. The key features of a dismissing individual include low elaboration and coherence, downplays importance of relationships, high self-confidence, avoidance of intimacy and compulsive self-reliance. Bartholomew utilized self report questionnaires and interviews to assess an individual's perception of the quality of their relationships, and the extent to which they have a positive or negative view of both the self and others in order to situate them within her model. Bartholomew's model has been chosen as a framework for conceptualizing the current study. Bartholomew recognized that although most clinicians recognized that a few individuals suffered from unhealthy or pathological dependence it is equally important to understand why some "healthy" individuals avoid close affectional bonds.

Many other researchers have used attachment as a lens through which to view interpersonal interaction in a variety of populations. For instance, Alonso-Aribol, Shaver and Yarnoz (2002) categorized participants in Basque County, Spain into attachment styles to evaluate dependency differences in gender. Allen \& Baucom (2004) utilized Bartholomew's four category model of attachment to understand possible motivations for extra dyadic involvement (EDI) in romantic relationships. EDI can be conceptualized as a situation where one partner in a committed relationship seeks physical or emotional attachments outside of the primary relationship. Recently, attachment style has also been researched as an important predictor of interpersonal problems and difficulties in therapeutic relationships of 
individuals with mental health patients (Berry, Barrowclough \& Wearden, 2008).

More closely related to the current study, researchers such as Marsa, O'Reilly, Carr, Murphy, O'Sullivan, Cotter et al. (2004) used attachment style as a mechanism to try to understand what may lead to sexual offending behavior in adults.

\section{ATTACHMENT CONCERNS WITH CSA VICTIMS}

Researchers have agreed that attachment deficits represent a limited ability to form meaningful and satisfying relationships, engage in intimacy, develop the skills necessary to understand others, and engage in the behaviors, interactions, and relationships that are required to acquire "human goods" (Thakker, Ward \& Tidmarsh, 2006). Thakker and his collegues explained human goods as those aspects of social experience, life, and experience that the individual perceives as desirable. Kendall- Tackett et al. (1993) suggested that utilizing a developmental perspective in CSA research may encourage more theory-driven study and address methodological issues that frequently arise. Researchers have used attachment theory in examining both the risk factors for and the consequences of CSA. Alexander (1992) suggested that any attempt to predict the onset of abuse and its long term effects must include a consideration of the family context that mediates the experience of the abuse. Finkelhor \& Baron (1986) said that the absence of a biological parent, maternal unavailability, and a child's poor relationship with his or her parents are significant predictors for increased risk for all kinds of CSA. These predictors mirror the concepts upon which both Ainsworth and Bartholomew's research was built. 
It has been suggested by some researchers that attachment deficits may be transmitted between generations (Allen, Moore, Kuperminc, \& Bell, 1998; Goldberg, 1991). Attachment theory could be used to understand how survivors of CSA interact with others (Alexander, 1992). For example, Goodwin, McCarthy \& DiVaston (1981) found that women who were sexually abused as children are more likely to have daughters that are sexually abused. Alexander (1992) suggested that this intergenerational cycle could be explained by attachment deficits in more than one way. First, she proposed that when abuse survivors develop an insecure attachment style as a result of abuse, they may experience anxiety surrounding relationships with others. This anxiety could lead to a distorted perception of their relationship with their own children. In turn, this distortion could lead to a failure of the survivor to establish healthy attachment with her own children. This failure to attach (Alexander, 1992) may prohibit the mother from monitoring her child closely or preventing situations where abuse could happen. Alexander also offered that some survivors might develop a disorganized pattern of relating to others. In this more probable scenario, the abuse survivor may become so disoriented when having to acknowledge the familiar circumstances surrounding the abuse that she may not be able to recognize evidence of her own child's abuse or hear her child's cries for help (Alexander, 1992). Alexander, Anderson, Brand, Schaeffer, Grelling, \& Kretz (1998) found that survivors of incest had a higher likelihood of exhibiting insecure attachment style and, specifically, a fearful attachment style, than individuals from the general population. 
Lyons-Ruth \& Jacobvitz (1999) agreed with Alexander (1992) when suggesting that erratic behavior by parents who have been exposed to trauma may, in turn, frighten their children. This puts the child in a paradoxical position. The perception of a threat activates the attachment system, and the infant is then motivated to approach the parent (Martorell, 2009). Additionally, when children suffer abuse at the hands of their caregivers, a child can experience increased levels of fear in response to being near that caregiver. The conflicting feelings of seeking proximity to the caregiver while experiencing fear can be more than a child's immature selfregulation abilities can manage and can lead to the child developing a disorganized attachment style (Main \& Hesse, 1990).

Kendall-Tackett et al. (1993) suggested applying a developmental approach would allow researchers to recognize that the symptomatology (or consequences) of CSA are different for each victim. For example, a 15 year old who is molested at age 4 may be differentially impacted than a 15 year old who is molested at 14 years of age. Harter (2006) addressed how abuse can affect children differently based on where they are located developmentally. Very young children (toddlerhood to age 4) understand the self only as separate, taxonomic attributes that are physical, such as "I have blonde hair" or "I have blue eyes". While this inability to understand the general concept of self worth does not mean that they do not experience self esteem, the normative all-ornone thinking that exists in this developmental stage can lead abused children to view themselves as all bad. In early to middle childhood (ages 5 to 7 ) the major source of self representations and self evaluations continues to derive from the care giving of 
significant others. Children assume at this stage of development that their parents and adult authority figures are always right. This may lead to a conclusion by the child that suffers abuse at the hands of their caregivers that they are bad and that they deserve to be "punished". In her synthesis, Harter (2006) acknowledges that there is considerable consensus that the vast majority of maltreated children form insecure attachments with their caregivers. Harter goes on to say that that continued abuse at the hands of these significant others can not only derail self esteem, as in earlier stages, but may also be more evident at this later stage due to the child's improved ability to verbalize negative self evaluations.

In the developmental stage, middle to late childhood (8-11 years of age), children begin to compare themselves to others in order to self evaluate (Harter, 2006). They are better able to see themselves in a more global way. They begin to gather emotional support from more than just their caregivers. This support can come from not only parents, but teachers, classmates and friends. However, experiencing abuse from caregivers in the form of rejection, neglect or punitive punishment can lead children to feel unlovable, incompetent, and unworthy. Finally, Harter (2006) explains that in adolescence children develop the ability to think abstractly and to see the self as differentiated. This ability to see themselves differently in differently situations may allow children victimized at this age to separate themselves from the abuse and reduce the possibility that negative self attributes resulting from abuse spills into all spheres of their life. The different cognitive abilities of children in different developmental 
stages are critical considerations in designing interventions to best address the consequences and meet the needs of abuse survivors.

It is important to understand that one of the most deleterious consequences of childhood abuse, sexual or otherwise, is one that often lasts for a lifetime. The emotional and psychological consequences of CSA can be the most damaging, leading to diminished self esteem, and a negative view of self. Leading researchers have suggested that childhood abuse is one of the most traumatic events an individual can experience (Briere \& Elliot, 1994; Briere, 1998). In fact, in review of the literature, Briere \& Elliot (1994) concluded that a variety of studies have documented chronic self-perceptions of helplessness and hopelessness, impaired trust, self-blame, and low self-esteem in abused children. Additionally, Bolger \& Patterson (2001) found that both sexual abuse and physical abuse are associated with low self-esteem. Earlier, the prevalence of childhood sex abuse was discussed; unfortunately sex abuse is not the only form of maltreatment from which American children suffer. Neglect and physical abuse are also widespread. Of the 1 million substantiated cases of serious abuse and neglect in the United States each year, about 800,000 of those children are estimated to have severe attachment disorder (Lyons-Ruth, 1996). The actual number of cases of serious abuse and neglect may be 10-16 times higher ( 8 million -12.8 million), increasing the number of children with severe attachment disorder to $6,400,000-$ $10,240,000$ (Gallup, Moore, \& Schussel, 1997). Other researchers have found that children who have suffered abuse early in their life, especially neglect, have been shown to have this negative view of self (Toth, Cicchetti, Macfie, \& Emde, 1997; 
Toth, Cicchetti, Macfie, Maughan, \& Vanmeenen, 2000; Waldinger, Toth, \& Gerber, 2001; Kolko, 1996). Research has also shown that individuals who are abused during childhood suffer from diminished self esteem (Marshall, 1993; Bolger \& Patterson, 2001) and an increased incidence of depression (Lahoti et al., 2001; Beitchman et al., 1992; McGrath et al., 1990; Alter-Reid et al., 1986, Banyard \& Williams, 1991), which would also manifest within an internal working model as a negative view of self. Researchers have directly linked neglect in early life to attachment problems (Perry, Pollard, Blakely, Baker, \& Vigilant, 1995; Kolko, 1996).

The developmental approach used in attachment theory may foster an enhanced understanding of the etiology of adolescent-perpetrated CSA. Researchers have used attachment theory not only to look at the family context that may lead to the perpetration of CSA by juvenile offenders but also how it may predispose certain individuals to be more vulnerable to sexual victimization. Recent theorists including William Marshall, Howard Barbaree, Phil Rich, Michael Miner and others have suggested that some adolescents and adults who sexually offend do so as a result of attachment deficits (Marshall, 1989; Marshall, 1993; Marshall, Laws \& Barbaree, 1990; Marshall, Hudson, \& Hodkinson, 1993; Rich, 2006; Miner, 2002).

\section{ATTACHMENT IN JUVENILE SEX OFFENDERS}

Prentky, Knight, Sims-Knight, Straus, Rokous and Cerce (1989) recognized the important role of childhood familial experiences in the development of sexual aggression. Other attachment theorists have attempted to develop a quantifiable way to measure social connectedness. This approach offers both a means of identifying ways 
to improve individuals' quality of life and mechanisms for evaluating those individuals for whom relationships have led to harm (i.e. to self or others). Smallbone \& Dadds (2001) found that insecure parent-child attachment relationships are related to aggressive and antisocial dispositions in adults, including the tendency to engage in inappropriate forms of sexual expression. This study replicated their findings in a previous study published in 2000 .

Recent theories promulgated by experts in the field suggest that some adolescents and adults who sexually offend do so as a result of attachment deficits (Marshall, Laws \& Barbaree, 1990; Marshall, 1993; Ward et al., 1995). Despite the recognition that the ability to connect to others or exhibit a secure attachment style is an important consideration in evaluating the etiology of sexually offending there is a paucity of existing studies that have examined this relationship in juvenile offenders.

Marshall and his colleagues' work (Marshall et al., 1990) reflects one example of the small body of research that has been conducted to evaluate the role of attachment in juvenile sexual offending. These authors suggested that negative experiences which occur during crucial developmental stages in children and adolescents can contribute to the development of sexual offending behavior. Their work provided not only a theoretical foundation, but also a practical framework for clinical interventions. As mentioned previously, attachment is typically used as a framework to evaluate the social connectedness and the ability to develop working relationships with others. In evaluating why juvenile sex offenders show evidence of attachment deficits, it is important to examine how their relationships are related to 
their offending behavior. Marshall et al. (1990) outlined a number of factors they considered influential in childhood development that lead to or maintain sexually abusive behavior. Although they recognized that biology may play a minor role in the development of a sex offending, their theory focused on social and environmental influences, as well as personal experiences. Their primary emphasis was on childhood developmental experiences during puberty and early adulthood including: sexual preference, self-esteem, intimacy and empathy. Their research suggested that the majority of adult sex offenders grew up in families where there was a disruption in the attachment relationship between the child and his/her parents.

The work of Marshall et al. (1990) indicated that experiencing physical, sexual or emotional abuse and neglect, as well as witnessing violence, were commonly reported by adult sex offenders. They also recognized that few families are purely abusive or purely nurturing; most families exist on a continuum from nurturing to abusive. This continuum also shifts throughout time depending on a variety of influences throughout the child's life. On one end of the continuum, a nurturing family facilitates close attachments and the ability to form close interpersonal relationships. Within this nurturing context an individual learns how to relate to and be respectful of others. On the other end of the continuum exists the abusive family, where children experience disrupted attachment and learn behaviors that are manipulative, coercive and maladapted to developing effective interpersonal skills. Marshall et al. (1990) also suggested that when children who have grown up in an abusive family attempt to 
develop relationships outside of their primary family unit, the interpersonal strategies that they have learned lead to relationship failures.

William Marshall (1993), a recognized leader in the field of sex offender research, went on to assert that offenders' poor attachment to their parents creates a unique vulnerability that makes the transition to peer relationships during puberty especially difficult. He also suggested that individuals with attachment deficits objectify others, portray people as instruments of sexual pleasure, emphasize power and control over others, and deny the need for social skills and compassion for others (Marshall, 1993). Marshall also indicated that poor quality parental attachment also provides the basis for loneliness as an adult and poor intimacy in relationships. In turn, emotional loneliness breeds aggression and a self-serving life style (Marshall, 1993). Marshall and other researchers have explained JSO's focus on younger children to meet their intimacy needs as their desire for interpersonal closeness, coupled with a fear of rejection from peers (i.e. they perceive themselves to be an unattractive partner and/or their experience with peers tells them that such rejection is likely; Marshall, 1989; Marshall, 1993; Marshall, Hudson, and Hodkinson, 1993).

As previously discussed, attachment theorists have posited that an individual's initial "attachment" with their primary caregiver is established early in the developmental process. This relationship provides the cognitive framework that suggests how an individual will perceive and interact with his/her world beyond early childhood (DiTommaso, Brannen-McNulty, Ross \& Burgess, 2003). In other words, an attachment style may partially explain the quality of social skills an individual 
develops. Linking this back to JSOs, the literature suggests that adolescent sexual offenders lack appropriate social skills and that this may be associated with their offending behavior (Becker \& Kaplan, 1988; Davis \& Leitenberg, 1987; Marshall et al., 1990; Ward et al., 1995). In 1989 Marshall linked the ideas of intimacy deficits in adolescence to sexual offending. He suggested that during adolescence, emotional loneliness and lack of intimacy (or connection to others) becomes more salient and that some adolescents turn to impersonal and non-affectionate sexual themes (both in fantasy and reality) to fulfill their need for intimacy without the fear of rejection (Marshall, 1989). Other researchers have investigated this area demonstrated the connection between intimacy deficits and emotional loneliness to sexual offenses (Garlick, Marshall, \& Thornton, 1996; Seidman, Marshall, Hudson, \& Robertson, 1994; Ward, McCormack, \& Hudson, 1997).

Although research into attachment deficits is not the "silver bullet" that Patty Wetterling so eloquently said we are all looking for (Tofte, 2007), it may be an important addition to the tool box used by professionals in the assessment and treatment of juvenile sex offenders. Rich (2006) suggests that an assessment and treatment framework informed by attachment theory may allow us to see how damaged attachment may have helped shape an interpersonal pathway that includes sexually abusive behavior. During a recent presentation, Dr. Phil Rich stated "that in our field, there's an increasing assumption that disturbed or insecure attachments exist in sexual offenders, with an almost implicit supposition that the onset and maintenance of sexually abusive behavior is fueled by what we might call attachment deficits" 
(Rich, 2007). He went on to say that it is "in this formulation, poor or suboptimal, early attachment experiences serve as a historical risk factor because it sets the pace for and begins to define the developmental pathway along which dysfunctional and antisocial behavior may later develop, disconnected from the needs of other people or society as a whole".

Studies exploring attachment in sex offenders have increased since the early work of Marshall and Barbaree. However, a majority of these studies are based on the retrospective reporting of the childhood experiences of adult sex offenders. By their nature, these studies are limited by offenders' memory and the perspective of an adult looking back on their behavior as an adolescent. Studies that have focused on adolescent participants have been few in number and have been restricted to including only other non-sexual offenders as comparison groups. In their review, Mulloy \& Marshall (1999) noted that several studies have found that adult sexual offenders are more deficient in intimacy and lonelier than both their nonsexual offender counterparts and community samples. The current study improves on the this existing research by using dual comparison groups, both non-sexual offenders and non offending populations, and by using incarcerated juvenile participants within a relatively short amount of time after their conviction. To date, this research design has been used by only a few small studies and almost always with adult offenders.

One recent study conducted by Marsa et al. (2004) attempted to develop profiles of adult CSA offenders utilizing Bartholomew's four category model with a limited sample comprised of 29 child sex offenders, 30 violent non-sex offenders, 30 
nonviolent non-sex offenders, and 30 community comparisons (i.e., no history of criminal behavior). The participants were categorized into four different attachment styles based on their positive working models of self and other, much like the current study. Their study resulted in two significant findings. First, as compared to the other groups the child sex offender group: (1) contained a significantly lower proportion individuals exhibiting signs of secure attachment; and (2) had a significantly larger proportion of individuals who exhibited a fearful attachment style. Specifically, fiftynine percent (59\%) of the child sex offender group had a fearful adult attachment style which was more than 8 times larger than the number of participants with a secure attachment style (Marsa et. al., 2004).

A second related study conducted by Stirpe, Abracen, Stermac \& Wilson (2006) evaluated adult sexual offenders' attachment styles contrasting non-sexual violent offenders with a group of non-sexual non-violent offenders. The researchers then compared the data gathered from these groups to normative archival data. Stirpe and her colleagues (2006) found the distribution of dismissing attachment in sexual offenders to be similar to that in the general "normative" population. They also found that the percentage of Preoccupied and Dismissing classifications was twice as high in the sexual offending group as in the general population and that the non-sexual offenders were most likely to have been classified as dismissing when compared to participants in the other groups (sexual offenders and normative) but were more secure than the sexually offending group. Finally, Stirpe and her colleagues found partial support to for the hypothesis that insecure attachment is a factor in criminality in 
general. However, sexual offenders, in particular, evidence more insecurity than their non sexual offender counterparts. They based this conclusion not only on their findings, but on the work of Smallbone and Dadds (1998), which suggested that insecure childhood attachments may be generally related to offending behavior. The most important implications of recognizing how attachment style is related to the etiology of sexual offending lie in how addressing the individual offender's styles can shape and enhance treatment. Therapeutic interventions can be tailored based on individual offenders' internal working models of relationships to assure that treatment plans including social skills training can be maximally effective (Stirpe et al, 2005).

The work of Marsa et. al. (2004) and Stirpe et al. (2006) discussed above are a few examples of the limited research available linking attachment style and the perpetration of sexual crimes by adult offenders. Even less research has been done with adolescents. Michael Miner is one of the handful of researchers currently studying the links between anxiously or fearfully attached juveniles who have sexually assaulted peers and adults Miner, 2004). The current research project seeks to explore how sexual offenses against peers or younger children by juveniles may be linked to attachment style and how those attachment deficits may be opportunities for levers of change in treatment. In order to categorize attachment style, measurement techniques must be utilized. The following section discusses how attachment has been measured in the past and how it was assessed in the current project. 


\section{ATTACHMENT MEASUREMENT}

As previously mentioned attachment is a rather abstract concept and is difficult to measure. Researchers have attempted to measure the quality of attachment relationships using self report questionnaires, observational studies, and directed interviews. In infants attachment is measured by observing behavior. Infant observational studies have included the previously described "strange situation" assessment paradigm, developed by Mary Ainsworth (1978), which was also used by Main \& Solomon (1990). Structured interview approaches have also been used to assess attachment. The Inventory of Parent and Peer Attachment (IPPA) is a self report questionnaire developed by Armsden \& Greenberg (1987) to evaluate the perception of adolescents' relationship with their parents and friends. The Child Attachment Interview (CAI) is a semi-structured interview designed by Target, Fonagy \& Schmueli-Goetz (2003) for use with pre-adolescent children. The CAI is based on the Adult Attachment Interview and measures representations of parent-child relationships and important attachment related events. The Adult Attachment Interview (AAI) was developed by Main \& Goldwyn (1998) to measure a person's state of mind regarding their attachment in their family of origin. The AAI contains 20-questions that ask the participant about their perceptions about their experiences with parents and other attachment figures.

In addition to interviews, self-report measures represent the most frequent approach to assessment in this area. The Relationship Questionnaire and the Close Relationships- Revised Adult Attachment Questionnaire reflect two examples of self- 
report measures used to assess attachment. The Relationship Questionnaire developed by Bartholomew and Horowitz (1991) attempts to measure the closeness of relationships. The Close Relationships-Revised (ECR-R) Adult Attachment Questionnaire (Hazan \& Shaver, 1987) was designed to assess individual differences with respect to attachment-related anxiety and attachment-related avoidance based on responses to questions about comfort levels in romantic relationships and desires for closeness.

Previous attempts to measure attachment have been based on the number of and quality of relationships an individual has or the extent to which an individual views others, either positively or negatively and how an individual views themselves, either positively or negatively. The proposed study uses a portion of the self-report Supervision Questionnaire (SQ) (Kaufman, 2001) to evaluate participants' relationship with their parents. The SQ was developed by Dr. Keith Kaufman for the purpose of understanding the role that supervision plays as a risk factor in child sexual abuse. The SQ was piloted with adolescent sexual offenders incarcerated by the State of Ohio, Department of Youth Services. During the development of the SQ, individuals with diverse education, training and experiences were consulted in order to assure construct validity of this measure. These individuals included, but were not limited to: offenders, victims, victims' and offenders' parents, a reading specialist, a test construction specialist, and experts in caregiver supervision, child and adolescent development, victim treatment, and offender treatment. Efforts were made to include suggestions from persons of color to make the measure culturally relevant to African 
American and Latino/Hispanic participants. Prior to data collection, the resulting measure was also translated into Spanish and then back-translated to assure that it was an equivalent measure for Spanish speaking participants.

The focus of this study was on the participants' self reported perception of their relationship with their supervisor broken down into three categories: (1) the activities parents participate in with their children; (2) parents' expectations of their behavior; and (3) the topics about which they communicate with their parents. A detailed list of the questions used for this portion of this study can be found in Appendix II ("Relationship with Parents"). The twenty-seven (27) variables taken from the demographic questionnaire were used to assess participants' perception of their relationship with their parents. This information was gathered using a 5 point Likert scale (0-Never, 1-Almost Never, 2-Sometimes, 3-Almost Always, 4-Always).

Cernkovich and Giordano (1987) suggested that parent-child communication was a good indicator of attachment and incorporated a self- report measure into their research that reflected this dimension. In previous studies, self-reports of parent-child communication have been found to be good indicators of attachment (Cernkovich \& Giordano, 1987). Notably, Armsden \& Greenberg (1987) utilized the Inventory of Parent and Peer Attachment (IPPA) to measure adolescent attachment. The IPPA has been shown to be a reliable and valid measure of perceived quality of close relationships (Armsden \& Greenberg, 1987). In order to establish convergent validity of the PRS, the IPPA was compared systematically. Table 1 shows the similarity between questions in the IPPA and the SQ used in the current study. 


\begin{tabular}{|l|l|}
\hline Question from IPPA & $\begin{array}{l}\text { Question from Questionnaire used in } \\
\text { current study }\end{array}$ \\
\hline $\begin{array}{l}\text { My mother/female caregiver accepts me } \\
\text { as I am. }\end{array}$ & $\begin{array}{l}\text { My supervisor accepted me for who I } \\
\text { was. }\end{array}$ \\
\hline $\begin{array}{l}\text { My mother/female caregiver trusts my } \\
\text { judgment. }\end{array}$ & My supervisor trusted me. \\
\hline
\end{tabular}

Table 1: IPPA and SQ comparison 1

The measure used in the current study also evaluates some of the same concepts as the IPPA, only in more depth. Table 2 gives examples of the questions asked by the IPPA and the more detailed questions asked by the SQ used in the current study

. Finally, participants were categorized based on their view of self within Bartholomew's model. This assessment was accomplished by analyzing the self reported history of abuse provided by study participants (see Appendix III for a detailed list of questions) as a proxy for a self esteem measurement. This subscale was also taken from the SQ developed by Kaufman (2001). As discussed in the introduction and detailed within a previous section ("Consequences to Victims"), many researchers have documented the strong correlation between a history of abuse and a negative view of self.

The National Center for Victims of Crime (NCVC) states that child abuse is not unique to a particular segment of society (2009). It crosses all racial, gender, socio-economic and demographic boundaries. While it may be more likely to be reported and, thus, reflected in greater numbers of cases involving lower income families, it is by no means a problem limited to members of one economic or racial group. Some of the more recognized consequences of childhood abuse include 


\begin{tabular}{|c|c|}
\hline Question from IPPA & More detailed questions asked in this study \\
\hline \multirow{8}{*}{$\begin{array}{l}\text { I tell my } \\
\text { mother/female } \\
\text { caregiver about my } \\
\text { problems and troubles. }\end{array}$} & $\begin{array}{l}\text { How often did you talk with your supervisor about your } \\
\text { school work? }\end{array}$ \\
\hline & $\begin{array}{l}\text { How often did you talk with your supervisor about your } \\
\text { behavior at school? }\end{array}$ \\
\hline & $\begin{array}{l}\text { How often did you talk with your supervisor about your } \\
\text { behavior at home? }\end{array}$ \\
\hline & $\begin{array}{l}\text { How often did you talk with your supervisor about your } \\
\text { friends? }\end{array}$ \\
\hline & $\begin{array}{l}\text { How often did you talk with your supervisor about dating } \\
\text { relationships? }\end{array}$ \\
\hline & How often did you talk with your supervisor about sex? \\
\hline & $\begin{array}{l}\text { How often did you talk with your supervisor about } \\
\text { something good that happened? }\end{array}$ \\
\hline & $\begin{array}{l}\text { How often did you talk with your supervisor about } \\
\text { something bad that happened? }\end{array}$ \\
\hline \multirow{6}{*}{$\begin{array}{l}\text { I don't get much } \\
\text { attention from my } \\
\text { mother/female } \\
\text { caregiver }\end{array}$} & $\begin{array}{l}\text { My supervisor and I did activities together (like played } \\
\text { games). }\end{array}$ \\
\hline & $\begin{array}{l}\text { My supervisor went to my activities (like watched me play } \\
\text { sports). }\end{array}$ \\
\hline & My supervisor taught me things. \\
\hline & My supervisor helped me with my homework. \\
\hline & We ate our meals together. \\
\hline & We went to the park together \\
\hline
\end{tabular}

Table 2: IPPA and SQ comparison 2

diminished self esteem, aggressive behavior, suicidal tendencies, withdrawal, school and social adjustment problems (Ackerman and Graham, 1990). Wolfe \& McGee (1991) found that children in abusive environments are more aggressive, frustrated and non-compliant than their "normal" counterparts. They also found that abused children suffer from deficient social skills and are immature and dysfunctional. 
Researchers have found that maltreated children have fewer satisfactory relationships with peers and lower self-esteem than children that have not experienced abuse (Bolger, Patterson \& Kupersmidt, 1998; Cicchetti, Lynch, Shonk \& Manly, 1992; Mueller \& Silverman, 1989).

As discussed earlier, the data set utilized in the current study is a subsample from a larger data set previously gathered by Dr. Kaufman and his colleagues. The measures used in the collection of that information did not contain questions specifically evaluating self esteem. In the absence of this information, and in light of the wealth of research supporting the correlation between childhood abuse and low self esteem, an expressed history of abuse was used as a proxy for low self esteem. The use of abuse history as a proxy is reinforced by the well-documented evidence that abused children are often denied the benefits of secure attachment with their parents (Crittenden \& Ainsworth, 1989). Additionally, Carlson, Cicchetti, Barnett, and Braunwald (1989) found that over $80 \%$ of maltreated infants had disorganized/disoriented attachments, which are analogous to fearful attachment in Bartholomew's model.

\section{SUMMARY}

As elucidated above, CSA is a serious problem and affects a significant portion of our population. The effects of CSA are numerous, long lasting, and affect more than just the individual victim. The deleterious outcomes are also felt by the victim's family, the offender, the offender's family, both the victim's and offender's 
community and society as a whole. It has also been recognized that a significant number of the perpetrators of CSA are adolescents.

Researchers have further come to understand that there are a number of etiological factors that can lead to sexual offending including poor attachment. The current study strives to build upon the work of William Marshall, Howard Barbaree, Michael Miner, and Phil Rich, among others, in understanding how attachment deficits can influence sexual offending behavior in adolescents. The ultimate goal of the current research project is to provide evidence that will shape and support the treatment of juvenile sex offenders. If evidence of attachment deficits is found in the youth in this sample who sexually offended, this knowledge can be used to develop a lever or mechanism to decrease recidivism and ultimately protect society.

Research in the field of attachment in adolescent sex offenders has been limited to date. The few existing studies have had significant methodological concerns. Some have suffered from small sample size and limited comparison groups. Other methodological concerns include asking adult offenders to reflect retrospectively about their feelings and behavior many years later. The current study offers advantages over previous literature by assessing adolescents and utilizing comparison groups that include both non-sexual offenders and adolescents with no history of criminal behavior. Additionally, this study negates concerns with previous retrospective studies regarding flawed memory. Information was gathered from all participants while they were still adolescents or emerging adulthood. All offenders (sexual or non sexual) were incarcerated as adolescents (between the ages of 12 and 
18). To date, there have been relatively few studies in this area that have included appropriate comparison groups (e.g., non-sex offending delinquents and non-offending juveniles). When a non offending comparison group has been used (e.g. Marsa et al., 2004), the sample size has typically been small (i.e. 30 participants or under in each group) The current study reflects methodological improvements in the study of juvenile sex offenders not only because of the larger sample size $(\mathrm{N}=1041)$, but also by virtue of including two comparison groups (non-sexual offenders, and community comparisons with no offense history), and the limited time between the commitment of the offense and the collection of the study data. The large sample size is more than sufficient to provide adequate power to conduct statistical analysis. Finally, the participant sample in this study is comprised of a population diverse in both in ethnicity and age.

\section{HYPOTHESES}

The current study seeks to clarify whether an individual's attachment style (as measured by relationship with supervisor and history of childhood abuse) is related to offender status (i.e., non-offender, non-sexual offender or a sexual offender). As the data analyzed for the current study came from an archival data sample gathered using a measure that has not yet been validated, our first hypothesis was that the Perceived Relationship with Supervisor measure is made up of significantly correlated questions that measure one underlying construct.

Secondly, the sample juvenile sex offenders (JSOs) were hypothesized to be more likely categorized as "Fearful" in Bartholomew's model than non-sexual 
offenders/ Juvenile Delinquents, (JDs, who in turn are more likely to be categorized as "Fearful" than JCs. This gradient approach that a greater percentage of JSOs will exhibit "Fearful" attachment than JDs and more JDs will exhibit "Fearful" attachment than JCs is based on two assumptions. First, crimes of sexual abuse on children are considered by society to be more heinous than non-sexual criminal behavior (Vidmar, 1997). Secondly, those individuals who engage in criminal activity are predisposed to that behavior due to individual differences established early in life (Nagin \& Paternoster, 1994). Therefore, those individuals who commit the worst offenses have a history of more detrimental experiences during their early developmental years.

Researchers have found that a large proportion of adolescent sexual offenders have experienced some form of abuse, either sexual or physical, during childhood (Aljazireh, 1993). Given this, it was also hypothesized that a significant portion of the JSOs in this study will have suffered childhood abuse than either the JDs or JC, and in turn more JDs will have suffered childhood abuse (i.e., sexual abuse, physical abuse, neglect) than JCs. This hypothesis is also based on the assumption that those individuals who commit a sexual assault on a child are doing so, in part, because of negative experiences in their own social development that resulted in weaker social bonds. These individuals are less deterred by the idea of damaging social bonds by committing crime because these bonds do not exist (Nagin \& Paternoster, 1994). 


\section{RESEARCH DESIGN AND METHODS}

\section{OVERVIEW}

The information used in the current research was taken from a larger data set currently being collected under the direction of Keith L. Kaufman, Ph.D. (CDC Grant R49/CCR016517-01). Dr. Kaufman's research investigates how parental supervision is related to offense related behavior and modus operandi. Although Dr. Kaufman's work in collecting this information continues, only data collected before June 1, 2008 was included in the current research. Participants were prescreened for IQ and diagnosis with perception altering conditions by administrators and staff in facilities and programs. JSO and JD participants were obtained from incarceration facilities and outpatient programs in seven states: (i.e., Oregon, Texas, Ohio, New York, New Jersey, South Carolina, and Florida). JC participants were recruited from various community settings in these states (e.g., community centers).

\section{PARTICIPANT SAMPLE}

Researchers have suggested that etiological research needs to be conducted using appropriate comparison groups (Aljazireh, 1993). In response to this concern, this study will compare juvenile sex offenders (JSOs) to juvenile delinquents (JDs) who are non-sexual offenders and adolescents (JCs) located within the community with no history of criminal offense on dimensions related to attachment. The original participant sample for this study was 1,041 divided into the three subgroups: the JSO group was comprised of 368 participants; the JD group was comprised of 402 participants; and finally, the JC group was comprised of 271 participants. The average 
age of the participants was $16.23(\mathrm{SD}=2.13)$ years of age at the time of their completion of the self report questionnaire (SQ). The average participant had not yet completed the $10^{\text {th }}$ grade. Most participants (766 or $91.5 \%$ ) reported the United States to be their place of birth. When questioned about family income level, approximately $57 \%$ (476) of the participants stated they did not know their caregivers' income. The self reported ethnicity of the participants ranges from $40 \%$ identifying as White or Caucasian, $23 \%$ identifying as Black or African-American, $16 \%$ identifying as Hispanic or Latino, $15 \%$ identifying as mixed race, $4 \%$ identifying as Native American, and 2\% identifying as Asian. The remaining participants declined to answer or answered with unrecognized ethnic categories.

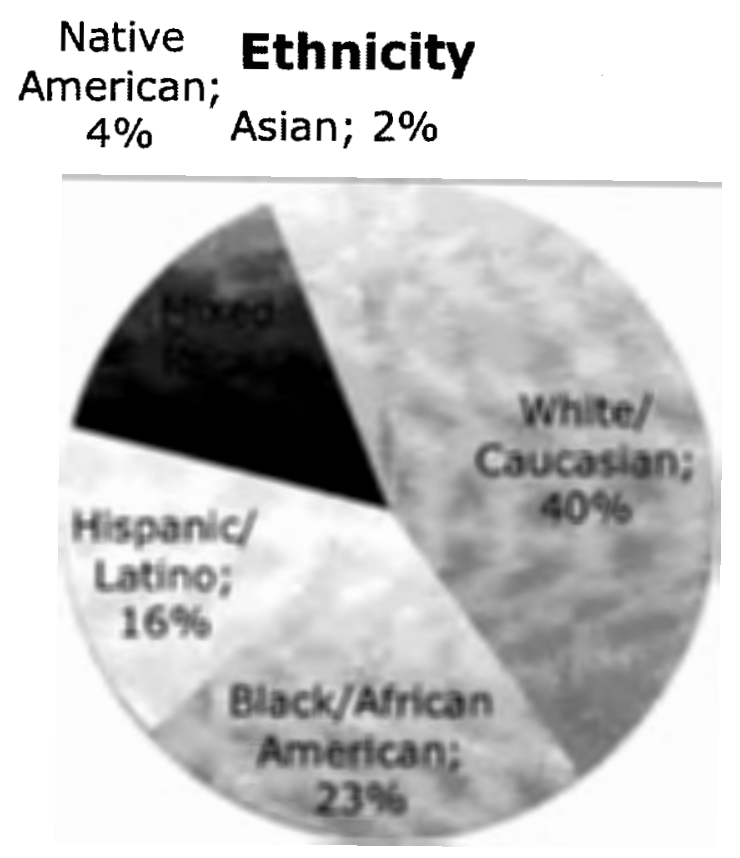

Figure 3: Participant Sample Demographics 
As is often the case, there are concerns about the over representation of certain minority ethnic groups in incarcerated participant samples. Data obtained during the 2000 U.S. Census describes the United States' population at that time as approximately $69.1 \%$ white, $12.3 \%$ Black or African American, $12.5 \%$ Hispanic or Latino, 3.6\% Asian, .9\% American Indian, with the remaining1.6\% participants self identifying as two or more races. The racial disparity between population and rates of incarceration has been studied by many researchers. Jackson (1997) found that the prominent differences were truly based on socioeconomic status (SES) not race. He found that the economic inequalities (e.g. fewer employment opportunities, lower education) have led minority youth to view crime and the underground economy associated with it as a means of economic survival. The current study could not remove SES as a covariate due to the fact that less than half of the participants provided the answer regarding family income. Furthermore, the overall measure of SES was diluted because the number of individuals in the family dependent on the known caregiver'(s) income was not provided, Additionally, one of the stated goals of Dr. Kaufman's original grant used to collect the data used was to oversample minority participants to ensure adequate information was obtained from these populations and to explore supervision differences by culture and their relation to offending behavior. After applying exclusion criteria, the sample used for analysis included 837 males between the ages of 12 and 18 years of age. The JSO group consisted of 273 participants, the JD group consisted of 304 participants and, finally, the JC group 
consisted of 260 participants. The mean participant age was 15.74 years of age ( $S D$ $=1.65$ ).

\section{SCREENING}

All participants completed the Wide Range Achievement Test (WRAT) Third Edition reading scale (Wilkinson, 1993) to ensure at least a sixth grade reading level in order to fulfill the requirements not only of the funding agency (CDC) but the Institutional Review Board (IRB) at The Ohio State University and Columbus Children's Hospital with whom Dr. Kaufman, the principle investigator, was affiliated at the time of grant award. This project was also approved by the Portland State University's Institutional Review Board. Additional exclusion criteria included inability to comprehend questionnaire material, inadequate reading abilities, or significant mental disorders (e.g., Schizophrenia). For the current study, participants were dropped from the sample if they were older than 18 at the time of survey completion, failed to answer at least 24 of the 27 research questions regarding their relationship with their parents, did not answer the three questions regarding their history of abuse, or did not self identify as male. Parental consent forms were presented, reviewed and signed in the case of non institutionalized participants. For participants residing in institutions (JSOs and JDs) the state agency, which had custody at the time of participation, provided consent. However, in these cases, offender assent forms were also presented, reviewed and signed by the participants. Participation in data collection was voluntary and anonymous. Data was collected in groups of between 15-25 participants. 


\section{MEASURES}

Demographic questionnaire. This measure asked participants questions regarding their demographic information. The questions used in the current study included: A-1 How old are you?; A-2, Which sex are you? Male or Female; as well as the following question which asked the participants to self-identify their ethnicity:

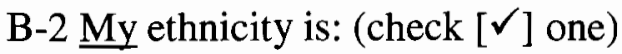

[ ] Asian, Asian-American, or Oriental

[ ] Black or African-American

[ ] Hispanic or Latino

[ ] White, Caucasian, European (not Hispanic)

[ ] American-Indian

[ ] Mixed (parents are from two different groups)

[ ] Other:

Perceived relationship with supervisor (PRS). A 27-item questionnaire was used to examine perceived relationship with supervisor (Kaufman, 2001) along three subscales: activities with supervisor; relationship with supervisor; and communication with supervisor.

The first subcategory, activities with supervisor, includes 7 questions that assessed the perceived time spent with the participant's supervisor. The items included statements such as "My supervisor and I did activities together, like played games" and "We ate our meals together". Participants were asked to indicate their answer on a 5 point scale, ranging from 0 (never) to 4 (always). 
The second group of 6 questions measured perceived relationship with supervisor and included statements such as "My supervisor trusted me" and "My supervisor understood where I was coming from." The participants answers were given with the same 5 point scale as described above.

The final subsection, consisting of 14 questions, measured how often the participants perceived they talked with their supervisor about specific subjects including "your school work?", "your behavior at school" and "dating relationships". Participants answers were given on a 5 point scale ranging from 0 (never) to 4 (1-2 times a week).

Participant self-reported history of abuse. The final questions used in the current study measured the participants' history of abuse. Participants were asked if they had been neglected, physically abused or sexually abused. Responses for all 3 questions were a circled yes or no. 


\section{RESULTS}

\section{DATA ANALYSIS}

As this was the first analysis of an existing data sample with an untested measure it was imperative to explore and confirm the factor structure in our measure. First, a correlation matrix was created using SPSS 17.0 to ascertain whether the 27 questions asked on the Perceived Relationship with Supervisor (PRS) measure were significantly correlated. Second, an initial exploratory factor analyses was conducted to examine the structure of the data and to determine whether the anticipated three clear factors (i.e., time spent with supervisor, perceived relationship with supervisor and communication with supervisor) existed within the data.

A subsequent multi-factor confirmatory factor analysis was conducted using the other half of the sample enabled the examination of specific fit indices as well as a clear indication of the contribution of each factor on the overall latent construct (Klein; Tabachnick \& Fidell, 1996). After the validation of the Perceived Relationship with Supervisor (PRS) measure, tests were conducted utilizing multinomial regression to evaluate whether or not an individual's specific category of attachment (secure, fearful, dismissing, or preoccupied), as situated within Bartholomew's four category model, significantly predicted group measurement (JSO, JD or JC).

\section{CORRELATIONS}

A correlation matrix was calculated using SPSS 17.0 which found that all 27 items were significantly correlated at the $\mathrm{p}<.01$ level with the exception of "my supervisor expected me to do the right thing" and "talking about dating relationships" 
which were correlated at the $\mathrm{p}<.05$ level. This correlation demonstrates a close relation to all of the items on the PRS (Kaufman, 2001).

\section{EXPLORATORY FACTOR ANALYSIS}

To examine the structure of the relationship with supervisor measure, the data sample was systematically split in half in order to perform an exploratory factor analysis (EFA) and confirmatory factor analysis (CFA). Starting with the first subject in the data file, every other participant was placed into one data file containing 137 JSO participants, 152 JD participants and 130 JC participants. The average age of the participants was approximately 15.7 years of age. The average participant age for this subgroup was 15.69 years of age. The ethnic diversity of the sub-sample was similar to the total participant sample as follows: $40.1 \%$ (a difference of .1\%) identifying as White or Caucasian, $23.9 \%$ (a difference of .9\%) identifying as Black or AfricanAmerican; $17.7 \%$ (a difference of 1.7\%) identifying as Hispanic or Latino, 14.8\% (a difference of .25) identifying as mixed race, $2.9 \%$ (a difference of $1.1 \%$ ) identifying as Native American, and .5\% (a difference of 1.5\%) identifying as Asian.

The EFA was conducted using SPSS 17.0. This EFA retained any variables with an Eigenvalue greater than 1.0 and was conducted with direct oblimin rotation and revealed a four-factor structure that accounted for $56.57 \%$ of the variance. The EFA confirmed that the items on PRS were significantly correlated at the p .05 level, and all items are measuring one over all construct. The pattern matrix obtained in the analysis can be viewed in Table 3 . As a result of the EFA, the subscale identified as communication with supervisor in the PRS (Kaufman, 2001) can be separated into two 


\begin{tabular}{|c|c|c|c|c|c|}
\hline \multicolumn{6}{|c|}{ EFA Pattern Matrix } \\
\hline number & question & 1 & 2 & 3 & 4 \\
\hline $323^{2}$ & talk about behavior at school & 0.831 & -0.021 & -0.049 & -0.020 \\
\hline 32. & talk about school work & 0.755 & 0.114 & -0.236 & -0.182 \\
\hline 328 & talk about other things at school & 0.698 & 0.107 & -0.011 & -0.003 \\
\hline $32 d$ & talk about behavior at home & 0.668 & -0.151 & 0.080 & -0.110 \\
\hline 324 & talk about something bad that happened & 0.664 & 0.106 & 0.094 & 0.056 \\
\hline 82 & talk about chores & 0.548 & -0.047 & 0.106 & -0.113 \\
\hline 32$)$ & talk about something good that happened & 0.535 & 0.201 & 0.144 & -0.125 \\
\hline 328 & talk about your friends & 0.508 & -0.018 & 0.410 & -0.005 \\
\hline 321 & talk about family issues & 0.483 & -0.071 & 0.345 & -0.054 \\
\hline $32 \pi$ & talk about your supervisors life & 0.435 & 0.137 & 0.430 & -0.087 \\
\hline 32 & talk about your life & 0.414 & 0.126 & 0.412 & -0.079 \\
\hline 316 & supervisor accepted me for who I was & 0.119 & 0.804 & -0.049 & 0.141 \\
\hline $31 \mathrm{~d}$ & $\begin{array}{l}\text { supervisor understood where I was coming } \\
\text { from }\end{array}$ & -0.195 & 0.804 & 0.243 & -0.027 \\
\hline $31 \mathrm{e}$ & supervisor asked for my opinion on things & -0.032 & 0.713 & 0.204 & -0.052 \\
\hline $31 \mathrm{a}$ & supervisor trusted me & 0.089 & 0.710 & -0.163 & -0.119 \\
\hline $31 \mathrm{f}$ & $\begin{array}{l}\text { talked to my supervisor about personal } \\
\text { things }\end{array}$ & -0.166 & 0.486 & 0.389 & -0.268 \\
\hline $31 \mathrm{c}$ & supervisor expected me to do the right thing & 0.104 & 0.348 & -0.127 & -0.104 \\
\hline 320. & talked about drugs or alcohol & 0.031 & 0.030 & 0.723 & -0.024 \\
\hline 328 & talk about questions of sex & 0.137 & 0.115 & 0.679 & -0.089 \\
\hline 321 & talk about dating relationships & 0.187 & 0.000 & 0.667 & -0.077 \\
\hline $30 f$ & went to park with supervisor & -0.134 & -0.085 & 0.071 & -0.902 \\
\hline $30 \mathrm{e}$ & ate meals with supervisor & 0.037 & -0.001 & 0.014 & -0.746 \\
\hline $30 a$ & played games with supervisor & 0.067 & 0.100 & -0.081 & -0.726 \\
\hline $30 \mathrm{~b}$ & supervisor went to my activities & 0.138 & 0.040 & 0.091 & -0.649 \\
\hline $30 \mathrm{~g}$ & went to church with supervisor & 0.043 & -0.038 & 0.008 & -0.642 \\
\hline $30 \mathrm{c}$ & supervisor taught me things & -0.003 & 0.062 & 0.132 & -0.586 \\
\hline $30 d$ & supervisor helped with homework & 0.341 & 0.195 & -0.140 & -0.439 \\
\hline
\end{tabular}

Table 3 
subscales. The items in the second communication subscale measures the amount of perceived time participants spoke with their supervisor about drugs or alcohol, dating relationships and sex. This grouping of items appears logical as adolescents are often uncomfortable discussing these topics with their parents (Wallace, 2008). Two of the items loaded comparatively to two subscales. The question "talk about your supervisor's life" loaded on the first communication with supervisor subscale (.435) and time spent with supervisor (.430). Based on the face validity of this item, it should stay with the communication subscale as the question specifically addresses talking/communicating. This line of reasoning applies to the other question which loads similarly on two subscales, "talk about your life" which loads on the first communication subscale (.414) and the time with supervisor subscale (.412).

\section{CONFIRMATORY FACTOR ANALYSIS}

Utilizing the remaining participants (137 JSO participants, 152 JD participants and $130 \mathrm{JC}$ participants), a CFA was conducted. The average age of the participants in this sub group was approximately 15.8 years. The ethnic diversity of the sub sample was similar to the total participant sample: $36.5 \%$ (a difference from the overall sample of $3.5 \%$ ) identifying as White or Caucasian; $26.3 \%$ (a difference of $2.7 \%$ ) identifying as Black or African-American; $16.2 \%$ (a difference of .2\%) identifying as Hispanic or Latino, $14.6 \%$ (a difference of $.4 \%$ ) identifying as mixed race, $4.1 \%$ (a difference of .1\%) identifying as Native American, and 1.7\% (a difference of .3\%) identifying as Asian. A multi-group confirmatory factor analysis (CFA) was conducted using AMOS 6.0 to evaluate whether or not the data fit a four-dimensional 
model (Figure 4). The model was constructed using the four factor model indentified in the EFA described above. The factor loadings revealed that every factor loading was statistically significant $(p<.001)$. In addition, fit indices were acceptable for the multiple group model, $\mathrm{RMSEA}=.08, \mathrm{CFI}=.86$, and $\mathrm{PCFI}=.73$. A root means

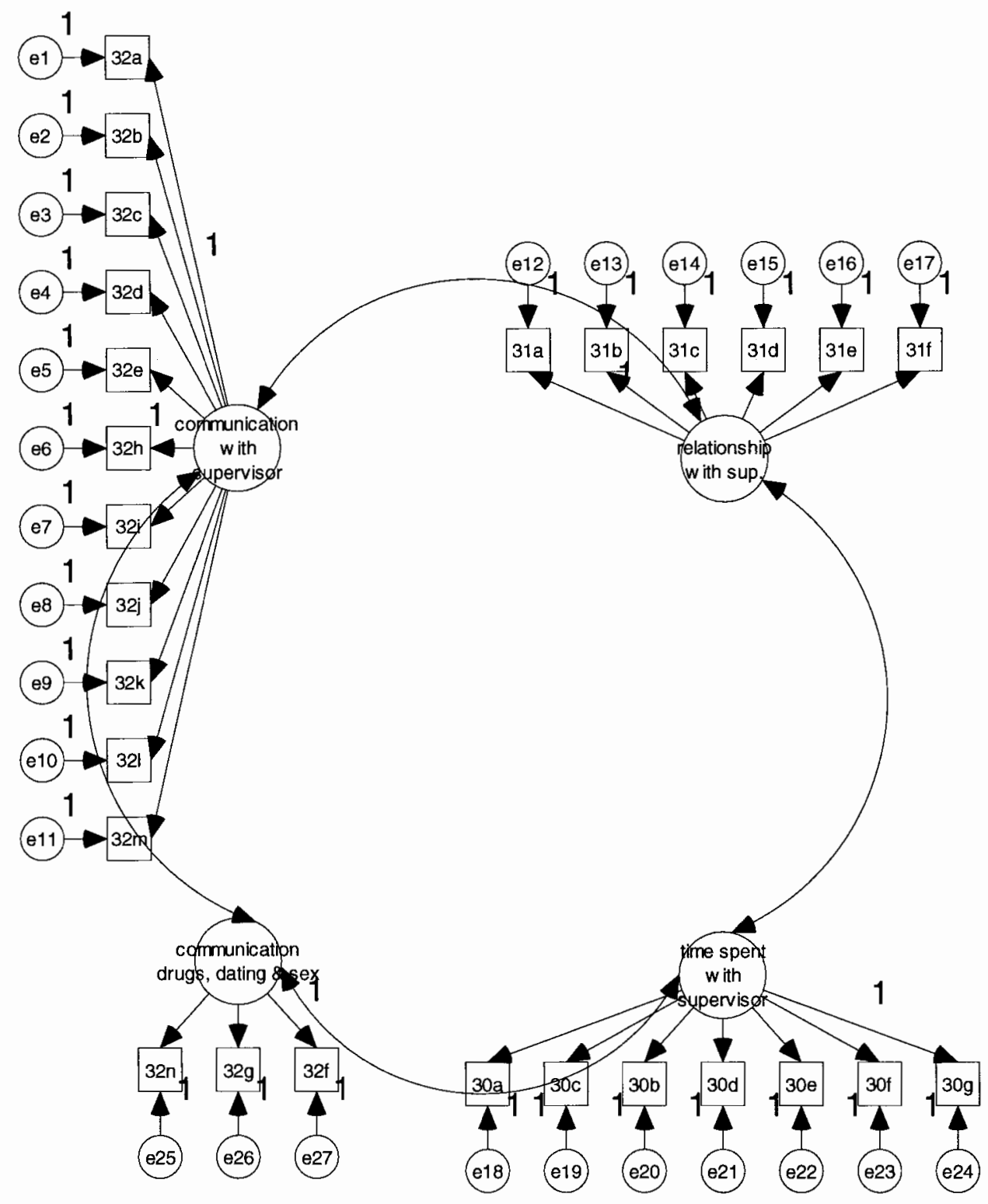

Figure 4: Model 
square error of approximation (RMSEA) of .08 or less is considered acceptable (MacCallum, Brown and Sugawara, 1996). Usually, model fit is evaluated in simple models using the comparative fit index (CFI). Values closer to 1 with a CFI of more than .90 indicate an "acceptable fit". The current result of .86 is adequate considering the complexity of the model; however, in a more complicated model, such as the model used in the current project, the parsimony comparative fit index (PCFI) is often considered a more suitable option. More specifically, the PCFI takes into account the complexity of a model where more than a few indicators load on multiple factors (in this case, 4) and measure one overall latent construct. It is generally accepted that complex models with a PCFI of more than .70 is good fit and above .50 are acceptable (Newsom, 2005). These results indicate that the PRS measure is an acceptable measure to use in further analyses.

\section{SAMPLE DIFFERENCES}

Following the application of exclusion criteria, 837 male participants between the ages of 12 and 18 remained in the sample. The average overall mean age of the participants was 15.7 years of age, with the mean age of the participants in each group as follows: JSO $-15.9, \mathrm{JD}-16.4, \mathrm{JC}-14.7$. Although there was a statistically significant difference in the mean ages of each group, middle adolescence has been defined by the period between 14-17 years of age for males (Greenberg, Bruess, Chisolm, Conklin \& Conklin, 2007) making the groups developmentally, if not chronologically, comparable. In comparing the ethnic make up of the participant sample for the current study, a significant difference was found in the percentage of 
White/Caucasian participants in the JSO group, as compared to both the JD and JC groups. However, because White or Caucasian parents are more likely to report sexual victimization of their children to authorities (Thigpin, Pinkston \& Mayefsky, 2003), it follows that the percentage of representation of Caucasian/White participants would therefore be higher in the JSO group. However, this sample mirrors those found in other prison populations (State of Ohio Office of Criminal Justice Services, 2006) and reflects the fact that juvenile sexual offenders are much more likely to be Caucasian (Schram \& Milloy, 1991).

In order to ascertain whether there were group differences on the four individual subscales identified on the PRS measure, an ANOVA was conducted. The ANOVA found significant differences between groups on three of the four subscales: time spent with supervisor $F(2,836)=4.75, \mathrm{p}<.01$, perceived relationship with supervisor $F(2,837)=9.35$ and communication with supervisor about drugs, dating and $\operatorname{sex} F(2,835)=12.61, p<.01$. Consequently, the effect sizes were small, $\eta 2=$ $.012, .022$ and .029 respectively, and therefore, the overall mean score for the PRS was used to categorize participants into the four attachment styles.

\section{ATTACHMENT STYLE}

For the purposes of this study, all participants were categorized into an attachment style based on their average supervisor score (AVG_Super) score and their self reported history of childhood abuse. Individuals with an AVG_Super score of 2 or higher were categorized as having a positive view of others (+VOO) and those individuals with an AVG_Super score less than 2 were categorized as having a 
negative view of others (-VOO). Because of the long standing recognition of a strong correlation between having suffered childhood abuse and suffering from low self esteem (Briere, 1988; Briere \& Elliot, 1994), individuals who self reported as having experienced any type of childhood abuse were categorized as having a negative view of self (-VOS) and those with no self reported history of abuse were categorized as having a positive view of self (+VOS). Participants were then placed into one of Bartholomew's four categories of attachment styles based on their positive or negative View of Others (VOO) and positive or negative View of Self (VOS). Table 4 below demonstrates the distribution of the participants based on attachment style. A chi-square analysis found that the assigned attachments styles were significantly different than expected by chance, $\chi^{2}(1, \mathrm{~N}=837)=26.201, \mathrm{p}<.01$. In the JSO group, the percentage of participants in each attachment category was: Fearful $-24.2 \%$, Dismissing $-8.8 \%$, Preoccupied $-48 \%$ Secure $-19 \%$. In the JD group the percentage of each participant in each attachment category was: Fearful $-15.1 \%$, Dismissing $14.5 \%$, Preoccupied - $18.1 \%$, Secure $52.3 \%$.

Participant distribution in Bartholomew's Model

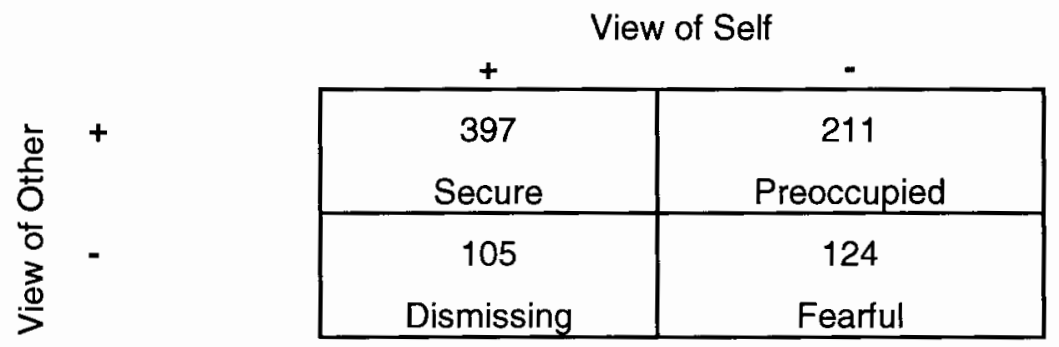


Finally in the JC group the percentage of participants in each attachment category was: Fearful $-4.6 \%$, Dismissing - 14.2\%, Preoccupied - 9.6\%, Secure $71.5 \%$.

\section{ATTACHMENT STYLE PREDICTING GROUP MEMBERSHIP}

A multinomial logistic regression was conducted to see if group membership (JSO, JD, JC) could be predicted based on attachment style (Fearful, Secure, Preoccupied, Dismissing). The predictor variables were significantly related to the log odds of group membership, $\chi^{2}=216.5, \mathrm{df}=6, \mathrm{p}<.001$, Cox and Snell $\mathrm{R}^{2}=.228$. The regression equation supported the hypothesis that fearful attachment style in contrast with a dismissing attachment style significantly predicted group membership for the participants in both the JSO and JD group. Being categorized with a fearful as opposed to a dismissing attachment style increases the log odds of being a JSO rather than a JC by 2.138 , Wald Statistic 27.33 , p value $<.01$. While being categorized with a fearful as opposed to a dismissing attachment style increases the log odd of being a JD rather than a JC by 1.170 , Wald Statistic $8.85, \mathrm{p}$ value $<.01$. Being categorized as Secure in contrast with Dismissing decreased the log odds of being a JSO rather than a JC by .842. Examining the results beyond the original hypothesis, findings indicate that being categorized as Preoccupied in contrast with Dismissing increases the log odds of being a JSO rather than a JC by 2.089 , Wald Statistic 37.52 , p value <.01.

\section{ABUSE TYPE}

To further evaluate the difference in amount and type of childhood abuse experienced by JSOs, JDs and JCs, the groups were compared, first by a simple frequency analysis and then by conducting a MANOVA to evaluate whether the 
participant groups differed on self reported abuse histories. Significant differences were found between groups on all three types of abuse: neglect $F(2,837)=26.83$, p< .001 ; physical abuse $F(2,837)=74.81, \mathrm{p}<.01$ and sexual abuse $F(2,837)=198.24, \mathrm{p}$ $<.01$. As the MANOVA found that the participants in the three groups (JSO, JD, JC) further analysis is warranted via a series of one-way ANOVAs. A bar chart demonstrating the frequency analysis can be seen in Figure 5. A greater percentage of participants in the JSO group self reported as having suffered more of each individual type of abuse than the other two groups. Close to $31 \%$ of JSOs reported having experienced neglect, as compared to $19.4 \%$ of JDs and only $6.5 \%$ of JCs.

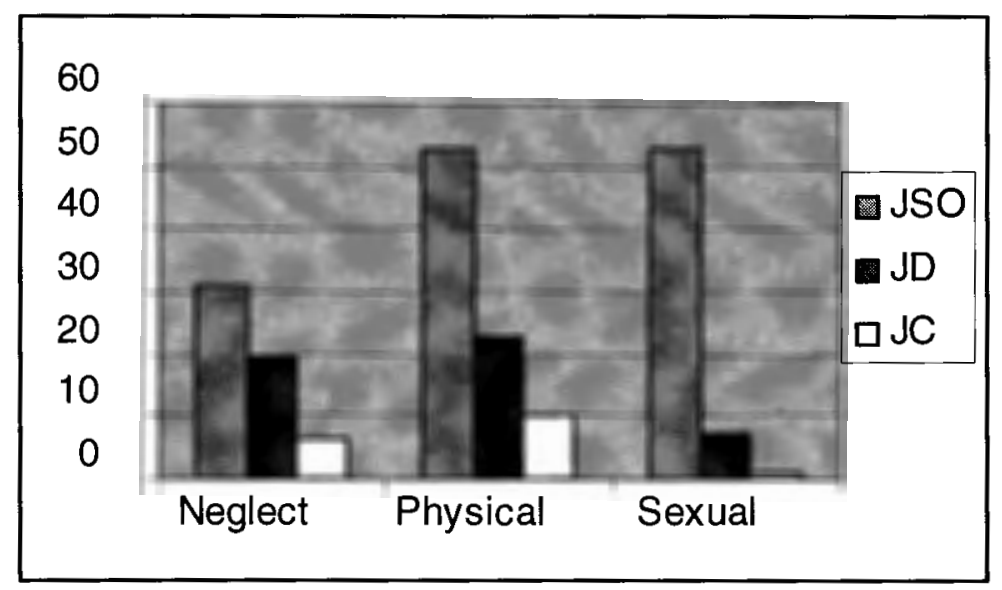

Figure 5: Abuse Comparison - (Neglect, Physical, and Sexual) by group When comparing histories of physical abuse, $52.7 \%$ of JSOs reported this type of abuse as compared to $22.7 \%$ of JDs and $10 \%$ of JCs. The difference in self reported history of sexual abuse in their personal histories is even more striking. Almost 53\% of JSOs reported that they had experienced childhood sexual abuse compared to $7.2 \%$ of JDs and only $1.2 \%$ of the participants in the JC group. A series of one-way 
ANOVAs was conducted to compare the three groups (JSO, JD and JC) to see if the percentage of participants who reported experiencing all three types of abuse (Neglect, Physical, and Sexual) differed statistically. As hypothesized, the groups were significantly different. When comparing groups on history of neglect one-way analysis of variance (ANOVA) was calculated the analysis was significant, $F(2,837)=26.83$, $p>.01$. When comparing groups on history of physical abuse using an ANOVA the results were also significant, $F(2,837)=74.81, p>.01$. Finally, when comparing groups on history of sexual abuse the results of an ANOVA were the most striking. The difference between groups was significant, $F(2,837)=198.24, p>.01$.

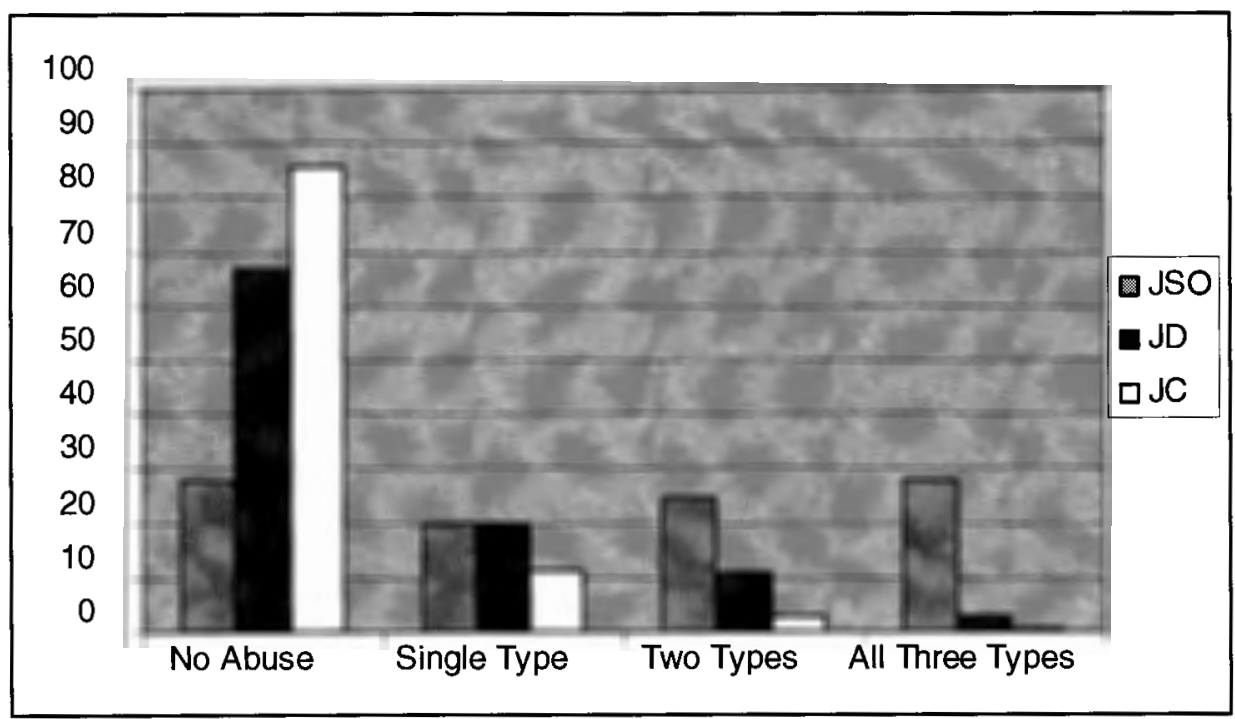

Figure 6: Abuse Comparison - Compound Abuse by Group

Some concern may exist that participants in the JSO group self-identified more abuse than they actually experienced. However the rates found in this study are similar if to those found in past studies. For instance, Prentky, Harris, Frizzell, \& Righthand (2000) found that $74 \%$ of their juvenile sex offender sample reported one form of 
abuse, with 54\% reporting physical abuse. A larger percentage of the participant sample in the current study did report higher rates of sexual abuse (53\% as compared to the $41 \%$ reported in Prentky et al.); however, similar percentages of participants reported experiencing all types of abuse in both Prentkey et al. (24\%) and the current study $(27.8 \%)$.

An environment that allows for abuse of one type often allows for multiple instances of different types of abuse (Mullen et al., 1996); thus, it is important to consider that it can be very difficult to obtain a clear picture of the abuse histories of some individuals. This study utilized a dual-approach to assessing and analyzing the abuse histories of the participants. First, the self-reported history of having suffered any type of abuse was measured to categorize each participant into Bartholomew's model under their view of self (VOS). Second, the reported abuse histories were analyzed for differences between the three participant groups, both on the percentage of individuals in each group (JSO, JD and JC) reporting having experienced one type of abuse (neglect, physical and sexual) and comparing the participant groups on the percentages of individuals reporting having suffered complex abuse. A one way ANOVA found that the participant groups were significantly different in the amount of complex abuse suffered, $F(3,837)=93.80, p>.01$. While only one participant, or $.4 \%$, of the JC group reported as having suffered from all types of measured abuse, 54 participants, or $27.8 \%$, of the JSO group reported experiencing all three. The statistics reported throughout this section pertain to the overall participant sample. In response to the differences in group (JSO, JD \& JC) composition, additional results detailing 
the findings by ethnic group have been provided in Tables 6-11 at the end of this document.

The results of this study show the importance of the participants' perception: Current behavior is determined by how an individual perceives past experiences. This is especially salient when looking at the behavior of adolescents. Ryan (1999b) addresses the importance of juvenile offenders' perceptions of their own childhood abuse experiences that often led to low self esteem. She stated that the most important goal of successful treatment of juveniles that have sexually offended is to change how they react when confronted with their perceptions of helplessness, hopelessness and outrage and foster competence and accountability. Before treatment many abusers believe that perpetrating abuse on others can be rationalized. The successfully treated offender uses the skills acquired in treatment to appropriately handle emotional stress and therefore not offend against others (Ryan, 1999b). 


\section{DISCUSSION}

Previous studies examining attachment in adolescent offenders have presented several methodological problems, including small sample size, lack of diversity, and lack of comparison groups. To address these concerns, the current study utilized a large, ethnically diverse sample taken from seven different geographic locations in the United States. After excluding participants based on gender, age and completeness of survey, the participant sample was comprised of 837 males between 12 and 18 years of age $(M=15.74)$. In order to allow for comparisons between juveniles who sexually offend, juveniles who commit non-sexual offenses, and juveniles with no history of offense, data was collected from three comparison groups: Juvenile Sexual Offenders ( $n=273)$; Juvenile Delinquents $(n=304)$; and Juvenile Comparisons $(n=250)$. Only a handful of existing studies previously employed the use of juvenile participants or utilized such extensive comparison groups; this design may be a critical component in the understanding of attachment deficits and differences in juveniles who sexually offend.

The current study proposed three hypotheses. The first suggested that the Perceived Relationship with Supervisor measure would demonstrate reliability (i.e., internal consistency) as well as validity (i.e., reflecting a single underlying construct). Second, in the current sample, juvenile sex offenders (JSOs) would be more likely to be categorized as "Fearful" as defined in this study in Bartholomew's model than juveniles convicted of non-sexual delinquency (JDs), who, in turn, are more likely to be categorized as "Fearful" than juvenile comparisons (JCs). The final hypothesis 
posited that a significantly larger proportion of participants who had sexually offended would have suffered childhood abuse (i.e., sexual abuse, physical abuse, or neglect) than participants in the JD or JC groups. Additionally, participants in the JD group would have experienced more childhood abuse than JCs.

Study findings indicated that the first hypothesis regarding the reliability and validity of the measure was strongly supported. The Perceived Relationship with Supervisor (PRS) scale was derived from a larger measure, the Supervisor Questionnaire (Kaufman, 2001), and was designed to evaluate how supervision relates to sexual offending behavior in juveniles. The similarity of the content of the questions asked in the PRS was documented to those asked by an accepted measure of attachment, the Inventory of Parent \& Peer Attachment (IPPA) developed by Armsden \& Greenberg (1987). Statistical techniques, including a correlation matrix, an exploratory factor analysis (EFA) and confirmatory factor analysis (CFA) showed that all of the questions in the measure were significantly related and measured one underlying construct. Although the factor analyses found four subscales instead of the expected three, there was only one difference. There was a distinction regarding the second communication subscale that explored how often adolescents perceive communication with their parents about topics surrounding drugs and alcohol, dating relationships and sex. The results of the CFA clearly demonstrate that the overall model is a good fit to the latent construct, accounting for $56.57 \%$ of the overall variance. This measure can now be considered to have support for its reliability and validity. Future studies should continue to explore the validity of the PRS by 
examining its performance compared to that of an established measure of attachment with well-documented reliability and validity, such as the IPPA (Armsden \& Greenberg, 1987). The PRS and the IPPA both measure adolescents' perceptions of their relationships with their female caregivers. Using a single sample to contrast scores on the PRS with those on the IPPA would provide further evidence of the validity of the PRS when compared to a standard attachment measure. Further validation of the PRS subscale measuring communication is an especially exciting opportunity. As already mentioned, researchers have found that self-reports of parentchild communication to be good indicators of attachment (Cernkovich \& Giordano, 1987). Given the literature previously reviewed (Armsden \& Greenberg, 1987; Target, Fonagy \& Schmueli-Goetz, 2003; Main \& Goldwyn, 1998; Bartholomew and Horowitz, 1991; Hazan \& Shaver, 1987), a closer examination of the relationship between the questions regarding abuse history in the PRS and a well-accepted measure of self-esteem (e.g., Rosenberg's Self Esteem Scale, 1965) represents the logical next step for this line of research. While a strong case was made for history of abuse as a proxy for self-esteem in this investigation, obtaining findings that directly link attachment concerns with deficits in self-esteem measured via a recognized assessment tool would greatly strengthen this link, improve construct validity and further promote the need for additional research in this area. Moreover, positive findings that link the PRS to an established measure of self-esteem would provide further validation for the PRS. Additional support for the PRS is significant given the paucity of reliable and valid tools available to measure attachment. As a fully- 
supported measure, the PRS could be integrated into further assessments of the attachment styles of juveniles convicted of sexual offenses. In addition to giving treatment providers more accurate and complete information about their clients, the PRS could also provide adolescents with valuable information into their own attachment styles. In this way, it could help them better understand how their experiences in their first social environment, the family, have affected the shape and direction of their current and future relationships with significant others.

Utilizing Bartholomew's Four Category Model of Attachment (Bartholomew \& Horowitz, 1991), the current study assigned participants to one of four possible attachment styles based on their average PRS scores and their self esteem, as measured by the proxy of self-reported histories of childhood neglect, physical abuse, and sexual abuse. Through this categorization, the remaining two proposed hypotheses were tested. Significant differences were found in attachment styles between the three comparison groups. Specifically, JSO participants were more likely to be classified as "Fearful" than JDs; in turn, JDs were more likely to be classified as "Fearful" than JCs. These findings provide strong support for the second hypothesis. Although not included in the original hypotheses, results indicated that a large percentage of JSO participants could be categorized as Preoccupied. This classification represents those participants who have a good view of others (primarily their primary female caregivers) and can depend on their supervisor, while having suffered some form of childhood abuse and, consequently, possessing a negative view of self. 
Results of this investigation demonstrating that a large percentage of the participants in the JSO group exhibit signs of preoccupied attachment styles are similar to adult offenders evaluated in studies by a number of researchers in the area (Stirpe et. al, 2006; Ward, Hudson, \& Marshall, W, 1996; Abracen, Looman, Di Fazio, Kelly \& Stirpe, 2006). Stirpe et al. (2006) offered an explanation for the relationship between preoccupied attachment styles and the offending behavior of adult child molesters. The authors suggest that the internal working models of preoccupied individuals result in their believing that they are unworthy or incapable of receiving love or support from caregivers. As a result of this lowered expectation for success in appropriate relationships with adults, they choose children to fulfill their intimacy needs (Stirpe et. al., 2006). These conclusions are supported by further descriptions of the sexual offender who confuses sexual activity with intimacy and victimizes others in order to "desperately, but vainly seek intimacy through sex" (Marshall, 1989, p.498). Ward et al. (1996) used this same logic in explaining the significantly larger percentage of adult child molesters categorized as preoccupied attachment style based on The Relationship Styles Questionnaire (RSQ) (Griffin \& Bartholomew, 1994). The RSQ is similar in style to the PRS and uses a very comparable 5-point Likert scale for collecting participants' responses. Abracen et. al (2006) used an abbreviated version of the self-report RSQ in their study, in which they also found that child molesters reported significantly higher preoccupied scores than did violent non-sexual offenders. Research outside the field related to juvenile and adult sex offending have found that 
individuals with preoccupied attachment style often use sex in an effort to experience intimacy (Shaver \& Hazan, 1993; Shaver \& Clark, 1996).

Next, a large percentage of participants identified as juvenile sex offenders were categorized as having a "Dismissing" attachment style. Wood \& Riggs (2008) suggest that individuals that engage in violence and crime do so because of their lack of concern for others, which demonstrates this disordered attachment style. This conclusion has also been supported by researchers in the field of sexual offenders. Ward, Hudson \& Marshall (1996) found rapists and violent non-sexual offenders were more likely to exhibit dismissing attachment style. Further, Hudson \& Ward (1997) found that "dismissing" men were more likely to endorse rape myths and place more blame of the victims of sexual assault.

The fact that results pertaining to juvenile offenders in the current investigation are similar to those obtained with adult offenders in previous studies provides further confirmation that attachment style may indeed be linked to the etiology of sexual offending behavior in some individuals. More importantly for efforts to reduce recidivism in individuals that sexually offend, this linkage encourages greater use of attachment informed treatment modalities. A frequent presenter on attachment informed treatment, Phil Rich (2009), suggests that preoccupied individuals lack trust and self-confidence. He also asserts that one of the goals of attachment-informed treatment includes developing a secure and coherent sense of self, including the experience of self-agency and self-efficacy. As discussed in the introduction, researchers have found strong correlations between childhood abuse and low self 
esteem. (Briere \& Elliot, 2003; Brown \& Finkelhor, 1986; Gross \& Keller, 1992;

Stern, et al., 1995; Briere, 1998). Specifically, abuse experiences seem to be associated with juvenile offenders' adoption of attachment styles that are less adaptive towards the development of appropriate relationships and may contribute to their offending behavior. With this in mind, treatment efforts to enhance self-esteem may result in shifts in juvenile's attachment style that may promote more adaptive and healthy interpersonal functioning.

Study findings also demonstrated that attachment style is a statistically significant predictor of offending behavior. Specifically, a multinomial logistic regression found that based on attachment style participant group membership (JSO, JD, or JC) could be predicted in a significant number of individuals. These results provide additional support for the second hypothesis and mirror those already present in the literature (Marshall, 1989; Miner \& Munns, 2005; Rich, 2009). The current study greatly improved on existing research by including a larger, ethnically diverse sample of juveniles, utilizing two comparison groups (JD and JC), and surveying offending participants shortly after their conviction. Study results support the idea that, while all adolescents who are involved in criminal perpetration have violated societal norms, those who commit sexual crimes against children often exhibit more signs of dysfunctional or deficient in their childhood development. These findings indicate that addressing the resulting attachment deficits and relationship difficulties in many JSOs experience may be critical for 
creating comprehensive therapeutic approaches that effectively reduce recidivism rates.

As discussed in the introduction of this paper, there is already strong support for the notion that treatment decreases recidivism in adults (Hanson et. al, 2002) and juveniles alike (Steinberg, 2006; Worling \& Curwin, 2000). Consensus in the field supports modalities of treatment that improves family relationships and social skills as well as helping those with a history of childhood abuse process and repair the damage caused by those abusive experiences (Worling \& Curwin, 2000). The current study framed the family relationship and history of abuse within Bartholomew's Four Category Model, which evaluates participants' view of others (VOO) and view of self (VOS). Although there have been a small number of studies evaluating attachment style and its connection to both sexual and non-sexual offending behavior the majority of these studies assessed adult offenders. Those that have employed adolescent participants had much smaller sample sizes but still found similar results. Miner \& Munns (2005) evaluated a participant sample of 78 adolescent sex offenders, 156 juvenile delinquents and a non delinquent comparison group of 80 individuals for their perceived connections to family, school and peers. Relationship to family, as operationalized through family isolation, was assessed through a 5-item, 5-point Likert-type scale measure that included items such as, "My family doesn't take much interest in my problems," and "I feel close to my family" (reverse scored) (Miner \& Munns, 2005). Responses range from strongly disagree to strongly agree, with higher scores indicating more isolation. Participants in the sex offender group exhibited 
significantly more isolation from family i.e. lack of attachment (Miner \& Munns, 2005). The researchers suggested that their results support the use of treatment modalities that emphasize and facilitate family, school, and peer social interactions or increased attachment to others. At the conclusion of their article they recognized the need for more ambitious research projects including the shared risk factors for the perpetration of child sex abuse and delinquent behavior based upon a number of factors including attachment style. Although the current study did not address all of their suggestions it did address some of the concerns they and others have raised including utilizing a larger sample size (McCann \& Lussier, 2008), evaluating connection to family (Miner \& Munns, 2005; Rich 2007, Marshall, 1989, 1993; Abracen, 2006), lessoning retrospective bias (McMillan, Hastings, Salter \& Skuse, 2007) by evaluating juveniles shortly after the commission of their offenses and garnering information from ethnically diverse participants (Katz-Schiavone, Levenson, \& Ackerman, 2008).

Still, there is the need for additional research in this area to enhance our understanding of the mechanisms that link attachment related concerns to sexual offending. For example, research studies that evaluate participant's perceptions of their relationship with their fathers, siblings and expanded family could provide a richer picture of attachment in the family structure. A broader understanding of how family formation influences attachment styles is especially important given the changing shape of the U.S. family (Bengtson, 2001). Since Bowlby (1944) first started looking into attachment in juvenile non-sexual offenders, the predominate models 
used for evaluating attachment has entailed quantifying the relationship between the individual and his mother or primary caregiver. It is important to recognize that as family structures change, the perspectives and measurement tools used to assess attachment must also change with them. One suggestion is to use adaptations of the IPPA that would evaluate relationships with important others beyond the nuclear family (i.e. teachers, mentors, coaches). This adaptation would also address concerns raised regarding cultural bias in existing studies.

Bell-Scott \& Taylor (1989) recognized that the differences in the magnitude of social problems between black and white adolescents reflect differences in family structure as well as exposure to differential environmental influences to positive psychosocial development. The development of minority youth and white youth of low SES is influenced by a number of factors not considered in measurement tools utilized by studies conducted from a majority perspective. These factors include living in depressed, unstable and socially isolated inner-city neighborhoods. Black children and youth in America are far more likely that their white counterparts to live in single parent homes with only one parent figure available to them (Bell-Scott \& Taylor, 1989) Future studies on the etiology of juvenile offending should include the consideration of factors in the child's exosystem and macrosystem (Bronfrenbrenner, 1995) that shape how they develop social competencies and what opportunities that are available to them.

Finally, as almost all research studies to date, including the current one, have evaluated participants attachment based on one specific time period. Bartholomew 
(1993) recognized that attachment is dynamic and changes throughout an individual's lifetime. This supports the need for etiological research to be longitudinal in nature, allowing for multiple assessments of a participants attachment style. In addition to providing a more accurate picture of how attachment developed in individual's preoffense this longitudinal approach would allow for assessment of positive changes in those offenders receiving attachment-informed treatment. 


\section{CONCLUSION}

\section{SIGNIFICANCE}

This study's findings are significant in a number of regards. First, they are the result of an investigation that presents a higher methodological standard than previous studies. Second, it provides greater support for the theory that some juveniles who offend sexually due so, in part, due to deficits in attachment. Third, the study supports long-standing claims by clinicians that a high proportion of children who sexually offend have their own history of childhood trauma. Finally, findings indicated to potential to contribute to offender prevention efforts by more systematically addressing child and adolescent victims of trauma. As with any research study, the current study had both strengths and weaknesses that are important to note.

\section{STRENGTHS}

This investigation utilizes a large, diverse participant sample $(\mathrm{N}=837)$. The sample sizes of previous studies have averaged closer to 100 participants, resulting in insufficient sample size to allow for accurate statistical analysis. The large sample offered greater power to identify group differences and isolate factors that help explain the role of attachment. The data used in the current study was collected with particular attention to gathering information from minority groups, including Black/African American and Hispanic/Latino populations, in order to be more generalizable to minority populations in the United States. Along with assuring comparable ethnic diversity in participant samples, further suggestions for future research are offered. Along with ethic affiliation, care should be taken to obtain accurate assessments of 
participant SES. The study design also included two juvenile comparison groups (i.e., juvenile delinquents and non-offending juveniles). This was an improvement over previous investigations and fostered a better assessment of the significance of attachment relative to non-sexual offenders as well as teens with no criminal history. Further, previous research using juvenile offenders to investigate this topic has been very limited, with most of the findings in the area based on retrospective accounts from adult offenders. The current study not only directly sampled adolescents, but focused on teens who account for a large proportion of sexual offending (i.e., teens between the age of 12 and 18 years of age). Additionally, the use of this narrower age range for participants ensured that they were all within the same developmental stage, "Middle Adolescence." This was important to minimize developmentally related factors that could have confounded the investigation of attachment. Finally, participants were purposely assessed regarding attachment shortly after their convictions. This feature was incorporated into the study design to not only alleviate concerns expressed in previous studies related to memory lapses, but also to assure that the offender participants' perceptions of familial relationships were solicited as close to the time that they were living with family members as possible. Additional research should evaluate participants using established measures of attachment, including self-esteem measures. Evidence from social and developmental psychologists strongly suggests that peer and family effects vary across the life stage of adolescence (Regnerus, 2002) and that friendships with peers (Heppler, 1997; Berndt, 1982) and involvement with organized structured activities with peers 
(Huebner, \& Betts, 2002) can be better predictors of secure attachment in adolescents. Inclusion of questions regarding active involvement in organized activities, such as group sports and civic organizations, should be included in further research.

\section{LIMITATIONS}

Conversely, there were a number of limitations associated with this study. The most obvious limitation was the use of archival data that was gathered using measures not specifically designed to measure attachment styles in juveniles. The analysis employed in the current study included using a self-reported history of childhood abuse as a proxy for a measure of self-esteem.

The second, related limitation of this study is the use of self-report measures; however, given the subject and scope of this investigation, such measures were necessary to achieving full disclosure during data collection. The use of self-report measures may increase participant perceptions of privacy during data collection which may, in turn, increase the accuracy of obtained data (Groves, Fowler, Couper, Leowski, Singer, \& Tourangeau, 2004) An increased sense of privacy was necessary to assure that participants felt free to answer all questions, particularly those asking for personal details regarding their own histories of abuse or, for offending participants, crimes they may have committed without fear of ramifications. This method of data collection has been found to provide comparable results to other methods of gathering sensitive information (Rosenbaum, Rabenhorst, Reddy, Fleming, \& Howells, 2006; Kaufman, Hilliker, Lathrop, Daleiden, \& Rudy, 1996). The over-representation of White or Caucasian participants in the JSO group may also be considered a limitation. 
It seems that this may be in large part due to the documented under- reporting of sexual assaults in minority populations. The ethnic makeup of this JSO sample reflects those found in other prison population samples. This disparity should be addressed in further research.

\section{IMPLICATIONS}

The results of this study empirically support what many front-line treatment professionals have long recognized: many adolescents who find their way within the jurisdiction of the courts, whether in juvenile detention facilities or in out-patient treatment centers, exhibit signs of attachment deficits. These individual often come from chaotic family environments marked by neglect, physical abuse, and sexual abuse. It is important for the institutions responsible for the care and treatment of juveniles who offend to consider assessing individuals in the population for attachment deficits and address any deficits with appropriate treatment plans. Treatment programs that address the constructs related to attachment and seek to improve family functioning, such as MST, already exist. This research indicates such approaches should be adopted into more juvenile treatment programs. As already stated, the overall goal of the current research was to help identify agents of change that may decrease recidivism of juvenile sexual offenders (Schaeffer \& Borduin, 2005). The most important implications of the current study is that attachment styles may play a part in the etiology of sexual offending behavior in some individuals and that recidivism rates are lower for juveniles that receive specialized treatment that addresses those attachment styles. Evaluation of individuals for attachment deficits 
can provide insight into how their socially unacceptable behaviors developed and what treatment options might best result in better-adjusted individuals who are less likely to reoffend. 


\section{REFERENCES}

Abracen, J., Looman, J., Di Fazio, R., Kelly, T., \& Stirpe, T. (2006), Patterns of attachment and alcohol abuse in sexual and violent non-sexual offenders. Journal of Sexual Aggression. 19-30.

Ackerman, R. \& Graham. D. (1990). Too old to cry: Abused teens in today's America. Blue Ridge Summit, PA: TAB Books.

Ainsworth. Mary D. (1978). Patterns of attachment: A psychological study of the strange Situation. Lawrence Erlbaum Associates.

Ainsworth M. (1989). Attachments beyond infancy. American Psychologist. 44, 709 716.

Ainsworth, M., Blehar, M. C., Waters, E., \& Wall, S. (1978). Patterns of attachment: A psychological study of the Strange Situation. Hillsdale, NJ: Erlbaum.

Alexander, P. C., \& Lupfer, S. L. (1987). Family characteristics and long-term consequences associated with sexual abuse. Archives of Sexual Behavior, 16, $235-245$.

Ainsworth, M., \& Bowlby, J. (1991). An ethological approach to personality development. American Psychologist. 46, 333-341.

Allen, E. \& Baucom, D. (2004). Adult attachment and patterns of extradyadic involvement. Family Process, 43, 467-488.

Allen, J., Moore, C, Kuperminc, G \& Bell, K. ( 1998) Attachment and adolescent psychosocial Functioning. Child Development. 69, 1406-1419.

Alexander, P. C. (1992). Application of attachment theory to the study of sexual abuse. Journal of Consulting and Clinical Psychology, 60, 185-195.

Alexander, M. (1999) Sexual offender treatment efficacy revised. Sexual Abuse: A Journal of Research and Treatment. 11, 101-116.

Alexander, P., Anderson, C., Brand, B., Schaeffer, C., Grelling, B. \& Kretz, L. (1998). Adult attachment and long term effects in survivors of incest. Child Abuse \& Neglect. 45-61. 
Aljazireh, L. (1993). Historical, environmental, and behavioral correlates of sexual offending by male adolescents: A critical review. Behavioral Sciences and the Law, 11, 423-440.

Alonso-Arbiol, I., Shaver, P. \& Yarnoz, S. (2002). Insecure attachment, gender roles, and interpersonal dependency in the Basque Country. Personal Relationships, 9, 479-490.

Alter-Reid, K., Gibbs, M.S., Lachenmeyer, J. R., Sigal, J. \& Massoth, N. A. (1986). Sexual abuse of children: A review of the empirical findings. Clinical Psychology Review, 6, 249-266.

Amato, P. (2005).The Impact of Family Formation Change on the Cognitive, Social, and Emotional Well-Being of the Next Generation. Future of Children 15, 7596.

Arias, I. (2004). The legacy of child maltreatment: Long-term health consequences for women. Journal of Women's Health, 468-473.

Armsden, G. \& Greenberg. M. (1987). The inventory of parent and peer attachment: Individual differences and their relationship to psychological well-being in adolescence. Journal of Youth and Adolescence. 16, 427-254.

Bachman. R., \& Saltzman, L. (1995). Violence against women: Estimates from the redesigned survey, Bureau of Justice Statistics Special Report National Crime Victimization survey, 1-8.

Bagley, C. R., \& Young, L. (1990). Depression, self-esteem, and suicidal behavior as sequels of sexual abuse in childhood: Research and therapy. In M. Rothery \& G. Cameron (Eds.), Child maltreatment: Expanding our concept of helping, 183-210.

Banyard, V. \& Williams, L. (1996). Characteristics of child sexual abuse as correlates of women's adjustment: A prospective study. Journal of Marriage and the Family, 58, 853-865.

Banyard, V., Williams, L., \& Siegel, J. (2001). The Long-Term Mental Health Consequences of Child Sexual Abuse: An Exploratory Study of the Impact of Multiple Traumas in a Sample of Women. Journal of Traumatic Stress, 14, 697-715. 
Baron-Cohen, S., O’Riordan, M., Stone, V., Jones, R., \& Plaisted, K. (1999). Recognition of faux pas by normally developing children and children with Asperger Syndrome or high-functioning autism. Journal of Autism and Developmental Disorders, 29,407-418.

Bartholomew, K. (1990). Avoidance of intimacy: An attachment perspective. Journal of Social and Personal Relationships, 7, 147-178.

Bartholomew, K. \& Horowitz, L. (1991). Attachment styles among young adults: A test of a four-category model. Journal of Personality and Social Psychology, 61, 226-244.

Bartholomew, K. (1993). From childhood to adult relationships: Attachment theory and research. In S. Duck (Ed.). Understanding Relationship Processes 2: Learning about Relationships (pp. 30-62), Beverly Hills: Sage Publications

Becker, J. (1998). What we know about the characteristics and treatment of adolescents who have committed sexual offenses. Child Maltreatment. 317329.

Becker, J. V., \& Kaplan, M. S. (1988). The assessment of adolescent sexual offenders. In R. J. Prinz (ed.), Advances in behavioral assessment of children and families (pp. 97-118). Greenwich, CT: JAI Press. Becker, J.

Bell-Scott, P., \& Taylor. R. (1989). The multiple ecologies of black adolescent development. The Journal of Adolescent Research. 119-124.

Beitchman, J. H., Zucker, K. J., Hood, J. E., daCosta, G. A. \& Akman, D. (1991). A review of the short-term effects of child sexual abuse. Child Abuse and Neglect, 15, 537-556.

Beitchman, J. H., Zucker, K. J., Hood, J. E.., daCosta, G. A., Akman, D. and Cassavia, E. (1992). A review of the long-term effects of child sexual abuse. Child Abuse and Neglect, 16, 101-118.

Berndt, T. (1982). The Features and Effects of Friendship in Early Adolescence, Society for Research in Child Development. 1447-1460.

Berry, K., Barrowclough, C. \& Wearden A. (2008). Attachment theory: A framework for understanding symptoms and interpersonal relationships in psychosis. Behavior Research and Therapy, 46,1275-1282. 
Bengtson, V. (2001). Beyond the nuclear family: The increasing importance of multigenerational bonds. Journal of Marriage and Family. 1 - 16.

Blatz, W.E. (1966). Human security: Some reflections. Toronto, Canada: University of Toronto Press.

Bolger, K. E., Patterson, C. J. (2001). Developmental pathways from child maltreatment to peer rejection. Child Development, 72, 549-568.

Bolger, K., Patterson, C., \& Kupersmidt, J. (1998). Peer relationships and self-esteem among children who have been maltreated. Child Development, 69, 1171-1197.

Botash, A. (2008). Pediatrics, Child Sexual Abuse. retrieved August 22, 2008 from http://www.emedicine.com/emerg/topic369.htm

Bowlby, J. (1944). Forty-Four Juvenile Thieves: Their Character and Home-Life. International Journal of Psychoanalysis, 25, 19-52.

Bowlby, J. (1969). Attachment and loss: Vol. 1. Attachment. New York. Basic Books.

Bowlby, J. (1973). Attachment and loss: Vol. 2. Separation. New York. Basic Books.

Bowlby, J. (1980). Attachment and loss: Vol. 3. Loss: Sadness and depression. New York. Basic Books.

Bowlby, J. (1988). A Secure Base: Parent-Child Attachment and Healthy Human Development, Tavistock professional book. London: Routledge.

Bretherton, I. (1992). The origins of attachment theory: John Bowlby and Mary Ainsworth. Developmental Psychology, 28, 759-775.

Briere, J. (1988). The long-term clinical correlates of childhood sexual victimization. Annals of the New York Academy of Sciences, 528, 327-335.

Briere, J. \& Elliot, D. (1994). Immediate and long-term impacts of child sexual abuse. The Future of Children. 4, 54-69.

Briere, J. \& Eliott, D. ( 2003). Prevalence and psychological sequelae of self-reported childhood physical and sexual abuse in a general population sample of men and women. Child Abuse and Neglect, 27, 1205-1222. 
Briggs, F., McVeity, M. \& Love, M. (2001). Teaching children to protect themselves: a resource for teachers and adults who care for young children. Crows Nest NSW, Australia, Allen \& Unwin.

Bronfenbrenner, U. (1979). The ecology of human development. Cambridge, MA: Harvard University Press.

Bronfenbrenner, U. (1995). Developmental Ecology Through Space and Time: A Future Perspective. In P. Moen, G.H. Elder, Jr., and K. Luscher (Eds.), Examining lives in context: Perspectives on the ecology of human development. Washington, D.C: APA Books.

Brown, J., Cohen, P., Johnson, J. G., \& Smailes, E. M. (1999). Childhood abuse and neglect: Specificity of effects on adolescent and young adult depression and suicidality. Child and Adolescent Psychiatry,. 38, 1490-1496.

Burton, D. (2000). Were adolescent sexual offenders children with sexual behavior problems? Sexual Abuse: A Journal of Research and Treatment. 12, 37-48.

Caldwell, M. F. (2002). What we do not know about juvenile sexual reoffense risk. Child Maltreatment, 7(4), 291-302.

Carlson V, Cicchetti D, Barnett D, \& Braunwald, K. (1989). Child maltreatment: theory and research on the causes and consequences of child abuse and neglect. In Finding order in disorganization: Cicchetti D, Carlson VK, (eds) New York: Cambridge University Press, 1989.

Center for Sex Offender Management (CSOM) (2002). Myths and facts about sex offenders. Retrieved April 25, 2008 from http://www.csom.org/pubs/mythsfacts.html.

Cellini, H. (1995). Assessment and treatment of the adolescent sexual offend. In B. K. Schwartz \& H. R. Celini (eds.) The sex offender: corrections treatment and legal practice, (pp: 6-11). Kingston NJ: Civic Research Institute, Inc.

Cerney, M. S. (1995). Treating the "heroic treaters." In C. R. Figley (Ed.), Compassion fatigue (pp. 131-148). New York: Brunner/Mazel.

Cernkovich, S., \& Giordano, P. (1987). Family relationships and delinquency. Criminology, 2, 295-319. 
Chaffin, M., Lawson, L., Selby, A., \& Wherry, J. N. (1997). False negatives in sexual abuse interviews: Preliminary investigation of a relationship to dissociation. Journal of Child Sexual Abuse, 6, 15-29.

Chaffin, M. \& Bonner, B. (1998) 'Don't shoot, we're your children' Have we gone too far in our response to adolescent sexual abusers and children with sexual behavior problems? Child Maltreatment, 3, 314-316.

Cicchetti, D., \& Toth, S. L. (1995). A developmental psychopathology perspective on child abuse and neglect. Journal of the American Academy of Child and Adolescent Psychiatry, 34, 541-565.

Cicchetti, D., Lynch, M., Shonk, S., \& Manly, J.T. (1992). An organizational perspective on peer relations in maltreated children. In R.D. Parked 7 G. W . Ladd (eds.) Family -peer relationships: Modes of linkage. Hillsdale, NJ: Erlbaum.

Cooper, C., Murphy, W., \& Haynes, M. (1986). Characteristics of abused and nonabused adolescent sexual offenders. Sexual Abuse: A Journal of Research and Treatment. 8, 105-119.

Council of State Government. Residency Restriction Zones. retrieved May 17, 2008 from http://www.csg.org/policy/pubsafety/documents/ResidencyRestrictionLaws.pdf.

Courtois, C. (1979). The incest experience and its aftermath. Victimology: An International Journal, 4. 337-347.

Critenden, P., \& Ainsworth, M. (1989). Child maltreatment and attachment theory. In D. Cicchetti \& V. Carlson (eds.), child maltreatment: Theory and research on the causes and consequences of child abuse and neglect. New York, Cambridge University Press.

Daro, D. (1988). Confronting child abuse: Research for effective program design. New York: Free Press.

Davis, G. E., \& Leitenberg, H. (1987). Adolescent sex offenders. Psychological Bulletin, 101, 417-427.

DiTommaso, E., Brannen-McNulty, C., Ross, L., \& Burgess, M. (2003). Attachment styles, social skills and loneliness in young adults. Personality and Individual Differences. 35 303-312. 
Daleiden, E., Kaufman, K., Hilliker, D. \& O'Neil, J. (1998). The sexual histories and fantasies of youthful males: A comparison of sexual offending, Nonsexual offending, and nonoffending groups. Sexual Abuse: A Journal of Research and Treatment, 195-209.

Dominquez, R. Z., Nelke, C.F., \& Perry, B.D. (2002). Child Sexual Abuse in: Encyclopedia of Crime and Punishment, Vol. 1.(David Levinson, Ed.) Sage Publications, Thousand Oaks pp 202-207.

Dube, S., Anda, R., Whitfield, C., Brown, D., Felitti, V., Dong, M. \& Giles (2005). Long-Term Consequences of Childhood Sexual Abuse by Gender of Victim. American Journal of Preventative Medicine. 28, 430-438.

Elliot, D. S., Huizinga, D., \& Morse, B. J. (1985). The dynamics of deviant behavior: A national survey report. Boulder, CO: Behavioral Research Institute.

Federal Reserve Bank (FRB) 1998. Foreign Exchange Rates - January 1998. retrieved from http://www.federalreserve.gov/releases/h10/19980126/ on December 18, 2008.

Feldman, S. \& Elliott, G. (1990). Adolescence: Path to a productive life or a diminished future? Carnegie Quarterly, 35, 1-13.

Fergusson, D., Horwood, J., \& Lynskey, M. (1997) Childhood sexual abuse, adolescent sexual behaviors and sexual revictimization. Child Abuse \& Neglect, 21, 789-803.

Fergusson, D.M, Horwood, L. J., \& Woodward, L. J. (2000). The stability of child abuse reports: A longitudinal study of the reporting behavior of young adults. Psychological Medicine, 30, 529-544.

Finklehor, D. (1991). Child Sexual Abuse in violence in America: A public health approach. Mark L. Rosenberg \& Mary Ann Fenly (eds.). Oxford University Press US.

Finkelhor, D., \& Baron, L. (1986). Risk factors for child sexual abuse. Journal of Interpersonal Violence, 1, 43-71.

Finkelhor, D. (1994). Current information on the scope and nature of child sexual abuse. The Future of Children, 4, 31-53

Finkelhor, D., \& Brown, A. (1985). The Traumatic Impact of Child Sexual Abuse: A Conceptualization. American Journal of Orthopsychiatry, 55, 530-541. 
Ford, M. E., \& Linney, J.A. (1995). Comparative analysis of juvenile sex offenders, violent nonsexual offenders, and status offenders. Journal of Interpersonal Violence, 10, 56-70.

Freeman-Longo, R. E. (1996). Prevention or problem? Sexual Abuse: A Journal of Research \& Treatment, 8, 91-100.

Freeman-Longo, R. E., Bird, S., Stevenson, W. F., \& Fiske, J. A. (1995). 1994 Nationwide survey of treatment programs and models. Brandon, VT, Safer Society Press.

Freeman-Longo, R. E. (1986). The impact of sexual victimization on males. Child Abuse \& Neglect. 10, 411-414.

Freyd, J. J. (1996). Betrayal trauma: The logic of forgetting childhood abuse. Cambridge, MA: Harvard University Press.

Friedrich, B. (2006) Child custody litigation: Allegations of child sexual abuse. Kathryn Kuehnle \& Leslie Drozd (eds.) Haworth Press.

Fromuth, M. E. (1986). The relationship of childhood sexual abuse with later psychological and sexual adjustment in a sample of college women. Child Abuse Neglect, 10, 5-15.

Freyd, J.J., Putnam, F.W., Lyon, T.D., Becker-Blease, K. A., Cheit, R.E., Siegel, N.B., $\&$ Pezdek, K. (2005). The science of child sexual abuse. Science, 308, 501.

Gallup, G.H., Jr., Moore, D.W., \& Schussel, R. (1997) Disciplining children in America. Princeton, NJ: The Gallup Organization.

Garlick, Y., Marshall, W. L., \& Thornton, D. (1996). Intimacy deficits and attribution of blame among sexual offenders. Legal and Criminological Psychology, 1, 251-258.

Gilbert, N. (1988). Teaching children to prevent sexual abuse. The Public Interest, 93, 3-15.

Goffman, E. (1962). Stigma: Notes on the management of a spoiled identity. New York: Touchstone Books.

Goldberg, S. (1991). Recent developments in attachment theory and research. Canadian Journal of Psychiatry, 36, 393- 400. 
Gomes-Schwartz, B., Horowitz, J. M., \& Sauzier, M. (1985). Severity of emotional distress among sexually abused preschool, school-age, and adolescent children. Hospital and Community Psychiatry, 36, 503-508.

Goodstein, L. (1979). Inmate adjustment to prison and the transition to community life. Journal of Research in Crime and Delinquency, 16, 246-272.

Goodwin, J., McCarthy, T., \& DiVaston, P. (1981). Prior incest in mothers of sexually abused children. Child Abuse \& Neglect, 5, 87-96.

Gorey, G. M., \& Leslie, D. R. (1997). The prevalence of child sexual abuse: Integrative review adjustment for potential response and measurement biases. Child Abuse \& Neglect, 21, 391-398.

Green A. H. (1996). Overview of child sexual abuse. In S. J. Kaplan (ed.), Family violence: A clinical and legal guide. pp. 73-104. Washington, DC: American Psychiatric Press.

Green, S., \& Salkind, S. (2007). Using SPSS for Windows and Macintosh. Prentice Hall. Upper Saddle River, New Jersey.

Greenberg, D., Bradford, J., Firestone, P., \& Curry, S. (2000). Recidivism of child molesters: a study of victim relationship with the perpetrator. Child Abuse \& Neglect, 24, 1485-1494.

Greenberg, J. S., Bruess, C. E., Chisolm, S., Conklin, S. \& Conklin. S. (2007). Exploring the dimensions of human sexuality. Jones \& Bartlett Publishers, Sudbury, Massachusetts.

Gross, A. \& Keller, H. (1992). Long-term consequences of childhood physical and psychological maltreatment. Aggressive Behavior, 18 171-185.

Groves, R., Fowler, F., Couper, M., Leowski, J., Singer, E., \& Tourangeau (2004). Survey Methodology. John Wiley \& Sons. Hoboken NJ.

Gutman, L. T., St. Clair, K.K., \& Weedy, C. (1991). Human Immunodeficiency Virus Transmission by Child Sexual Abuse, American Journal of Diseases of Children, 145, 137.

Hanna, L., Risden, K., \& Alexander, K. (1997). Guidelines for usability testing with children. Interactions. 4, 9-14. 
Hanson, R. K., \& Bussière, M. T. (1998). Predicting relapse: A meta-analysis of sexual offender recidivism studies. Journal of Consulting and Clinical Psychology, 66, 348-362.

Hanson, R. K., Scott, H., \& Steffy, R. (1995). A comparison of child molesters and nonsexual criminals: Risk predictors and long-term recidivism. Journal of Research in Crime and Delinquency, 32, 325-337.

Hanson, R. K., Gordon, A., Harris, A., Marques, J, Murphy, W., Quinsey, V. et al. (2002). First report of the collaborative outcome data project on the effectiveness of psychological treatment for sex offenders. Sexual Abuse: A Journal of Research and Treatment, 14, 169-104.

Harter S, Alexander P., \& Neimeyer, R. (1988). Long-term effects of incestuous child abuse in college women: social adjustment, social cognition, and family characteristics. Journal of Consulting and Clinical Psychology, 5- 8.

Harter, S. (2006). The self. In W. Damon (Series Ed.) \& N. Eisenberg (Volume Ed.), Handbook of child psychology, $6^{\text {th }}$ Ed. Vol.3. Social, emotional, and personality development (pp. 505-570). New York: John Wiley.

Hazan, C., \& Shaver, P. (1987). Romantic Love Conceptualized as an Attachment Process. Journal of Personality and Social Psychology, 52, 511-524.

Heppler, J. (1997). School Development of children: The role of peers. Social Work in Education, 19, 242-256.

Huebner, A. \& Betts, S. (2002) Exploring the utility of social control theory for your development: Issues of attachment, involvement and gender. Youth \& Society, Vol. 34, No. 2, 123-145 (2002)

Hunter, J. A., Figueredo, A. J., Malamuth, N. M. \& Becker, J. V. (2003). Juvenile sex offenders: toward the development of a typology. Sexual Abuse: A Journal of Research and Treatment, 15, 27-48.

Ingram, G. (1999). Sex Offenders. In P. Carlson \& J. Garrett (eds.) Prison and Jail Administration: Practice and Theory. pp 239-145. Sudbury, MA: Jones and Bartlett.

(The) Jacob Wetterling Crimes against Children and Sexually Violent Offender Registration Act, 42 USC Sec. 14071, (2008). 
Johnson, R., Ross, M., Taylor, W., Williams, M., Carvajal, R., \& Peters, R. (2006). Prevalence of childhood sexual abuse among incarcerated males in county jail. Child Abuse \& Neglect, 30, 75-86.

Johnson, C. (1992). Coping with compassion fatigue. Nursing, 22(4), 116-122.

Johnston, J. \& Ward, T. (1996) Social cognition and sexual offending: A theoretical framework. Sexual Abuse: A Journal of Research and Treatment, 8, 55-80.

Jones, K. D. (1999). The media and Megan's Law: Is community notification the answer? Journal of Humanistic Counseling, Education and Development, 3, 80-88.

Jones, M. (2007). How can you distinguish a budding pedophile from a kid with real boundary problems? New York Times. July 22, 2007.

Katz-Schiavone, S., Levenson, J., \& Ackerman, A. (2008). Myths and facts about sexual violence: Public perceptions and implications for prevention. Journal of Criminal Justice and Popular Culture, 291-311.

Kaufman, K. L. (2001). Supervision Questionnaire. Available from author, Portland, OR: Portland State University.

Kaufman, K.L., Hilliker, D.R., Lathrop, P., Daleiden, E.L. \& Rudy, L. (1996). Sexual offenders' modus operandi: A comparison of structured interview and questionnaire approaches. Journal of Interpersonal Violence, 11, 19-34

Kendall-Tacket, K., Williams, L., \& Finkelhor, D. (1993). Impact of sexual abuse on children: A review and synthesis of recent empirical Studies. Psychological Bulletin. 113, 164-180.

Kendler, K. (2000). Medical College of Virginia Commonwealth Univ.; Archives of General Psychiatry. 60, 702.

Kessler, D.B., \& Hyden, P. (1991). Physical, Sexual, and Emotional Abuse of Children. (CIBA-GEIGY Clinical Symposia, Vol. 43, No. 1). Summit, NJ: Pharmaceuticals Division, CIBA-GEIGY Corporation, 1991.

Kolko, D. (1996). Individual cognitive behavioral treatment and family therapy for physically abused children and their offending parents: a comparison of clinical outcomes. Child Maltreatment, 1, 322-342. 
Knopp, F. H. (1985). The youthful sex offender: The rationale \& goals of early intervention \& treatment. Syracuse, NY, Safer Society Press.

Lahoti, S., McClain, N., Girardet, R., McNeese, M. \& Cheung, K. (2001). Evaluating the child for sexual abuse. American Family Physician, 883-892.

Langan, P., \& Levin, D., (2002) Recidivism of Prisoners released in 1994. Washington D.C., U.S. Department of Justice. Bureau of Justice Statistics.

Laws, D. R. (1989), Relapse prevention with sex offenders. D. Richard Laws (ed). Guilford Press. New York, NY.

Levenson, J. S., \& Cotter, L. P. (2005a). The effect of Megan's Law on sex offender reintegration. Journal of Contemporary Criminal Justice, 21, 49-66.

Levenson, J. S., \& Cotter, L.P. (2005b). The impact of sex offender residence restrictions: 1,000 feet from danger or one step from absurd? International Journal of Offender Therapy and Comparative Criminology, 49, 168-178.

Levenson, J. (2004). Reliability of sexually violent predator civil commitment criteria in Florida. Law and Human Behavior, 28, 357-368.

Levi, R. (2000). Community notification laws: A step toward more effective solutions. Journal of Interpersonal Violence, 11, 298-300.

Lieb, R., Quinsey, V., and Berliner, L., (1998). Sexual predators and social policy in M. Tonry (ed.), Crime and Justice.(pp. 43-114), University of Chicago,

Lotke, E. (1997). Politics and irrelevance: Community notification statutes. Federal Sentencing Reporter, 10, 64-68.

Lyons-Ruth, K., \& Jacobvitz, D. (1999). Attachment disorganization. Unresolved loss, relational violence, and lapses in behavioral and attentional strategies. In J. Cassidy \& P.R. Shaver (Eds.), Handbook of attachment: Theory, research, and clinical applications (pp. 520-554). New York: Guilford Press.

Lyons-Ruth, K., Repacholi, B., McLeod, S., \& Silva, E. (1991). Disorganized attachment behavior in infancy: Short-term stability, maternal and infant correlates and risk related subtypes. Development and Psychopathology, 3, 377-396. 
Lyons, J. (1988). Posttraumatic stress disorder in children and Adolescents: A review of the literature in annual progress in Child psychiatry and child development, Stella Chess, Alexander Thomas, Margaret E. Hertzig (eds.). Philadelphia: Brunner/Mazel.

Lyons-Ruth, K. (1996). Attachment relationships among children with aggressive behavior problems: the role of disorganized early attachment patterns. Journal of Consulting and Clinical Psychology. 64, 64-73.

Lyons-Ruth, K., Connell, D., Zoll, D. \& Stahl, J. (1987). Infants at social risk: relations among infant maltreatment, maternal behavior, and infant attachment behavior. Developmental Psychology. 23, 223-232.

Lindsay, D. S., \& Read, J. D., (1994). Psychotherapy and memories of childhood sexual abuse: a cognitive perspective. Applied Cognitive Psychology. 8, 281338.

MacMillian, H., Fleming, J. E., Trocome, N., Boyle, M. H., Wong, M., Racine, Y. A. et al. (1997). Prevalence of child physical and sexual abuse in the community: Results from the Ontario Health Supplement. Journal of the American Medical Association, 278, 131-135

Main, M., \& Goldwyn, R. (1998). Adult attachment classification system. Unpublished manuscript. University of California: Berkeley, CA.Malamuth, N., Heavey, C., \& Linz, D. (1996). The confluence model of sexual aggression: Combining hostile masculinity and impersonal sex. Journal of Offender Rehabilitation, 23, 3, 13-37.

Main, M., \& Weston, D. (1981). The quality of the toddler's relationship to mother and to father: Related to conflict behavior and readiness to establish new relationships. Child Development, 52, 932-940.

Main, M. \& Hesse, E. (1990). Parents' unresolved traumatic experiences are related to infant disorganized attachment status: Is frightened and/or frightening parental behavior the linking mechanism? In In Greenberg, M., Cicchetti, D., and Cummings, M. (Eds.), Attachment In The Preschool Years: Theory, Research, and Intervention. Chicago: University of Chicago Press.

Main, M., \& Solomon, J. (1990). Procedures for identifying infants as disorganized/disoriented during the strange situation. In M. T. Greenberg, D. Cicchetti \& E. M. Cummings (eds.), Attachment in the preschool years: Theory, research, and intervention (pp. 121-160). Chicago: University of Chicago Press. 
Malamuth, N. (1996). Research on the confluence model of sexual aggression based on feminist and evolutionary perspectives. In Buss, D., \& Malamuth, N. (Eds.). Sex, power, conflict: Evolutionary and feminist perspectives. (pp. 269-295). New York: Oxford University Press.

Malamuth, N.M., Heavey, C., \& Linz, D. (1993). Predicting men's antisocial behavior against women: The "interaction model" of sexual aggression. In G. N. Hall, R. Hirschmann, J. R. Graham, \& M. S. Zaragoza (Eds.), Sexual aggression: Issues in etiology and assessment and treatment (pp. 63-97). New York: Hemisphere.

Malamuth, N., Sockloskie, R., Koss, M., \& Tanaka, J. (1991). The characteristics of aggressors against women: Testing a model using a national sample of college students. Journal of Consulting and Clinical Psychology, 59, 670-681.

Malesky, A., \& Keim, J. (2001). Mental health professionals' perspectives on sex offender registry web sites. Sexual Abuse: A Journal of Research and Treatment, 13, 53-63.

Malinosky-Rummell, R., \& Hansen, D. (1993) Long-term consequences of childhood physical abuse. Psychological Bulletin, 114, 68-79.

Margolin, G., \& Gordis. E. (2000). The effects of family and community violence on children. Annual Review of Psychology, 445-479.

Marsa, F., O'Reilly, G., Carr, A., Murphy, P., O’Sullivan, M., Cotter, A. \& Hevey, D. (2004) attachment styles and psychological profiles of child sex offenders in Ireland. Journal of Interpersonal Violence, 19, 228-251.

Marshall, W. L. (1989). Intimacy, loneliness and sexual offenders. Behaviour Research and Therapy, 27, 491-503.

Marshall, W. L. (1993). The role of attachments, intimacy, and loneliness in the etiology and maintenance of sexual offending. Sexual and Marital Therapy, 8, 109-121.

Marshall, W. L., Hudson, S. M., \& Hodkinson, S. (1993). The importance of attachment bonds in the development of juvenile sex offending. In H. E. Barbaree, W. L. Marshall \& S.M. Hudson (Eds.), The juvenile sex offender (pp. 164-181). New York: Guilford Press. 
Marshall, W. L., Laws, D. R., \& Barbaree, H. E. (Eds.). (1990). Handbook of sexual assault: Issues, theories, and treatment of the offender. New York: Plenum Press.

Martorell, G. (2009). Personal communication February 18, 2009.

Matson, S., \& Lieb, R. (1996). Community notification in Washington State: 1996 survey of law enforcement. Olympia, WA: Washington State Institute for Public Policy. Matson, S., \& Lieb, R. (1996b). Sex offender community notification: A review of state laws. Olympia, WA: Washington State Institute for Public Policy.

MacCallum, R.C., Browne, M.W., and Sugawara, H., M. (1996), "Power Analysis and Determination of Sample Size for Covariance Structure Modeling," Psychological Methods, 1, 130-49.

McGrath, E., Keita, G. P., Strickland, B. R., \& Russo, N. F. (1990). Women and depression: Risk factors and treatment issues. Washington, DC: American Psychological Association.

McCann, K., \& Lussier, P. (2008). Antisociality, sexual deviance, and sexual reoffending in juvenile sex offenders. Youth Violence and Juvenile Justice, 363-385.

McMahon, P.M., \& Puett, R.C. (1999). Child sexual abuse as a pubic health issue: Recommendations of an expert panel. Sexual Abuse: A Journal of Research and Treatment, 11, 257-266.

McMillan, D., Hastings, R., Salter, D., \& Skuse, D. (2007). Developmental risk factor research and sexual offending against children: A review of some methodological issues. Archives of Sexual Behavior. 877- 890.

Meiselman, K. (1978). Incest. San Francisco: Jossey-Bass.

Meloy, M. (2006). Sex Offenses and the Men Who Commit Them: An Assessment of Sex Offenders on Probation. Northeastern University Press.

Merrill, L., Newell, C., \& Thomsen C, Gold, S., Milner, J., Koss, M. \& Rosswork (1999) Childhood abuse and sexual revictimization in a female Navy recruit sample. Journal of Traumatic Stress, 12, 211-225.

Miller, B., Downs, W., Gondoli, D., \& Keil A. (1987) The role of childhood sexual abuse in the development of alcoholism in women. Violence Victims, 157. 
Miller, T., Cohen, M., \& Wiersma, B. (1996). Victim costs and consequences: a new look. Washington, DC: National Institute of Justice Research Report, US Department of Justice.

Miner, M. (2002). Factors associated with recidivism in juveniles: An analysis of serious juvenile sex offenders. Journal of Research in Crime and Delinquency, 39, 421-436.

Miner, M. (2004). Risk for sexual abuse: A study of adolescent offenders. National Center for Injury Prevention and Control, Centers for Disease Control and Prevention. Atlanta, GA.

Mintz, S., \& Kellogg, S., ( 2005) Domestic revolutions: A social history of American family life. New York, Free Press.

Molnar, B. E., Berkman, L. F. \& Buka, S. L. (2001). Psychopathology, childhood sexual abuse and other childhood adversities: relative links to subsequent suicidal behaviour in the US. Psychological Medicine. 31, 965-977.

Montebarocci, O., Codispoti, M., Baldara, B., \& Rossi, N. (2004). Adult attachment style and alexithymia. Personality and Individual Differences, 36, 499-507.

Morris, R. E. (2005). Health care for incarcerated adolescents: Significant needs with considerable obstacles. Ethics Journal of the American Medical Association, 7. Available online at http://virtualmentor.ama-assn.org/2005/03/pfor20503.html.

Motiuk, L., \& Porporino, F. (1992). The prevalence, nature and severity of mental health problems among federal male inmates in Canadian penitentiaries. A report by the Research and Statistics Branch Correctional Service Canada.

Mueller, E., \& Silverman, N. (1989). Peer relations in maltreated children in D. Cicchetti \& V. Carlson (eds.), Child maltreatment: theory and research on the causes and consequences of child abuse and neglect. New York, Cambridge University Press.

Mullen, P.E., Martin, J.L., Anderson, J.C., Romans, S.E., \& Herbison, G. P., (1996). The long-term impact of the physical, emotional, and sexual abuse of children: A community study. Child Abuse \& Neglect, 20, 7-21.

Mullen, P. E., Martin, J. L., Anderson, J. C., Romans, S. E., \& Herbison, G. P. (1994). The effect of child sexual interpersonal and sexual function in adult life. British Journal of Psychiatry, 165, 35-47. 
Mulloy, R., \& Marshall, W.L. (1999). Social functioning. In W. L. Marshall, D. Anderson, \& Y. Fernandez (Eds.), Cognitive behavioural treatment of sexual offenders (pp. 93-109). New York: John Wiley and Sons.

Nagin, D., \& Paternoster, R. (1994). Personal capital and social control: the deterrence implications of a theory of individual differences in criminal offendinghttp://www3.interscience.wiley.com/journal/119264740/abstract?CR ETRY=1\&SRETRY=0 - fn1\#fn 1. Criminology, $581-606$.

National Research Council (1993). Understanding Child Abuse Neglect, Washington, DC: National Academy Press.

National Resource Center on Child Sexual Abuse (1994). Statistics in child sexual abuse. Huntsville, AL.

National Society for the Prevention of Cruelty to Children (NSPCC) (2005). Protecting children our children from sexual abuse. Retrieved from http://www.enfield.gov.uk/if/ProtectingChildrenFromSexualAbuse.pdf on September 23, 2008.

O’Brien, M. 1991. Taking sibling incest seriously. In Family Sexual Abuse, edited by M.Q. Patton. Newbury Park, CA: Sage Publications, pp. 75-92.

(The) Pennsylvania Advisory committee of the Office of Mental Health and Substance Abuse Services (OMHSAS) (2006). Retrieved On September 23, 2008 from http://www.dpw.state.pa.us/Resources/Documents/Presentations/PaStrategyFor AdultSuicidePrevention.pdf.

Perry, B.D., Pollard, R.A., Blakley, T.L, Baker, W.L., Vigilante, D. (1995) Childhood Trauma, the Neurobiology of Adaptation and Use- dependent Development of the Brain: How States become Traits. Infant Mental Health Journal. 16, 271291.

Peters, J. J. (1976). Children who are victims of sexual assault and the psychology of offenders. American Journal of Psychotherapy, 30, 398-421.

Pickering, L. K. (2003) Red Book: 2003 Report of the Committee on Infectious Diseases by American Academy of Pediatrics, American Academy of Pediatrics Committee on Infectious Diseases, American Academy of Pediatrics. 
Polusny, M. A., \& Follette, V. M. (1995). Long-term correlates of child sexual abuse: Theory and review of the empirical literature. Applied and Preventive Psychology, 143-166.

Prentky, R. A., Knight, R. A., Sims-Knight, J. E., Straus, H., Rokous, F., \& Cerce, D. (1989). Developmental antecedents of sexual aggression. Development of Psychopathology, 1, 153-169.

Prentky, R. A. (1996). Community notification and constructive risk reduction. Journal of Interpersonal Violence, 11, 295-298.

Prentky, R \& Burgess, A.W. (1990). Rehabilitation of child molesters: A cost-benefit analysis. American Journal of Orthopsychiatry, 60. 108-117.

Prentky, R., Harris, B., Frizzell, K. \& Righthand, S. (2000). An actuarial procedure for assessing risk with juvenile offenders. Sexual Abuse: A Journal of Research and Treatment. 12, 71-93.

Prevent Child Abuse America (2009) Media Tips downloaded May 9, 2009 from http://www.preventchildabuse.org/learn_more/frame_analysis/index.html

Putnam, F. W. (2001). The Cost of Child Maltreatment: Who Pays? Edited by K. Franey, R. Geffner, R. Falconer. Family Violence and Sexual Assault Institute, San Diego, CA, pp. 185-198.

Radke-Yarrow, M., Cummings, M., Kuczynski, L. \& Chapman, M. (1985). Patterns of attachment in two- and three-year-olds in normal families and families with parental depression. Child Development. 56, 884-893

Regnerus, M. (2002). Friends influence on adolescent theft and minor delinquency: A developmental test of peer-reported effects. Social Science Research. 31, 681705 .

Rich, P. (2006). Understanding and applying attachment theory to the treatment of juvenile sexual offenders. John Wiley \& Sons. West Sussex England.

Rich, P. (2007, November). The attachment informed treatment environment and its implications for clinical work with sexual offenders. Seminar presented at the annual meeting of the Association for the Treatment of Sexual Abusers (ATSA). San Diego, CA.

Rich, P. (2009). Applying attachment theory to the treatment of sexually abusive youth. Seminar presented at the annual meeting of the National Adolescent Perpetrator Network (NAPN). Tampa, FL. 
Righthand, S., \& Welch, C. (2001). Juveniles who have sexually offended. Office of Juvenile Justice and Delinquency Prevention.

Rodgers, C.S., Lang, A.J., Laffaye, C., \& Satz, L.E., (2004). The impact of individual forms of childhood maltreatment on health behavior. Child Abuse \& Neglect, $28,575-586$.

Rosenbaum, A., Rabenhorst, M. M., Reddy, M. K., Fleming, M. T., \& Howells, N. L. (2006). A comparison of methods for collecting self-report data on sensitive topics. Violence and Victims, 21(4), 461-471.

Rosenberg, M. (1965). Society and the adolescent self-image. Princeton, NJ: Princeton University Press.

Rosenthal, D., Feldman, S., \& Edwards, D. (1998). Mum's the word: mothers' perspectives on communication about sexuality with adolescents. Journal of Adolescence, 21, 727-743.

Rumstein-McKean, O., \& Hunsley, J. (2001) Interpersonal and family functioning of female survivors of childhood sexual abuse. Clinical Psychology Review, Pages 471-490.

Russell, D. E. H. (1983). The incidence and prevalence of intrafamilial and extra familial sexual abuse of female children. Child Abuse \& Neglect, 9, 191-199.

Russell, D.E.H. (1986). The secret trauma: Incest in the lives of girls and women. New York: Basic Books.

Ryan, G. (1999a). Treatment of sexually abusive youth: The evolving consensus. The Journal of Interpersonal Violence, 14, 422-436.

Ryan, G. (1999b). The sexual abuser in The Battered Child (eds) Mary Edna Helfer, Ruth S. Kempe, Richard D. Krugman, University of Chicago Press, Chicago IL.

Salter, A. (2003). Predators, pedophiles, rapists, and other sex offenders: Who they are, how they operate and how we can protect ourselves and our children. Basic Books. New York, NY.

Sample, L. \& Bray, T. (2003). Are sex offenders dangerous? Criminology \& Public Policy. 3, 59-82. 
Sapsford, R. (1998). Ruther research applications of the "Parole Prediction Index". International Journal of Criminology and Penology. 6, 247-254.

Saunders, B., Kilpatrick, D., Hanson R., Resnick, H. \& Walker, M., (1999). Prevalence, case characteristics, and long-term psychological correlates of child rape among women: a national survey. Child Maltreatment, 4, 187-200.

Schram, D., \& Milloy, C. (1991). Juvenile Sex Offenders: A Follow-up Study of Reoffense Behavior. Washington State Institute for Public Policy. Document No. 91-09-1101, available at http://www.wsipp.wa.gov.

Seidman, B. T., Marshall, W. L., Hudson, S. M., \& Robertson, P. J. (1994). An examination of intimacy and loneliness in sexual offenders. Journal of Interpersonal Violence, 9, 518-534.

United States Department of Justice (2007). Frequently asked questions: The Sex Offender Registration and Notification Act (SORNA) Proposed Guidelines Retrieved from http://www.ojp.usdoj.gov/smart/pdfs/sorna_factsheet.pdf

Shaeffer, C. \& Borduin, C. (2005). Long-term follow-up to a randomized clinical trial of multisystemic therapy with serious and violent offenders. Journal of Consulting and Clinical Psychology. 73, 445-453.

Shanahan, M. \& Donato, R. (2001). Counting the cost: Estimating the economic benefit of pedophile treatment programs. Child Abuse \& Neglect, 25, 541-555.

Shaver, P. R. \& Clark, C. L. (1996). Forms of adult romantic attachment and their cognitive and emotional underpinnings. In G. G. Noam \& K. W. Fischer (Eds), Development and vulnerability in close relationships, Mahwah, NJ: Lawrence Erlbaum.

Shaver, P. R., \& Hazan, C. (1993). Adult romantic attachment: Theory and evidence. In D. Perlman \& W. Jones (Eds.), Advances in personal relationships. London, Jessica Kingsly.

Shaw, J. A. (1999). Sexual aggression. Washington, DC: American Psychiatric Press.

Sickmund, M., Snyder, H., \& Poe-Yamagata, E. (1997). Juvenile Offenders and Victims: 1997 Update on Violence. Office of Juvenile Justice and Delinquency Prevention, Washington, DC. 
Siegel, J. M., Sorenson, S. B., Golding, J. M., Burnam, M. A., \& Stein, J. A. (1987). The Prevalence of childhood sexual assault: The Los Angeles Epidemiologic catchment area. American Journal of Epidemiology, 126, 1141-1164.

Sipe, R., Jensen, E., \& Everett, R. (1998). Adolescent sexual offenders grow up recidivism in young adulthood. Criminal Justice and Behavior. 25, 109-124.

Smallbone, S., \& Dadds, M. (2001). Further evidence for a relationship between attachment insecurity and coercive sexual behavior in non-offenders. Journal of Interpersonal Violence, 16, 22-35.

Smallbone, S., \& McCabe, B. (2003). Child attachment, childhood sexual abuse, and onset of masturbation among adult sexual offenders. Sexual Abuse: A Journal of Research and Treatment 15, 1-9.

Smallbone, S. \& Dadds, M. (1998). Childhood attachment and adult attachment in incarcerated adult male sex offenders. Journal of Interpersonal Violence, 13, $555-573$.

Snyder, H. N. (2000a). Table 6: Victim-Offender Relationship in Sexual Assault in Sexual Assault of Young Children as Reported to Law Enforcement: Victim, Incident, and Offender Characteristics, U.S. Department of Justice, Bureau of Justice Statistics.

Snyder, H. N. (2000b). Sexual Assault of Young Children as Reported to Law Enforcement: Victim, Incident, and Offender Characteristics. The United States Department of Justice. retrieved August 29, 2008 from http://www.ojp.usdoj.gov/bjs/pub/pdf/saycrle.pdf

Sprott, J., Jenkins, J. \& Doob, A. (2000). Early Offending: Understanding the Risk and Protective Factors of Delinquency. Publication W-01-1-9E. Human Resources Development Canada Publications Centre., Quebec, Canada.

Stark, E. and Flitcraft, A. (1988). Women and children at risk: a feminist perspective on child abuse. International Journal of Health Services, 18, 97-118.

State of Ohio Office of Criminal Justice Services (2006). Report to the Ohio Criminal Sentencing Commission. Available online at www.ocjs.ohio.gov

Stewart, E. ( 2007). The sexual health and behaviour of male prisoners: The need for research. The Howard Journal of Criminal Justice, 46, 43-59. 
Stirpe, T., Abracen, J., Stermac, L., \& Wilson, R. (2006). Sexual offenders' state-ofmind regarding childhood attachment: A controlled investigation. Sexual Abuse: A Journal of Research and Treatment. 289-302.

Summit, R. (1983). The child sexual abuse accommodation syndrome. Child Abuse \& Neglect. 7, 177-193.

Steinberg, J. (2006) Evidence-Based Programming within Residential Settings to Reduce Recidivism. Presentation the Juvenile Services Juvenile Justice \& Delinquency Prevention 2006 Conference, June 2006. Williamsburg, Virginia.

Stern, A., Lynch, D., Oates, R.K., O’Toole, B \& Cooney, G. (1995). Self Esteem, Depression, Behaviour and Family Functioning in Sexually Abused Children. Journal of Child Psychology \& Psychiatry \& Allied Disciplines, 36, 1077 1089.

Target, M., Fonagy, P., \& Schmueli-Goetz, Y. (2003). Attachment representations in school-age children: the development of the Child Attachment Interview (CAI). Journal of Child Psychotherapy, 29, 2, 171-186.

Tewksbury, R. (2005). Collateral Consequences of Sex Offender Registration. Journal of Contemporary Criminal Justice, 21, 67-81.

Thakker, J., Ward, T. \& Tidmarsh, P. (2006). A reevaluation of relapse prevention with adolescents who sexually offend in The Juvenile Sex Offender (2nd edition)-Howard E. Barbaree and William L. Marshall (eds.). Guilford Press, New York, New York.

Thigpen, J. W., Pinkston, E. M. \& Mayefsky, J. H. (2003) Cross-cultural aspects - the African American perspective, in Bancroft, J. (Eds.) Sexual Development in Childhood. Bloomington: Indiana University Press

Tofte, S. (2007). No easy answers: Sex offender laws in the US. Human Rights Watch. Available at http://www.hrw.org/en/reports/2007/09/11/no-easy-answers.

Toth, S., Cicchetti, D., MacFie, J., \& Emde, R. (1997). Representations of self and other in the narratives of neglected, physically abused, and sexually abused preschoolers. Development and Psychopathology, 9, 781-796.

Toth, S., Cicchetti, D., MacFie, J., Maughan, A. \& Vanmeenen, K. (2000). Narrative representations of caregivers and self in maltreated pre-schoolers. Attachment \& Human Development, 
http://www.informaworld.com/smpp/title $\sim$ content $=t 713394054 \sim \mathrm{db}=\mathrm{all} \sim \mathrm{tab}=\underline{\mathrm{is}}$ sueslist $\sim$ branches $=2-\mathrm{v} 22,271-305$.

U.S. Department of Justice. (1996). Child victimizers: Violent offenders and their victims (NCJ-153258). Washington, DC: Government Printing Office.

U.S. Department of Justice. (1997b). Sex offender community notification (NCJ162364).Washington, DC: Government Printing Office.

U.S. Department of Justice (1999). Summary of state sex offender registry dissemination procedures: Update (NCJ 177620). Washington, DC: Government Printing Office.

U.S. Department of Justice (2008). The Dru Sjodin National Sex Offender Public Website Available at http:www.nsopw.gov/Core/About.Aspx.

Vidmar, N. (1997). Generic prejudice and the presumption of guilt in sex abuse trials. Law and Human behavior. 5-25.

Vogeltanz, N., Wilsnak, S., Harris, T. R, Wilsnack, R., Wondrlich, S., \& Kirsjanson, A. (1999). Prevalence and risk factors for childhood sexual abuse in women: National survey findings. Child Abuse \& Neglect, 23, 579-592.

Wakefield, H. (2006) The vilification of sex offenders: Do laws targeting sex offenders increase recidivism and sexual violence? Presented at the 22nd Annual Symposium of the American College of Forensic Psychology, March 17, 2006, San Francisco, California.

Waldinger, R., Toth, S., \& Gerber, A. (2001). Maltreatment and Internal Representations of Relationships: Core Relationship Themes in the Narratives of Abused and Neglected Preschoolers. Social Development, 10, 41-58.

Wallace, S. (2008). Reality Gap: Alcohol, Drugs, and Sex--What Parents Don't Know and Teens Aren't Telling. Union Square Press, New York.

Wang, C., \& Holton, J. (2007). Total Estimated Cost of Child Abuse and Neglect in the United States. Prevent Child Abuse America. Retrieved September 5, 2008 from http://member.preventchildabuse.org/site/DocServer/cost_analysis.pdf?docID= 144 
Ward, T., Hudson, S., Marshall. W. L., Siegert, R. (1995). Attachment style and intimacy deficits in sexual offenders: A theoretical framework. Sexual Abuse. 7, 317-335.

Ward, T., Hudson, S., \& Marshall, W. (1996). Attachment style in sex offenders: A preliminary study. The Journal of Sex Research, 33, 17-26.

Ward, T., McCormack, J., \& Hudson, S. M. (1997). Sexual offenders' perceptions of their intimate relationships. Sexual Abuse: A Journal of Research and Treatment, 9, 57-73.

Widom, C. S., \& Morris, C. (1997). Accuracy of adult recollections of childhood victimization (part 2): Childhood sexual abuse. Psychological Assessment, 9 , $34-46$.

Widom, C. S., \& Shepard, R. (1996). Accuracy of adult recollections of childhood victimization. Psychological Assessment, 8, 412-421.

Wilkinson, G. (1993). Wide range achievement test-Third edition. Wilmington, DE: Jastak Associates.

Williams, L. M. (1994). Recall of childhood trauma: A prospective study of women's memories of child sexual abuse. Journal of Consulting and Clinical Psychology, 62(6), 1167-1176.

Wolfe, V. V., Gentile, C., \& Wolfe, D. A. (1989). The impact of sexual abuse on children: A PTSD formulation. Behavior Therapy, 20, 215-228.

Wonderlich, S., Brewerton, T., Zeljko, J., Dansky, B., \& Abbott, D. (1997). Relationship of childhood sexual abuse and eating disorders. Journal of the American Academy of Child \& Adolescent Psychiatry, 36, 1107-1115.

Wolfe, David A. and Robin McGree. (1991). Assessment of emotional status among maltreated children. The Effects of Child Abuse and Neglect. Starr, Raymond H. Jr., and David A. Wolfe(eds.) New York, NY, The Guilford Press.

Wood, E., \& Riggs, S. (2008). Predictors of Child Molestation Adult Attachment, Cognitive Distortions, and Empathy. Journal of Interpersonal Violence, , 259-275.

Worling, J., \& Curwen, T. (2000). Adolescent sexual offender recidivism: Success of specialized treatment and implications for risk prediction, Child Abuse \& Neglect, 24, 965-982. 
Wyatt, G. E. (1985). The sexual abuse of African American and European American women in childhood. Child Abuse \& Neglect, 9, 507-519.

Wyatt, G.E. \& Peters S.D. (1986) Issues in the definition of child: Sexual abuse in prevalence research. Child Abuse and Neglect, 10, 231-240.

Wyatt, G., Loeb, T., Solis, B., Carmona, J. \& Romero, G. (1999). The prevalence and circumstances of child sexual abuse: Changes across a decade. Child Abuse \& Neglect, 23, 45-60.

Young, S. (1997). The use of normalization as a strategy in the sexual exploitation of children by adult offenders. The Canadian Journal of Human Sexuality. 6 , 285-295.

Zevitz, R. G. \& Farkas, M. (2000). Sex offender community notification: Managing high risk criminals or exacting further vengeance? Behavioral Sciences and the Law, 18, 375-391.

Zevitz, R (2004). Sex offender Placement and neighborhood Social Integration: The making of a scarlet letter community. Criminal Justice Studies. 17, 203-222. 
VICTIM-OFFENDER RELATIONSHIP IN SEXUAL ASSAULT

TABLE 5

\begin{tabular}{|c|c|c|c|c|}
\hline \multicolumn{5}{|c|}{ Victim-offender relationship in sexual assault, 1991-96 } \\
\hline & \multicolumn{4}{|c|}{ Offenders } \\
\hline Victim age & Total & Family member & Acquaintance & Stranger \\
\hline All victims & $\mathbf{1 0 0 . 0} \%$ & $\mathbf{2 6 . 7 \%}$ & $\mathbf{6 9 . 6 \%}$ & $\mathbf{1 3 . 8 \%}$ \\
\hline Juveniles & $\mathbf{1 0 0 . 0} \%$ & $\mathbf{3 4 . 2 \%}$ & $\mathbf{5 8 . 7} \%$ & $\mathbf{7 . 0 \%}$ \\
\hline 0 to 5 & $100.0 \%$ & $48.6 \%$ & $48.3 \%$ & $3.1 \%$ \\
\hline 6 to 11 & $100.0 \%$ & $42.4 \%$ & $52.9 \%$ & $4.7 \%$ \\
\hline 12 to 17 & $100.0 \%$ & $24.3 \%$ & $66.0 \%$ & $9.8 \%$ \\
\hline Adults & $\mathbf{1 0 0 . 0} \%$ & $\mathbf{1 1 . 5 \%}$ & $\mathbf{6 1 . 1 \%}$ & $\mathbf{2 7 . 3 \%}$ \\
\hline 18 to 24 & $100.0 \%$ & $9.8 \%$ & $66.5 \%$ & $23.7 \%$ \\
\hline Above 24 & $100.0 \%$ & $12.8 \%$ & $57.1 \%$ & $30.1 \%$ \\
\hline
\end{tabular}

SOURCE: Howard N. Snyder, "Table 6: Victim-Offender Relationship in Sexual Assault," in Sexual Assault of Young Children as Reported to Law Enforcement: Victim, Incident, and Offender Characteristics, U.S. Department of Justice, Bureau of Justice Statistics, July 2000 


\section{TABLES 6-11}

Table 6 Regression

\begin{tabular}{|c|c|c|c|c|}
\hline \multicolumn{5}{|c|}{ Attachment Style predicting group membership } \\
\hline & $\begin{array}{l}\text { Between- } \\
\text { groups } \\
\text { degrees of } \\
\text { freedom }\end{array}$ & $\begin{array}{l}\text { Within- } \\
\text { groups } \\
\text { degrees of } \\
\text { freedom }\end{array}$ & F Statistic & Sig. Level \\
\hline Total & 1 & 837 & 92.2 & $<0.01$ \\
\hline Asian & 1 & 8 & 2.99 & 0.13 \\
\hline Black/African American & 1 & 209 & 5.85 & 0.02 \\
\hline Hispanic/Latino & 1 & 141 & 13 & $<0.01$ \\
\hline Caucasian/White & 1 & 320 & 41.26 & $<0.01$ \\
\hline American Indian & 1 & 28 & 0.027 & 0.87 \\
\hline Mixed & 1 & 122 & 13.3 & $<0.01$ \\
\hline
\end{tabular}

Table 7 Chi-Square

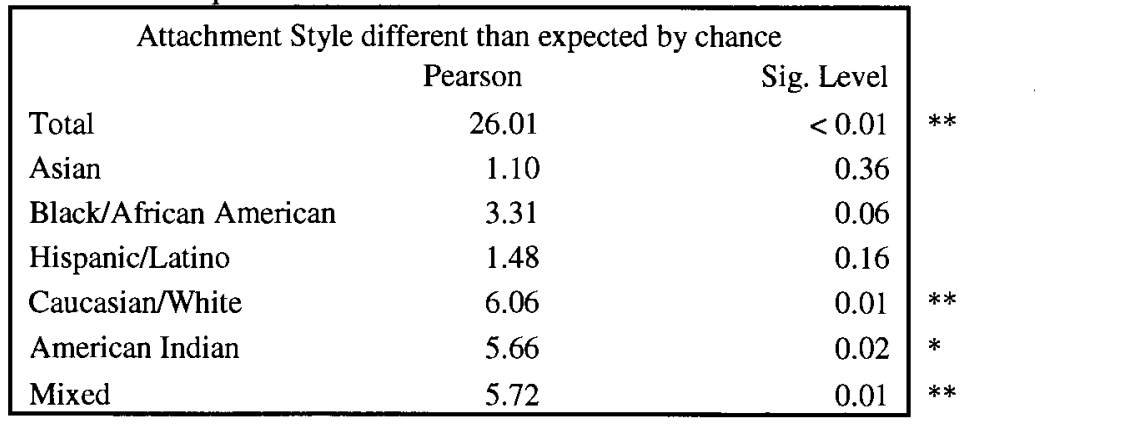

Table 8 ANOVA

\begin{tabular}{|c|c|c|c|c|}
\hline \multicolumn{5}{|c|}{ Differences in Neglect } \\
\hline & $\begin{array}{l}\text { Between- } \\
\text { groups } \\
\text { degrees of } \\
\text { freedom }\end{array}$ & $\begin{array}{l}\text { Within- } \\
\text { groups } \\
\text { degrees of } \\
\text { freedom }\end{array}$ & $\begin{array}{c}\mathrm{F} \\
\text { Statistic }\end{array}$ & Sig. Level \\
\hline Total & 2 & 837 & 26.83 & $<0.01$ \\
\hline Asian & 2 & 8 & 0.889 & 0.46 \\
\hline Black/African American & 2 & 209 & 4.04 & 0.02 \\
\hline Hispanic/Latino & 2 & 141 & 4.01 & 0.02 \\
\hline Caucasian/White & 2 & 320 & 11.74 & $<0.01$ \\
\hline American Indian & 2 & 28 & 0.693 & 0.51 \\
\hline Mixed & 2 & 122 & 2.74 & 0.07 \\
\hline
\end{tabular}

* significant at the $p=.05$ level

$* *$ significant at the $\mathrm{p}=.01$ level 
Table 9 ANOVA

\begin{tabular}{|c|c|c|c|c|}
\hline \multicolumn{5}{|c|}{ Differences in Physical Abuse } \\
\hline & $\begin{array}{l}\text { Between- } \\
\text { groups } \\
\text { degrees of } \\
\text { freedom }\end{array}$ & $\begin{array}{l}\text { Within- } \\
\text { groups } \\
\text { degrees of } \\
\text { freedom }\end{array}$ & F Statistic & Sig. Level \\
\hline Total & 2 & 837 & 74.81 & $<0.01$ \\
\hline Asian & 2 & 8 & 5.33 & 0.05 \\
\hline Black/African American & 2 & 209 & 11.51 & $<0.01$ \\
\hline Hispanic/Latino & 2 & 141 & 7.65 & $<0.01$ \\
\hline Caucasian/White & 2 & 320 & 28.27 & $<0.01$ \\
\hline American Indian & 2 & 28 & 3.63 & 0.04 \\
\hline Mixed & 2 & 122 & 8.97 & $<0.01$ \\
\hline
\end{tabular}

Table 10 ANOVA

\begin{tabular}{|c|c|c|c|c|}
\hline \multicolumn{5}{|c|}{ Differences in Sexual Abuse } \\
\hline & $\begin{array}{l}\text { Between- } \\
\text { groups } \\
\text { degrees of } \\
\text { freedom }\end{array}$ & $\begin{array}{l}\text { Within- } \\
\text { groups } \\
\text { degrees of } \\
\text { freedom }\end{array}$ & F Statistic & Sig. Level \\
\hline Total & 2 & 837 & 198.24 & $<0.01$ \\
\hline Asian & 2 & 8 & 0.33 & 0.73 \\
\hline Black/African American & 2 & 209 & 12.69 & $<0.01$ \\
\hline Hispanic/Latino & 2 & 141 & 29.10 & $<0.01$ \\
\hline Caucasian/White & 2 & 320 & 108.60 & $<0.01$ \\
\hline American Indian & 2 & 28 & 15.24 & $<0.01$ \\
\hline Mixed & 2 & 122 & 13.31 & $<0.01$ \\
\hline
\end{tabular}

Table 11 ANOVA

\begin{tabular}{|c|c|c|c|c|}
\hline \multicolumn{5}{|c|}{ Differences in Complex Abuse } \\
\hline & $\begin{array}{l}\text { Between- } \\
\text { groups } \\
\text { degrees of } \\
\text { freedom }\end{array}$ & $\begin{array}{l}\text { Within- } \\
\text { groups } \\
\text { degrees of } \\
\text { freedom }\end{array}$ & F Statistic & Sig. Level \\
\hline Total & 2 & 837 & 93.08 & $<0.01$ \\
\hline Asian & 2 & 8 & 0.89 & 0.46 \\
\hline Black/African American & 2 & 209 & 8.00 & $<0.01$ \\
\hline Hispanic/Latino & 2 & 141 & 7.67 & $<0.01$ \\
\hline Caucasian/White & 2 & 320 & 47.35 & $<0.01$ \\
\hline American Indian & 2 & 4.214 & 15.24 & 0.03 \\
\hline Mixed & 2 & 122 & 8.83 & $<0.01$ \\
\hline
\end{tabular}

* significant at the $\mathrm{p}=.05$ level

$* *$ significant at the $p=.01$ level 


\section{APPENDIX A}

\section{DEMOGRAPHICS (FORM JSO)}

This questionnaire will help us know more about you. The questions give us general information about you. They also ask about your history. The directions are at the beginning of each section. If you have any questions, please raise your hand.

\section{QUESTIONS ABOUT YOU}

\begin{tabular}{|c|c|}
\hline A-1 & How old are you? \\
\hline A-2 & Which sex are you? (circle one) FEMALE MALE \\
\hline A-3 & $\begin{array}{l}\text { What is your current marital status? (check [ } \checkmark \text { ] one) } \\
\text { [ ] Never been married [ ] Married } \\
\text { [ ] Divorced [ ] Separated } \\
\text { [ ] Widow }\end{array}$ \\
\hline A-4 & 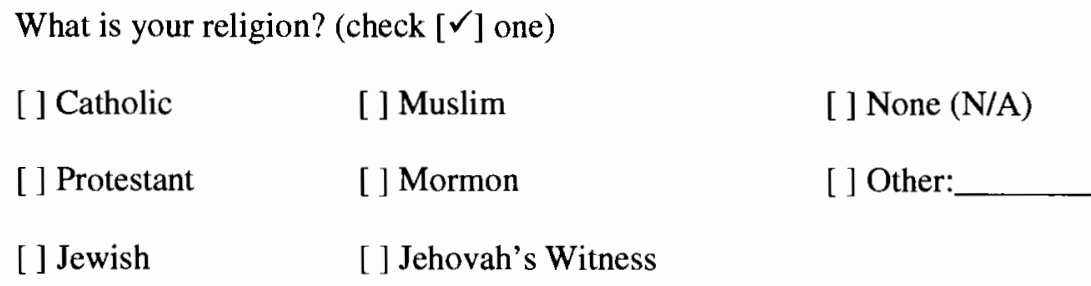 \\
\hline & Did you graduate from high school or get your G.E.D? (circle one) YES NO \\
\hline A-5 & If no, what is the highest grade you completed? \\
\hline & Are you still going to school? (circle one) YES NO \\
\hline A-6 & $\begin{array}{l}\text { If yes, which grade of high school or year of college? (check }[\checkmark] \text { one) } \\
\left.\text { [ ] } 9^{\text {th }} \text { grade high school [ ] } 11^{\text {th }} \text { grade high school [ }\right] 1^{\text {st }} \text { year college } \\
\text { [ ] } 10^{\text {th }} \text { grade high school [ ] } 12^{\text {th }} \text { grade high school [ ] } 2^{\text {nd }} \text { year college }\end{array}$ \\
\hline
\end{tabular}




\section{QUESTIONS ABOUT YOUR CULTURAL OR ETHNIC BACKGROUND}

In this country, people come from a lot of different cultures. There are many words to describe the different ethnic groups that people come from. Some names of ethnic groups are MexicanAmerican, Hispanic, Black, Asian-American, American-Indian, Anglo-American, and White. Every person is born into an ethnic group. People differ on how they feel about their ethnicity. These questions are about your ethnic group and how you feel about it.

B-1 a) Were you born in the United States? (circle one) YES NO

b) If no, which country were you born in?

c) How long have you lived in the United States? years

B-2 My ethnicity is: (check $[\checkmark]$ one)
[ ] Asian, Asian-American, or Oriental
[ ] Black or African-American
[ ] Hispanic or Latino
[ ] White, Caucasian, European (not Hispanic)
[ ] American-Indian
[ ] Mixed (parents are from two different groups)
[ ] Other:

B-3 a) Was your mother born in the United States? (circle one) YES NO

b) If no, which country was she born in?

c) How long has she lived in the United States? years

B-4 Her ethnicity is: (check $[\checkmark]$ one)
[ ] Asian, Asian-American, or Oriental
[ ] Black or African-American
[ ] Hispanic or Latino
[ ] White, Caucasian, European (not Hispanic)
[ ] American-Indian
[ ] Mixed (parents are from two different groups)
[ ] Other: 
b) If no, which country was he born in?

c) How long has he lived in the United States? years.

B-6 $\underline{\text { His }}$ ethnicity is: (check $[\checkmark]$ one)
[ ] Asian, Asian-American, or Oriental
[ ] Black or African-American
[ ] Hispanic or Latino
[ ] White, Caucasian, European (not Hispanic)
[ ] American-Indian
[ ] Mixed (parents are from two different groups)
[ ] Other: 


\section{APPENDIX B}

\section{YOUR RELATIONSHIP WITH YOUR SUPERVISOR}

Please use the following scale:

0

Never
1

Almost Never
2
3

Almost Always
4

Always

30. How often did you do these activities with your supervisor?

a) My supervisor and I did activities together (like played games).

b) My supervisor went to my activities (like watched me play sports).

c) My supervisor taught me things (like how to cook).

01234

d) My supervisor helped me with my homework.

01234

e) We ate our meals together.

01234

f) We went to the park together.

01234

g) We went to church together.

01234

31. How often were the following statements true about the relationship you had with your supervisor?

a) My supervisor trusted me.

01234

b) My supervisor accepted me for who I was.

01234

c) My supervisor expected me to do the "right thing."

01234

d) My supervisor understood where I was coming from.

01234

e) My supervisor asked for my opinion about things.

01234

f) I talked to my supervisor about personal things. 
32. How often did you talk with your supervisor about:

\begin{tabular}{|ccccc|}
\hline $\mathbf{0}$ & $\mathbf{1}$ & $\mathbf{2}$ & $\mathbf{3}$ & $\mathbf{4}$ \\
Never & $\begin{array}{c}\text { Almost } \\
\text { Never } \\
(1-2 \text { times } \\
\text { a year })\end{array}$ & Sometimes & $\begin{array}{c}\text { Almost } \\
\text { Always } \\
(1-2 \text { times } \\
(1-2 \text { times } \\
\text { a month })\end{array}$ & Always \\
week $)$ & (Daily) \\
\hline & & & & \\
\hline
\end{tabular}

Who usually started the conversation?

(Circle one.)

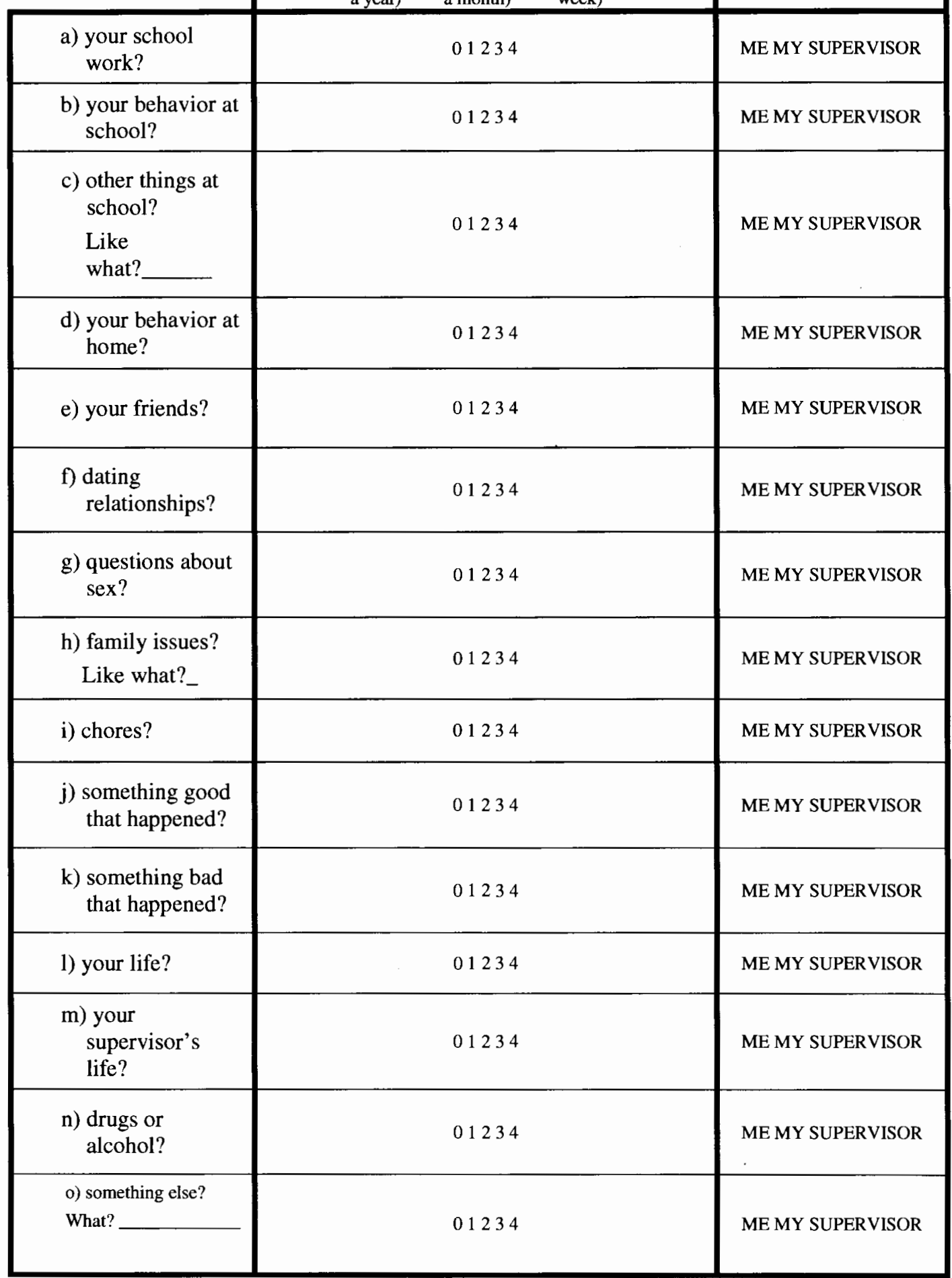




\section{APPENDIX C}

\section{QUESTIONS ABOUT YOUR ABUSE AND TREATMENT HISTORY}

NEGLECT happens when an adult:

a) leaves you where you can be physically harmed; and/or

b) does not remove you from a dangerous situation and you are physically harmed.

D-1 Have you ever been neglected? (circle one) YES NO

If you circled "NO" to question D-1, check [ $\checkmark$ ] here [ ] and skip to question D-5.

D-2 How many people neglected you?

Of the people in D.2, how many were:

D-3 Related to you? (Of these, how many were male? female? )

D-4 Not related to you? (Of these, how many were male? female?

PHYSICAL ABUSE happens when an adult:

a) physically harms you (like hits, kicks, or punches you).

D-5 Have you ever been physically abused? (circle one) YES NO

If you circled "NO" to question D-5, check [ $\checkmark$ ] here [ ] and skip to question D-9.

D-6 How many people have physically abused you?

Of the people in D-6, how many were:

D-7 Related to you? (Of these, how many were male? female?

D-8 Not related to you? (Of these, how many were male? female? 
SEXUAL ABUSE happens when an adult:

a) touches you sexually (does sexual things to you);

b) has you touch him/her sexually (has you do sexual things to her/him); and/or

c) forces, threatens, tricks, or bribes you to do sexual activities with her/him.

D-9 Have you ever been sexually abused? (circle one) YES NO

\section{If you circled "NO" to question D-9, check [ $\checkmark]$ here [ ] and skip to question D-20.}

D-10 How many people have sexually abused you?

Of the people in D-10, how many were:

D-11 Related to you? (Of these, how many were male? female?

D-12 Not related to you? (Of these, how many were male? female?

D-13 Did anyone ever find out that you were sexually abused? (circle one) YES NO

D-14 How old were you when the abuse began? yrs old

D-15 How old were you when someone found out that you were sexually abused? yrs old.

D-16 How old was the offender when the abuse began? yrs old

D-17 Did you get counseling after someone found out that you were sexually abused? (circle one) YES NO

If you NEVER got counseling for the sexual abuse you experienced, check $[\checkmark]$ here [ ] and skip to question D-20

D-18 How old were you the first time you got counseling for being sexually abused? yrs old

D-19 How much time have you spent in counseling for being sexually abused? (circle one)

\begin{tabular}{|c|c|c|c|c|c|c|}
\hline $\begin{array}{c}\text { Less than } \\
1 \text { month }\end{array}$ & $\begin{array}{c}1-2 \\
\text { months }\end{array}$ & $\begin{array}{c}2-3 \\
\text { months }\end{array}$ & $\begin{array}{c}3-6 \\
\text { months }\end{array}$ & $\begin{array}{c}6-12 \\
\text { months }\end{array}$ & $\begin{array}{c}1-2 \\
\text { years }\end{array}$ & $\begin{array}{c}2 \text { years or } \\
\text { more }\end{array}$ \\
\hline
\end{tabular}

D-20 Have you ever been sexually involved with anyone who was at least three years older than you AND

that you did not already list as an abuser?

(circle one) YES NO 


\section{If you circled "NO" to question D-20, check $[\checkmark]$ here [] and skip to question D-24.}

D-21 How many older people ( 3 yrs older than you) have you been sexually involved with?

\section{Of the people in D-21, how many were:}

D-22 Related to you? (Of these how many were male? female?

D-23 Not related to you? (Of these how many were male? female? )

Write in the number of months of each kind of treatment that you had in your lifetime. (Write in " $\varnothing$ " for types of treatment that you have not had.)

Depression/Anxiety

Learning Difficulties

Attention Deficit Disorder

Hyperactivity

Marital/Relationship Issues
Family Conflict

Alcohol Abuse

Drug Abuse

Anger Management

Emotional Abuse
_ Sexual Abuse

_ Physical Abuse

- Other: 


\section{APPENDIX D:}

\section{Residency Restriction Zones}

\begin{tabular}{|c|c|c|c|c|}
\hline$\underline{\text { State }}$ & Distance & Location & Citation & $\begin{array}{l}\text { ear } \\
\text { acted }\end{array}$ \\
\hline \multirow{2}{*}{$\begin{array}{l}1 \text { Alabama } \\
2 \text { Arizona }\end{array}$} & $2,000 \mathrm{ft} /$ & school, child care facility & Ala. Code $\$ 15-20-26$ & 2005 \\
\hline & $1,000 \mathrm{ft} /$ & $\begin{array}{l}\text { school, childcare facility } \\
\text { for level }\end{array}$ & $\begin{array}{l}\text { A.R.S. Title 13, } \\
\text { Chapter } 37 \text { 13-3726 }\end{array}$ & 2007 \\
\hline 3 Arkansas & $2,000 \mathrm{ft} /$ & school, day care center & Ark. Code Ann $\$ 5-14-128$ & 2003 \\
\hline 4 California & $2,000 \mathrm{ft} /$ & $\begin{array}{l}\text { school, park, where } \\
\text { children gather }\end{array}$ & Cal. Penal Code $\S 3003.5$ & 2006 \\
\hline 5 Florida & $1,000 \mathrm{ft} /$ & where children gather & Fla. Stat. ch. 948.30 & 2003 \\
\hline $\begin{array}{l}6 \text { Georgia } \\
7 \text { Idaho }\end{array}$ & $\begin{array}{l}1,000 \mathrm{ft} / \\
500 \mathrm{ft} /\end{array}$ & $\begin{array}{l}\text { where children gather } \\
\text { school with children }\end{array}$ & Ga. Code Ann. $\S 42-1-15$ & 2006 \\
\hline & & under 18 & Idaho Code $\S 18-8329$ & 2006 \\
\hline 8 Illinois & $500 \mathrm{ft} /$ & school 720 & Ill. Comp. Stat. 5/11-9.4 & 2006 \\
\hline 9 Indiana & $1,000 \mathrm{ft} /$ & $\begin{array}{l}\text { school, park, youth } \\
\text { program center }\end{array}$ & Ind. Code $\S 35-42-4-11$ & 2006 \\
\hline 10 Iowa & $2,000 \mathrm{ft} /$ & school, child care facility & Iowa Code $\S 692 \mathrm{~A} .2 \mathrm{~A}$ & 2002 \\
\hline 11 Kentucky & $1,000 \mathrm{ft} /$ & $\begin{array}{l}\text { school, child care facility, } \\
\text { playground, ball field }\end{array}$ & Ky. Rev. Stat. $\S 17.545$ & 2006 \\
\hline 12 Louisiana & $1,000 \mathrm{ft} /$ & $\begin{array}{l}\text { school, related activities, } \\
\text { school buses }\end{array}$ & La. Rev. Stat. Ann. § 14:91.1 & 2006 \\
\hline 13 Maryland & & $\begin{array}{l}\text { Parole Commission } \\
\text { restricts where feasible }\end{array}$ & $\begin{array}{l}\text { Md. Code Ann., Crim. } \\
\text { Procedure } \$ 11-724\end{array}$ & 2006 \\
\hline 14 Michigan & $1,000 \mathrm{ft} /$ & $\begin{array}{l}\text { school (student safety } \\
\text { zone) }\end{array}$ & Mich. Comp. Laws $\S \S 28.733-735$ & 2006 \\
\hline 15 Minnesota & & $\begin{array}{l}\text { End-of-Confinement } \\
\text { Review Committee } \\
\text { decides }\end{array}$ & Minn. Stat. Ann. § 244.052 & 1996 \\
\hline 16 Mississippi & $1,500 \mathrm{ft} /$ & $\begin{array}{l}\text { school, child care } \\
\text { facility }\end{array}$ & Miss. Code Ann. $\S 45-33-25$ & 2006 \\
\hline 17 Missouri & $1,000 \mathrm{ft} /$ & $\begin{array}{l}\text { school, child care } \\
\text { facility }\end{array}$ & Mo. Rev. Stat. $\S 566.147$ & 2006 \\
\hline 18 Montana & & Judge decides & Mont. Code Ann. $\S 46-18-255$ & 2001 \\
\hline $\begin{array}{l}19 \text { Nebraska } \\
20 \text { New Mexico }\end{array}$ & $500 \mathrm{ft} /$ & $\begin{array}{l}\text { school, child care facility } \\
\text { School/day care center } \\
\text { in } 1 \mathrm{mile}\end{array}$ & Neb. Rev. Stat. § 29-4017 & 2006 \\
\hline 21 Ohio & $1,000 \mathrm{ft} /$ & $\begin{array}{l}\text { radius contacted } \\
\text { school, child care }\end{array}$ & N.M. Stat. Ann. § 29-11A-5.1 & 2000 \\
\hline 22 Oklahoma & $2,000 \mathrm{ft} /$ & $\begin{array}{l}\text { facility } \\
\text { where children gather } \\
\text { school, day care center }\end{array}$ & Ohio Rev. Code Ann. $\S 2950.031$ & 2003 \\
\hline 23 Oregon & & $\begin{array}{l}\text {, park } \\
\text { Department of }\end{array}$ & Okla. Stat. tit. $57 \S 590$ & 2006 \\
\hline & & Corrections decides & Or. Rev. Stat. $\$ \S 144.642,144.644$ & 2001 \\
\hline 24 South Dakota & $500 \mathrm{ft} /$ & community safety zones & S.D. Codified Laws & \\
\hline
\end{tabular}


25 Tennessee $\quad 1,000 \mathrm{ft} /$

26 Texas

27 Virginia $\quad 100 \mathrm{ft}$

28 Washington $880 \mathrm{ft}$

29 West Virginia $1,000 \mathrm{ft} /$
$\S \S 22-24 \mathrm{~B}-22,23,24$

2006

school, child care

facility, victim

Distance specified by

Parole Board

Tenn. Code Ann. § 40-39-211

2004

Tex. Gov’t Code Ann. $\$ 508.187$

1997 school, child care center

school, day care center

Va. Code Ann. § 18.2-370.2

2000

Wash. Rev. Code

$\S \S 9.94 \mathrm{~A} .030,9.94 \mathrm{~A} .712$

school, child care facility W. Va. Code $\$ 62-12-26$

Source: The Council of State Government retrieved from

http://www.csg.org/policy/pubsafety/documents/ResidencyRestrictionLaws.pdf 


\section{APPENDIX E:}

\section{Child Abuse Laws State-by-State}

Alabama

Alaska

Arizona

Arkansas

California

Colorado

Connecticut

Delaware

District Of

Columbia
Statute defines child abuse as harm or threatened harm of physical abuse, neglect, sexual abuse, sexual exploitation, or emotional/mental injury against a child under the age of 18 . Statute contains an exemption for religious reasons for a parent's failure to obtain medical help for the child.

Statute defines child abuse as harm or threatened harm of physical abuse, neglect, sexual abuse, sexual exploitation, or emotional/mental injury of a child under the age of 18. Statute contains an exemption for religious reasons for a parent's failure to obtain medical help for the child.

Statute defines child abuse as inflicting or allowing physical abuse, neglect, sexual abuse, sexual exploitation, emotional/mental injury, or abandonment of a child under the age of 18. Statute contains an exemption for Christian Scientists or unavailability of reasonable resources for a parent's failure to obtain medical help for the child.

Statute defines child abuse as intentionally, knowingly, or negligently without cause inflicting physical abuse, neglect, sexual abuse, sexual exploitation, abandonment or emotional/mental injury of a child under the age of 18 . Statute contains exemptions for poverty or corporal punishment.

Statute defines child abuse as inflicting by non-accidental means physical abuse, neglect, sexual abuse, or sexual exploitation of a child under the age of 18 .

Statute contains exemptions for religion, reasonable force, and informed medical decision.

Statute prohibits threats to a child's health and welfare due to physical abuse, neglect, sexual abuse, sexual exploitation, emotional/mental injury, or abandonment. Statute contains exemptions for corporal punishment, reasonable force, religious practices, and cultural practices.

Statute prohibits injuries inflicted by non-accidental means involving physical abuse, neglect, sexual abuse, sexual exploitation, emotional/mental injury, or abandonment. Statute contains exemption for Christian Scientists.

Statute prohibits injuries inflicted by non-accidental means involving physical abuse, neglect, sexual abuse, sexual exploitation, emotional/mental injury, or abandonment. Statute contains exemption for religion.

Statute prohibits persons from inflicting and requires people to take reasonable care not to inflict injuries involving physical abuse, neglect, sexual abuse, sexual exploitation, or emotional/mental injury. Statute contains exemption for poverty and religion.

Florida 
physical abuse, neglect, sexual abuse, sexual exploitation, abandonment, or emotional/mental injury. Statute contains exemptions for religion, poverty, or corporal punishment.

Georgia

Hawaii

Idaho

Illinois

Indiana

Kentucky

Maryland

Michigan

Mississippi

Nebraska

New Mexico
Statute prohibits injuries inflicted by non-accidental means involving physical abuse, neglect, sexual abuse, or sexual exploitation. Statute contains exemption for religion and corporal punishment.

Statute prohibits acts or omissions resulting in the child being harmed or subject to any reasonably foreseeable, substantial risk of being harmed with physical abuse, neglect, sexual abuse, sexual exploitation, or emotional/mental injury. Statute contains no exemptions.

Statute prohibits conduct or omission resulting in physical abuse, neglect, sexual abuse, sexual exploitation, abandonment, or emotional/mental injury. Statute contains exemption for religion.

Statute prohibits persons from inflicting, causing to be inflicted, or allowing to be inflicted, or creating a substantial risk, or committing or allowing being committed, physical abuse, neglect, sexual abuse, sexual exploitation, or emotional/mental injury. Statute contains exemptions for religion, school attendance, and plan of care.

Statute prohibits act or omission resulting in physical abuse, neglect, sexual abuse, sexual exploitation, abandonment, or emotional/mental injury. Statute contains exemptions for religion, prescription drugs, or corporal punishment.

Statute prohibits harm or threat of harm, or infliction or allowance of infliction of physical abuse, neglect, sexual abuse, sexual exploitation, abandonment, or emotional/mental injury. Statute contains exemptions for religion.

Statute prohibits harm or substantial risk of harm resulting in physical abuse, neglect, sexual abuse, sexual exploitation, or emotional/mental injury. Statute contains no exemptions.

Statute prohibits harm or threatened harm of physical abuse, neglect, sexual abuse, sexual exploitation, or emotional/mental injury. Statute contains exemptions for religion.

Statute prohibits persons from causing or allowing to be caused physical abuse, neglect, sexual abuse, sexual exploitation, or emotional/mental injury. Statute contains exemption for religion and corporal punishment.

Statute prohibits knowingly, intentionally, or negligently causing or permitting physical abuse, neglect, sexual abuse, sexual exploitation, or emotional/mental injury. Statute contains no exemptions.

Statute prohibits knowingly, intentionally, or negligently causing or permitting physical abuse, neglect, sexual abuse, sexual exploitation, abandonment, or emotional/mental injury. Statute contains exemption for religion. 
North Dakota

Oklahoma

Pennsylvania

South Dakota

Tennessee

Utah

Washington
Statute prohibits serious harm caused by non-accidental means resulting in physical abuse, neglect, sexual abuse, sexual exploitation, abandonment, or emotional/mental injury. Statute contains no exemptions.

Statute prohibits harm or threat of harm resulting in physical abuse, neglect, sexual abuse, sexual exploitation, abandonment, or emotional/mental injury. Statute contains exemptions for religion or corporal punishment.

Statute prohibits recent act or failure to act resulting in physical abuse, neglect, sexual abuse, sexual exploitation, or emotional/mental injury. Statute contains exemptions for religion or poverty.

Statute prohibits threat with substantial harm resulting in physical abuse, neglect, sexual abuse, sexual exploitation, abandonment, or emotional/mental injury. Statute contains no exemptions.

Statute prohibits persons from committing or allowing to be committed physical abuse, neglect, sexual abuse, sexual exploitation, or emotional/mental injury. Statute contains no exemptions.

Statute prohibits harm or threat of harm resulting in physical abuse, neglect, sexual abuse, sexual exploitation, or emotional/mental injury. Statute contains no exemptions.

Statute prohibits harm of health, welfare, or safety resulting from physical abuse, neglect, sexual abuse, or sexual exploitation. Statute contains exemptions for Christian Scientists, corporal punishment, or physical disability. 